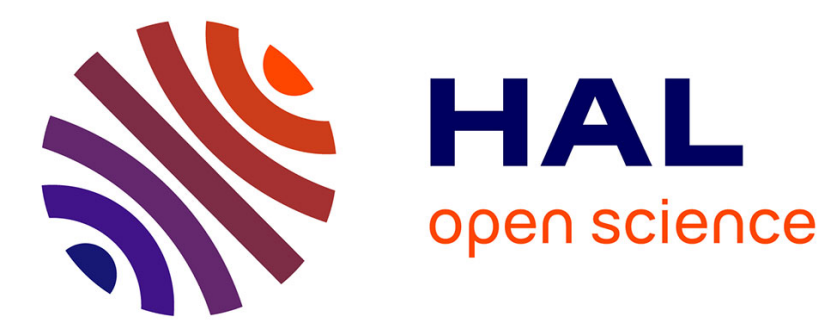

\title{
How to study anxiety and depression in rodent models of chronic pain?
}

Mélanie Kremer, Léa Becker, Michel Barrot, Ipek Yalcin

\section{To cite this version:}

Mélanie Kremer, Léa Becker, Michel Barrot, Ipek Yalcin. How to study anxiety and depression in rodent models of chronic pain?. European Journal of Neuroscience, In press, 10.1111/ejn.14686 . hal-03001587

\section{HAL Id: hal-03001587 \\ https://hal.science/hal-03001587}

Submitted on 2 Dec 2020

HAL is a multi-disciplinary open access archive for the deposit and dissemination of scientific research documents, whether they are published or not. The documents may come from teaching and research institutions in France or abroad, or from public or private research centers.
L'archive ouverte pluridisciplinaire HAL, est destinée au dépôt et à la diffusion de documents scientifiques de niveau recherche, publiés ou non, émanant des établissements d'enseignement et de recherche français ou étrangers, des laboratoires publics ou privés. 
DR. MÉLANIE KREMER (Orcid ID : 0000-0003-2814-5706)

Article type : Special Issue Review

European Journal of Neuroscience

Special Issue: Depression

\section{How to study anxiety and depression in rodent models of chronic pain?}

Running Title: Anxiodepressive-like consequences of chronic pain

Mélanie Kremer ${ }^{1}$, Léa J. Becker ${ }^{1}$, Michel Barrot ${ }^{1 *}$, Ipek Yalcin ${ }^{1 *}$

${ }^{1}$ Centre National de la Recherche Scientifique, Université de Strasbourg, Institut des

Neurosciences Cellulaires et Intégratives, Strasbourg, France.

Number of pages: 73

Number of figures: 6

Number of tables: 3

Number of words: 11715 (163 in abstract, 21429 with references)

Corresponding authors:

Ipek Yalcin, $\mathrm{PhD}$, PharmaD

INCI CNRS UPR3212

8 allée du Général Rouvillois

67000 Strasbourg, France

E-mail: yalcin@unistra.fr

Michel Barrot, $\mathrm{PhD}$

INCI CNRS UPR3212

8 allée du Général Rouvillois

67000 Strasbourg, France

This article has been accepted for publication and undergone full peer review but has not been through the copyediting, typesetting, pagination and proofreading process, which may lead to differences between this version and the Version of Record. Please cite this article as doi: $\underline{10.1111 / \mathrm{EJN} .14686}$

This article is protected by copyright. All rights reserved 
Keywords: depression, anxiety, pain, models, tests

Acknowledgements: This work was supported by the "Centre National de la Recherche Scientifique" (contract UPR3212), the University of Strasbourg, the "Agence Nationale de la Recherche" (Euridol ANR-17-EURE-0022), and a NARSAD Young Investigator Grant from the Brain \& Behavior Research Foundation (24736).

\section{Declaration of Conflicting Interests}

The authors declared no potential conflict of interest with respect to the research, authorship, and/or publication of this article. The authors declare that they have no competing interests.

\section{Author's Contributions}

M.K. and L.B. did the bibliographic research; M.K. wrote parts 1, 2, 3 and 5; L.B. wrote parts 4 and 5; M.K. realized all the figures and L.B. has completed Figures 2 and 5; I.Y. and M.B. have supervised and revised the article.

No data available. 


\section{Abbreviations}

ACC: Anterior Cingulate Cortex; BT: Burrowing Test; CCI: Chronic Constriction Injury: CeA: Central Nucleus of the Amygdala; CFA: Complete Freund's Adjuvant; CION: Infraorbital Nerve Constriction; DM3T: Dimethyl-3-transferase; EPM: Elevated Plus Maze; EZM: Elevated Zero Maze; FST: Forced Swim Test; HB: Hole-Board test; HDAC: Histone Deacetylase; HIV: Human Immunodeficiency Virus; IASP: International Association for the Study of Pain; ICS: Intermittent Cold Stress; IDO1: Indoleamine 2,3-dioxygenase 1; IL: Interleukin; LC: Locus Coeruleus; LDB: Light/Dark Box test; MAPK: Mitogen-Activated Protein Kinases; MB: Marble Burying test; MDD: Major Depressive Disorder; NAc: Nucleus Accumbens; NSF: Novelty Suppressed Feeding; OF: Open Field; PAG: Periaqueductal Gray; PFC: Prefrontal Cortex; PSNL: Partial Sciatic Nerve Ligation; RCS: Repeated Cold Stress; SCI: Spinal Cord Injury; SI: Social Interaction test; SNI: Sciatic Nerve Injury; SNL: Spinal Nerve Ligation; SPT: Sucrose Preference Test; ST: Splash Test; TIC: Trigeminal Inflammatory Compression; TNF: Tumor Necrosis Factor; TNT: Tibial Nerve Transection; TST: Tail Suspension Test 


\section{Abstract}

Mood disorders such as depression and anxiety are frequently observed in patients suffering from chronic pain. Over time, different tests and models have been developed in rodents to study the anxiodepressive-like consequences of chronic pain. This review describes these pre-clinical tools (models and tests) used for studying behavioural aspects of the comorbid relationship between chronic pain and anxiety and/or major depressive disorder (MDD). Three major types of chronic pain strongly associated with anxiodepressive-like comorbidity as well as their animal models are presented: neuropathic pain, inflammatory pain and fibromyalgia. After a description of chronic pain animal models and of the tests that allows determining nociceptive responses, this review presents and discusses the various behavioural tests that have been used to assess anxiety and depressive-like behaviours in these models of chronic pain. Finally, this review highlights the progress that remains to be made to homogenize the results in the field of pain-induced mood disorders and summarizes the recent advances achieved through these tests and models. 


\section{Introduction}

Pain is a multidimensional and subjective experience which is considered as a debilitating disease when it becomes chronic. Chronic pain does indeed affect various aspects of the patient's quality of life, including mood, sleep and cognitive processes (Maletic \& Raison, 2009; Haanpaa et al., 2011; Radat et al., 2013). In chronic pain patients, mood disorders such as major depressive disorders and anxiety are frequently observed (Bair et al., 2003; Gustorff et al., 2008; Maletic \& Raison, 2009; Radat et al., 2013).

Major depressive disorders are highly disabling psychiatric disorder which affects around $16 \%$ of the population at some point over their lifespan (Bromet et al., 2011) and is among the main contributors to the disease burden worldwide (Kessler et al., 2003; Olesen et al., 2012). Due to its multifactorial nature and heterogeneous symptomatology, the precise aetiology of this debilitating disorder remains poorly understood (Menard et al., 2016). However, besides chronic stress and psychosocial trauma (Liu \& Alloy, 2010), chronic pain can also be cited among the first determinants of mood disorders (McWilliams et al., 2004; Breivik et al., 2006; Attal et al., 2011), as shown by the mean prevalence rate around $50 \%$ for major depressive disorder reported in these patients (Bair et al., 2003). Besides, anxiety is also among mood disorders frequently diagnosed in chronic pain patients. Indeed, this psychopathology, defined by excessive fear and worry, affects up to $60 \%$ of chronic pain patients. This prevalence is however highly dependent on the considered type of pain, with the lowest rate (between 1 and 27\%) for neuropathic pain and the highest (between 18 and 60\%) for fibromyalgia (Hooten, 2016).

Different models have been developed in rodents to study the various types of clinically observed chronic pain conditions (Mogil, 2009; Jaggi et al., 2011; Muley et al., 2016; Sluka \& Clauw, 2016; Fischer et al., 2017; Kumar et al., 2018), as well as their anxiodepressive consequences (Liu \& Chen, 2014; Leite-Almeida et al., 2015). While several groups successfully achieved to model this comorbidity in animals (Narita et al., 2006a; Narita et al., 2006b; Suzuki et al., 2007; Goncalves et al., 2008; Matsuzawa-Yanagida et al., 2008), many initial studies and some of the recent ones failed to show any association between chronic neuropathic or inflammatory pain and anxiety- and depression-related behaviours (Kontinen et al., 1999; Hasnie et al., 2007b; Urban et al., 2011; Pitzer et al., 2019). However, some of the negative studies (but not all) were done at early pain stages, i.e. during the first week or the first 3 weeks following inflammatory and neuropathy induction, respectively. While it may not be the only aspect that allows explaining the presence or not of anxiodepressive-like consequences in rodent models of 
chronic pain, the time factor appears as critical (Yalcin et al., 2011; Yalcin \& Barrot, 2014; Humo et al., 2019). Others factors, such as the species, the strains of animals, the chosen models of chronic pain, and the time of the day-night cycle when the animals are tested, could also be involved.

In this review, based on the literature up to December 2019, we summarized the pre-clinical tools (models and tests) used over the past two decades and pertaining to behavioural aspects of the comorbid relationship between chronic pain and anxiety and/or major depressive disorder (MDD). After a brief description of the types of chronic pain and of their animal models, as well as the tests that allow determining nociceptive responses, we will present and discuss the various behavioural tests that have been used to assess anxiety and depressive-like behaviours in these models of chronic pain.

\section{Animal models of pain that have been used in research on anxiety and/or depression}

Pain is defined by the International Association for the Study of Pain (IASP) as "an unpleasant sensory and emotional experience associated with actual or potential tissue damage, or described in terms of such damage”. Acting as an alarm signal, acute pain triggers reactions to preserve the integrity of the organism (Scholz \& Woolf, 2002; Morrison et al., 2013). When pain persists beyond several months, it is considered as chronic. Contrary to acute pain, chronic pain is regarded as an illness per se, and mood disorders are among its comorbidities (Attal et al., 2011; Haanpaa et al., 2011). According to the epidemiological studies the prevalence rate of major depressive disorder in patients with chronic pain (Bair et al., 2003; Maletic \& Raison, 2009) varies from around $30 \%$ for patients suffering from neuropathic pain (Gustorff et al., 2008; Radat et al., 2013), to around $80 \%$ in fibromyalgia patients (Fietta et al., 2007). Up to recently, the mechanism(s) underlying this comorbidity remained unclear (Yalcin \& Barrot, 2014; Doan et al., 2015; Fasick et al., 2015; Zis et al., 2017). However, main advances have been achieved in the past decade, thanks to the development of animal models that allow studying anxiodepressive consequences of chronic pain (Yalcin \& Barrot, 2014; Leite-Almeida et al., 2015). We will focus here three major types of chronic pain strongly associated with anxiodepressive-like comorbidity: neuropathic pain, inflammatory pain and fibromyalgia.

\subsection{Neuropathic pain and its animal models}

By definition, neuropathic pain arises as a direct consequence of a lesion or disease affecting the somatosensory system (Treede et al., 2008). It is a syndrome usually chronic, with various 
possible aetiologies. For most patients it has a peripheral origin, arising as a consequence of peripheral nerve injury (nerve section or compression), or as a consequence of a metabolic disease such as diabetes. Nerve injuries and diabetic peripheral neuropathy account for almost two-thirds of the patients. However, neuropathic pain can also result from infectious diseases, as in postherpetic neuralgia, from exposure to neurotoxic compounds, such as those used for cancer chemotherapy, or be of central origin, as observed after spinal cord injury or local post-stroke ischemia (Attal et al., 2008; Colloca et al., 2017; Zilliox, 2017; Scholz et al., 2019).

A large number of animal models of neuropathic pain has been developed (Sorkin \& Yaksh, 2009; Colleoni \& Sacerdote, 2010; Jaggi et al., 2011; Kumar et al., 2018), but their exhaustive presentation is beyond the scope of this review. Here, we will simply focus on the few models in which most of the comorbidity studies on anxiodepressive aspects were performed. Almost $90 \%$ of the published studies used trauma models based on chronic nerve compression (see Figure 1). This nerve compression has been achieved either by ligation, as for the partial sciatic nerve ligation (PSNL) which is a tight ligation of one-third to half of the sciatic nerve (Seltzer et al., 1990), the spinal nerve ligation (SNL) which is a tight ligation of L5 and L6 spinal nerves (Kim \& Chung, 1992) or of L5 spinal nerve only (LaBuda \& Little, 2005), the chronic constriction injury (CCI) consisting in four loose ligatures applied around the sciatic nerve (Bennett \& Xie, 1988), or by the implantation of a polyethylene cuff around the main branch of the sciatic nerve (Mosconi \& Kruger, 1996). Another frequently used trauma model is the spared nerve injury (SNI), which relies on the axotomy of two of the three branches of the sciatic nerve (Decosterd \& Woolf, 2000). The tibial nerve transection (TNT) is a variant of this model in which the axotomy concerns the tibial nerve only (Andrews et al., 2012). The anxiodepressive comorbidity has also been studied using trigeminal neuralgia models, such as the infraorbital nerve constriction (CION) which corresponds to CCI of the infraorbital nerve (Vos et al., 1994), or in animals with trigeminal inflammatory compression (TIC) induced by a chromic gut suture alongside the infraorbital nerve (Ma et al., 2012).

Beside nerve lesion, diseases affecting the somatosensory system constitute another main aetiology of neuropathic pain (Jolivalt et al., 2016). In this regard, anxiodepressive-like comorbidities have also been studied in a streptozotocin model, which is a common model of diabetic polyneuropathy (Lenzen, 2008), and in models of human immunodeficiency virus (HIV) 1 protein gp120 (Wallace et al., 2007b) or zoster varicella virus (Hasnie et al., 2007a) as infection models. Exposure to neurotoxic drugs, such as the HIV antiretroviral stavudine (Joseph et al., 
2004) or the chemotherapy drugs oxaliplatin (Cavaletti et al., 2001) or paclitaxel (Cavaletti et al., 1995), have also been used to study the comorbidity between neuropathic pain and anxiety/depressive-like behaviours.

Concerning central neuropathies, studies of anxiety/depressive-like behaviours have been done using a model of spinal cord injury (SCI) induced by dropping a weight over the exposed spinal cord (Behrmann et al., 1992), or by using a photochemical reaction to form a thrombosis and occlusion in small vessels supplying the spinal cord (Verdu et al., 2003).

\subsection{Inflammatory pain and its animal models}

When inflammation becomes chronic, it loses its role as natural physiological response to tissue injury or infection, and it becomes a maladaptive and physiopathological condition. The chemical mediators that are responsible for tissue inflammation affect nociceptive nerve endings to lower neuronal excitation thresholds and sensitize afferent firing rate, leading to the development of allodynia and hyperalgesia, respectively (Kidd \& Urban, 2001; Lipnik-Stangelj, 2013). One of the main organ systems that is particularly susceptible to the development of inflammatory pain is joints.

Arthritis, which literally means joint inflammation, refers to a group of rheumatic diseases and other conditions that can cause pain, stiffness and swelling in the joints. It includes forms ranging from those related to wear and tear of cartilage (such as osteoarthritis (Kuyinu et al., 2016)), to those associated with inflammation resulting from an overactive immune system (such as rheumatoid arthritis) (Di Paola \& Cuzzocrea, 2008). Recent surveys report that rheumatoid arthritis is one of the most common chronic inflammatory pain conditions in developed countries, affecting approximately 15 million people worldwide (Fiest et al., 2017). Rheumatoid arthritis is a chronic debilitating autoimmune disorder characterized by synovitis that leads to cartilage and bone erosion by invading fibrovascular tissue (Scott et al., 2010). The pathogenesis of rheumatoid arthritis is complex and involves genetic predispositions as well as environmental factors (Imboden, 2009). Psychiatric disorders are highly associated with rheumatoid arthritis (Nerurkar et al., 2019). Depression is diagnosed in up to $66 \%$ and anxiety in up to $70 \%$ of individuals with rheumatoid arthritis (Fiest et al., 2017).

Animal models have contributed to improve our understanding of the pathophysiological mechanisms responsible for the generation of chronic inflammatory pain and its associated comorbidities (Kuyinu et al., 2016; Muley et al., 2016; Fischer et al., 2017). The most widely used model for studying the comorbidity between inflammatory pain and anxiodepressive-like disorders 
has been the complete Freund's adjuvant (CFA)-induced inflammation of the paw (Fehrenbacher et al., 2012). This model is based on a unilateral intraplantar injection of CFA, which can produce a long-lasting ( $>3$ weeks) decrease in mechanical and thermal thresholds compared to the contralateral non-inflamed paw (Cook \& Moore, 2006). Carrageenan can also be injected into the paw to model arthritis, but this model is more acute than chronic because the associated mechanical and thermal hypersensitivity usually lasts no longer than 72 hours (Mert et al., 2014). Monoarthritis models have also been used, by injecting an inflammatory agent such as CFA, uric acid or a kaolin-carrageenan mix directly into the tibiotarsal (Butler et al., 1992), knee (LopezMunoz \& Salazar, 1993; Radhakrishnan et al., 2003) or temporomandibular (Harper et al., 2001) joint. Obesity is also a main risk factor for the development of arthritis (Georgiev \& Angelov, 2019), and a model of arthritis based on dietary obesity (Silberberg \& Silberberg, 1950) has also been used to test anxiodepressive-like aspects (Griffin et al., 2010).

\subsection{Fibromyalgia and its animal models}

Fibromyalgia is a condition characterized by chronic widespread musculoskeletal pain, which includes widespread tenderness to pressure stimuli and morning stiffness (Clauw, 2014; Hauser et al., 2015; Sluka \& Clauw, 2016). The pathogenesis of fibromyalgia is complex and controversial, but some recent advances in the field showed the possible involvement of lipid mediators (Hsu et al., 2019), autoimmunity, neuroinflammation and small fiber neuropathy (Ryabkova et al., 2019). There is however no evidence of any single event causing this condition; instead, it is considered to be triggered or aggravated by multiple physical and/or emotional stressors, such as infections, or emotional and physical trauma (Schmidt-Wilcke \& Clauw, 2011; Sluka \& Clauw, 2016). Fibromyalgia is more common in women than in men, and its worldwide prevalence is 2 to $3 \%$ (Cabo-Meseguer et al., 2017). Fibromyalgia is also associated with a number of other symptoms, including pronounced fatigue, sleep disturbances and psychological disturbances (depression and/or anxiety) (Hauser et al., 2015). Overall depression and anxiety are among the most common comorbidities of fibromyalgia, with prevalence rates ranging from $20-80 \%$ and $13-64 \%$ respectively (Maletic \& Raison, 2009).

Some studies tried to address the anxiodepressive consequences in animal models of fibromyalgia. However, as there is no well-defined aetiology of fibromyalgia, the validity of animal models remains imperfect and simply based on symptoms and on the response to treatment (mostly antidepressant drugs). The most frequently used fibromyalgia model addressing depression-like behaviours is based on biogenic amine depletion by systemic reserpine 
administration (Nagakura et al., 2009). However, the chronic widespread musculoskeletal pain model induced by repeated intramuscular acid injections in rodents has been suggested to have better face validity to human's conditions, but few studies have dealt with the anxiodepressive consequences in this model yet (Liu et al., 2014). Anxiodepressive consequences have also been described in stress-induced fibromyalgia models, such as the cold stress models, i.e intermittent (ICS) (Nishiyori \& Ueda, 2008) or repeated cold stress (RCS) (Nasu et al., 2019), the unpredictable sound stress model (Khasar et al., 2008), or the subchronic swim stress inducing chronic widespread-like pain (Nazeri et al., 2018). Although existing models mimic some symptoms of fibromyalgia, it is still critical to develop new models which can reflect the different aspects of this syndrome.

\section{Nociceptive tests frequently used to evaluate chronic pain}

An important notion in the field of pain is the distinction between pain and nociception. If nociception corresponds to "neural process of encoding noxious stimuli" (i.e. stimuli presenting a risk for the integrity of the body) (Basbaum, 2000), pain is defined as "an unpleasant sensory and emotional experience associated with actual or potential tissue damage, or described in terms of such damage" (Box 1) (Loeser \& Melzack, 1999; Basbaum et al., 2009; Baliki \& Apkarian, 2015; Apkarian \& Reckziegel, 2019). These two facets of the same phenomenon distinguish the sensation (nociception) from its interpretation (pain). In patients, pain is evaluated verbally, which is not possible in rodents. Thus, rodent "pain tests" are actually nociceptive tests, based on reflex responses, and the preclinical measurement of pain itself is still a challenge for this field of research (Barrot, 2012; Deuis et al., 2017). For a long time, fundamental research on pain and its preclinical treatments has been based on nociceptive tests performed on naive animals, i.e. not painful (Le Bars et al., 2001). But in the past decades, the combination of nociceptive tests and pain models has improved the relevance of studies in the field of pain research (Mogil, 2009).

The main nociceptive tests used in animal studies addressing the comorbidity between pain and anxiodepressive-like disorders are based on thermal or mechanical stimuli (Barrot, 2012; Leite-Almeida et al., 2015). Some of them, like the tail-flick test, the hot- or cold-plate tests and the radiant heat paw-withdrawal test, rely on the latency for avoidance behaviour: a withdrawal reflex of the paw or the tail (Barrot, 2012; Deuis et al., 2017). Here, the stimulus may be considered as fixed. The tail withdrawal test, the first developed (D'Amour \& Smith, 1941), is based on the latency of the withdrawal reflex after applying a heat beam at the end of the tail or 
after having immersed it in a bath at fixed temperature. Although the observed response results from a spinal reflex, it remains under the influence of supraspinal controls as well as mechanisms of thermoregulation (Barrot, 2012). This test, sensitive to opiates, has been used extensively for analgesic research. Nevertheless, this test is much less used in models of chronic pain such as inflammatory pain or trauma models of neuropathic pain since these models rather focus on one of the paws of the animal. The hot-plate (Woolfe \& MacDonald, 1944; O'Callaghan \& Holtzman, 1975 ) is another classic test developed in the 1940 s, most often with a plate temperature set at 52 or $55^{\circ} \mathrm{C}$ for rodents. These temperatures, which are 10 to $15^{\circ} \mathrm{C}$ higher than the nociceptor response thresholds, are necessary for the increase in skin temperature to activate the nociceptors and thus to observe a supraspinal response within less than 10 seconds. The measurement is most often the latency of withdrawal and licking of the paw, but in the mouse the jump of the animal is sometimes taken into consideration (Deuis et al., 2017). In the late 1980s, Hargreaves et al. have described a test to differentiate the nociceptive response of the two hind paws in rodents: the Hargreaves test or Plantar ${ }^{\circledR}$ test (Hargreaves et al., 1988; Muley et al., 2016). The animal is placed on a glass floor and the point source of heat is brought under the paw to be tested, the system automatically detects the withdrawal of the paw. This test is useful in unilateral pain models, like most models of inflammatory and neuropathic pain. Similarly, the cold nociceptive response can be tested using a cold-plate test (Bennett \& Xie, 1988; Choi et al., 1994), but this measure can be more difficult to establish as the response latency is sometimes unreliable, and the number of responses over a given period of time is generally preferred (Deuis et al., 2017).

Finally, some of the thermal nociceptive tests are based on the observation and quantification of nociceptive behaviours, as is the case with the acetone test. To assess cold allodynia, a drop of acetone can be applied on the hind paws (Choi et al., 1994). Its evaporation produces a cold stimulus, which is usually not detected as nociceptive by naive animals but results in cold allodynia in pain models (Barrot, 2012; Deuis et al., 2017).

Other nociceptive tests, such as the von Frey filaments or the Randall-Selitto analgesimeter, can rely on the mechanical stimulus threshold necessary to elicit an avoidance behaviour (Barrot, 2012; Muley et al., 2016; Deuis et al., 2017). In this case, the stimulus is variable with increasing value. An advantage of these tests is to measure allodynia, i.e. the response to a normally nonnociceptive stimulus, or hyperalgesia, an exaggerated response to a nociceptive stimulus. While all mechanical tests are feasible in rats, the von Frey test mostly remains preferred in mice. These filaments of various diameters are generally applied to the plantar surface, until they bend exerting 
a calibrated pressure. The threshold filament inducing a response gives the value of the mechanical sensitivity threshold. This value is nevertheless influenced by the speed and the duration of application of the filaments, and the standardization of the procedure is therefore particularly important (Barrot, 2012). In recent years, automated versions of this test have been developed (Deuis et al., 2017). Manual or motorized, based on pressure gauges, they have the advantage of offering a continuous scale and no longer logarithmic values. With the RandallSelitto analgesimeter (Randall \& Selitto, 1957; Kayser et al., 1990), the plantar surface of the rat's paw is placed on a fixed element and a mobile element exerts an increasing pressure on the other face. According to the protocols, the parameter measured will be either the threshold expressed in grams of appearance of a withdrawal reflex or that of a vocalization. This test gives highly stable and reproducible values, but requires a strong behavioural expertise (Barrot, 2012; Deuis et al., 2017). Indeed, the rat is restrained in a vertical non-natural position to maintain its paw on the apparatus. A similar system has been developed to assess mechanonociception in models of arthritis where calibrated forceps are oriented along the joint line and an increasing compression force is applied (Ji et al., 2007; Amorim et al., 2014).

The various tests that we described above have been used to validate the presence of nociceptive hypersensitivity in animal models of pain used to study the anxiodepressive comorbidity. Most of these studies were based on measuring the evoked nociceptive response instead of spontaneous or ongoing pain since the latter cannot be easily measured in rodents. In the past decade, however, an effort from some research groups has focused on the search for objective and quantitative measures of pain, or at least for indirect parameters that may reflect the ongoing pain in the animal (Mogil, 2009; Deuis et al., 2017). One of the strategies to obtain such parameters has been based on the evaluation of the affective dimension of the pain experience, which comprises its unpleasantness and salient fear negative-stimuli-related escape and avoidance behaviours (Price, 2000; Fuchs \& McNabb, 2012; Navratilova et al., 2013). One of the most frequently used methods to evaluate such avoidance consists in giving the choice to the animal between environments associated or not with the painful experience. This can for example be done in response to mechanical stimulation (LaBuda \& Fuchs, 2000; Llorca-Torralba et al., 2018), by using plates with temperature gradient or allowing the choice between two surfaces with different temperatures (Moqrich et al., 2005). Another indirect measure of ongoing pain has been done by using a modified version of the conditioned place preference test, which is based on an animal's preference for a context paired with a pain-relieving treatment (King et al., 2009; Barthas et al., 
2015; Sellmeijer et al., 2018), such as intrathecal or systemic administration of non-rewarding analgesic drug (Sufka, 1994; Navratilova et al., 2013).

Another strategy is to consider the emotional component of pain through facial or vocal expression. The "grimace scale" of pain can actually be recognized and evaluated in rats (Sotocinal et al., 2011) and mice (Langford et al., 2010) exposed to acute or short-term pain. Unfortunately, as observed in chronic pain patients, this facial signature may not necessarily be present in chronic pain models (Langford et al., 2010). The evaluation of pain through ultrasonic vocalizations has also been explored by some teams (Calvino et al., 1996; Han et al., 2005; Kurejova et al., 2010), but the reliability of this parameter still remains low, limited to certain pain models and not necessarily relevant in a context of chronic pain (Jourdan et al., 2002; Wallace et al., 2005).

\section{Evaluating anxiety-like and depression-like behaviours in animal models of chronic pain}

\subsection{Anxiety-like behaviours}

\subsubsection{Elevated plus maze}

One of the most widely used test to assess anxiety-like behaviours in rodents is the elevated plus maze (EPM). It has been pharmacologically validated in rats (Pellow et al., 1985) and in mice (Lister, 1987) using chlordiazepoxide, diazepam, phenobarbitone and yohimbine. The EPM apparatus consists in a cross composed of two open and two closed arms, joined by a common central platform (Narita et al., 2006a). This apparatus is set 40 to $80 \mathrm{~cm}$ above the floor and the closed arms are enclosed by 15 to $40 \mathrm{~cm}$ walls depending on the considered species (Narita et al., 2006a; Hasnie et al., 2007b; Goncalves et al., 2008; Roeska et al., 2008). Animals are placed in the middle of the apparatus and let free to explore the maze. The number of entries as well as time spent in both closed and open arms is assessed over 5 to 15 minutes depending on the protocols (Narita et al., 2006a; Ji et al., 2018). Arm entry and exit are often considered when all four paws are into or out of a given arm. This paradigm induces a conflict between the innate exploratory behavior of the rodent and the fear generated by the open and heighten environment. Thus, a decrease in the amount of time spent in open arms is thought to reflect anxiety-like behaviour. To strengthen the aversion created by the open arms, it is possible to create a contrast in light setting between open and close arms. Thus, light intensity in closed arms may sometimes be below 10 lux while it can go up to 100 lux for the open arms. However, since very few studies indicate the light 
intensity used in their paradigm it is difficult to conclude about the optimal light setting. Besides, analysis of the number of arm entries can be used as an indicator of the animal locomotion, a decrease in the number of arm entries suggesting a deficit in locomotion. This internal control is then very useful to make sure that the effect seen in the EPM arises from anxiety-like behaviour and not from motor impairment (Benbouzid et al., 2008).

Concerning pain induced-anxiety, the majority of published studies using the EPM test succeeded in highlighting the presence of anxiety-like behaviours in both mouse and rat pain models (Figure 2). Indeed, a decreased time spent in the open arms of the EPM has been observed after 5 to 14 post-induction days in fibromyalgia models (Green et al., 2011; Liu et al., 2014; Wu et al., 2017; Nazeri et al., 2018) (see also Table 3) and within a few hours to one day (FernandezGuasti et al., 2005; Ji et al., 2007; do Nascimento \& Leite-Panissi, 2014) in inflammatory models (Table 2). The anxiety-like behaviours observed in the EPM for rodents with inflammatory pain have also been shown to last up to 3-4 weeks post-pain induction (Narita et al., 2006a; Narita et al., 2006b; Parent et al., 2012; Amorim et al., 2014; Borges et al., 2014; Wang et al., 2015b). In traumatic neuropathic pain models, a decrease in the time spent in the open arms has mainly been observed after 3 to 4 weeks post-surgery (Table 1, Figure 3) (Narita et al., 2006a; Narita et al., 2006b; Benbouzid et al., 2008; Matsuzawa-Yanagida et al., 2008; Roeska et al., 2009; LeiteAlmeida et al., 2012; Caspani et al., 2014; Jiang et al., 2014; Li et al., 2014; Sawada et al., 2014; Ji et al., 2017; Wang et al., 2017; Ferreira-Chamorro et al., 2018; Chen et al., 2019). This phenotype is usually still present at 8 weeks post-surgery (Suzuki et al., 2007; Lyons et al., 2015; Descalzi et al., 2017; Sang et al., 2018) or even at 19-24 post-operative weeks in the SNI model (Seminowicz et al., 2009), but it can also start to recover at this time point in PSNL (GonzalezSepulveda et al., 2016). Some studies, however, failed to show the presence of anxiety-like behaviours, in some cases due to the time point chosen for the test. Indeed, anxiety-like behaviours related to peripheral neuropathic pain in this test tend to mostly develop around 3-4 weeks following induction of the chronic pain, so testing too early may sometimes explain the lack of anxiety-like behaviours in some studies (Kontinen et al., 1999; Hasnie et al., 2007b; Roeska et al., 2008; Gregoire et al., 2012; Pitzer et al., 2019). Conversely, anxiety-related behaviours generally disappear after a certain delay, thus testing this component of chronic pain at a very late time points can be misleading (Goncalves et al., 2008; Pitzer et al., 2019). Moreover, it has been shown that the side of the nerve lesion might also impact the affective consequences of chronic pain. For instance, Leite-Almeida et al. showed that when SNI is performed on the left nerve, male Wistar- 
Han rats displayed more pronounced anxiety-like profile than when SNI was performed on the right nerve (Leite-Almeida et al., 2012). Finally, the repetition of the EPM procedure on the same animals can also effect the interpretation of results (Hubbard et al., 2015). Indeed, the EPM has been depicted as sensitive to one-trial tolerance phenomenon, namely a decrease of time spent in open arms with the repetition of the test and independent of experimental groups (Tucker \& McCabe, 2017).

\subsubsection{Elevated zero maze}

To avoid the one trial tolerance phenomenon, the elevated-zero maze (EZM) was developed and validated for anxiety assessment using diazepam and chlordiazepoxide treatments (Shepherd et al., 1994). It consists of an elevated (40-70 cm above from floor) annular platform (5-10 cm wide; 46$120 \mathrm{~cm}$ diameter) with two opposite closed quadrants and two open quadrants (Urban et al., 2011; Alba-Delgado et al., 2016). Animals are placed in one of the enclosed quadrants and let free to explore the apparatus. As for the EPM, the number of entries and time spent in open quadrants are usually recorded during 5 minutes (Alba-Delgado et al., 2016; Llorca-Torralba et al., 2018; Martinez-Navarro et al., 2019). Other parameters can also be considered like head dips or "stretch attend" postures if a finest assessment of anxiety-related behaviours is searched for (Alba-Delgado et al., 2016; Alba-Delgado et al., 2018). As for the EPM, the EZM produces a conflict between exploratory behaviour and fear induced by a bright (the light intensity is set between 40 and 100 lux) and open environment (Kulkarni et al., 2007). Thereby, a decrease in the time spent in open quadrants suggests the development of anxiety-like behaviours.

Using this test, studies showed that neuropathic pain conditions, either caused by traumatic event (Alba-Delgado et al., 2013; Dimitrov et al., 2014; Alba-Delgado et al., 2016; Alba-Delgado et al., 2018; Llorca-Torralba et al., 2018) or by streptozotocin-induced diabetes (Alba-Delgado et al., 2016), can decrease the time spent in open quadrants at 4 to 6 weeks post-surgery, indicating the development of chronic pain-induced anxiety-like behaviours (Table 1, Figure 3). Interestingly, Martinez-Navarro and collaborators selected Swiss albino male mice based on their high or low anxiety trait at the beginning of the experiment, and demonstrated that animals expressing higher anxiety-like behaviours prior neuropathic pain induction developed anxiety-like behaviours at earlier time points (2 weeks) (Martinez-Navarro et al., 2019). In CFA-induced inflammatory pain, anxiety-like behaviours were observed using the EZM one day after induction (Refsgaard et al., 2016), while these behaviours were observed at week 41 in an osteoarthritis 
model (Griffin et al., 2010) (Table 2). However, Urban and collaborators couldn't observe anxiety-like behaviours using the EZM in the SNI, CCI and CFA models (Urban et al., 2011). For the CFA model, the late time point used in this study, 33 days post-induction (against 1 to 10 days for other studies), could explain the lack of effect in EZM. Indeed, conversely to Urban and collaborators, other studies assessing anxiety-like behaviours (with either the EPM or the EZM) in CFA-induced inflammation never tested it after 4 post-induction weeks (Chen et al., 2013; do Nascimento \& Leite-Panissi, 2014; Refsgaard et al., 2016). Regarding the results obtained in the SNI and CCI models, the authors suggest that the absence of effect could arise from the protocol used in their study (Urban et al., 2011).

\subsubsection{Open field}

Anxiety-related behaviours can also be assessed with the open field test (OF). The OF consists in a

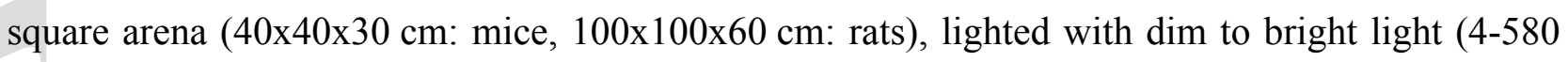
lux) (Wallace et al., 2007b; Zhu et al., 2017). Animals are placed in the centre of the OF (Hasnie et al., 2007a) or facing one wall of the arena (Zhu et al., 2017) and let free to explore the test. The time spent as well as the number of entries in the centre of the arena (area located $10 \mathrm{~cm}$ (mice) or $40 \mathrm{~cm}$ (rats) to the walls) are measured during 5 to 15 minutes. Again, this paradigm creates a conflict between the innate exploratory behaviour and the fear generated by an open and bright area. Administration of anxiolytic drugs such as diazepam or chlordiazepoxide was shown to elicit an increase in time spent and entries in the center area (Choleris et al., 2001).

When conducted in an inflammatory pain model, a decrease in time spent in the centre of the OF is observed from one to 28 post-induction days (Kim et al., 2012; Parent et al., 2012; Chen et al., 2013; Amorim et al., 2014; Gregoire et al., 2014; Guo et al., 2016; Sun et al., 2016; Tian et al., 2017; Yue et al., 2018) (Table 2). Liu and collaborators tested anxiety-like behaviours in the acid-induced hyperalgesia model of fibromyalgia and observed an effect 13 days after induction (Liu et al., 2014) (Table 3). Regarding models of neuropathic pain, OF results are quite heterogeneous (Table 1, Figure 2). Indeed, over 39 published studies, 25 showed decreased time spent in the centre of the OF at time points mainly between 2 and 8 weeks after pain induction; while the other 14 studies failed to find any effect in this test (Figure 3). A main explanation for these discrepancies could again arise from the time point used to assess anxiety-related behaviours. Indeed, some studies (Kontinen et al., 1999; Norman et al., 2010; Kodama et al., 2011) only tested animals at early or very late stage of chronic pain (Goncalves et al., 2008) 
although it is known that the temporality of the development of affective consequences of chronic pain is a critical parameter (Yalcin et al., 2011). The choice of the neuropathic model has also an impact on results obtained in OF. For instance, in spinal cord injury models either no differences or cohort-dependent effect was observed (Galan-Arriero et al., 2014; Maldonado-Bouchard et al., 2016; Boadas-Vaello et al., 2018). Also, in the PSNL model (Figure 1), near 50\% of the studies didn't report change in OF (Hasnie et al., 2007a; Hasnie et al., 2007b; Kodama et al., 2011). The reason why huge variability is frequently observed with this test can also be due to the protocol parameters, such as light setting (from 4 to more than 100 lux), test duration (4 to $60 \mathrm{~min}$ ), area size, definition of the central zone etc. Indeed, over the 18 studies for which light parameters are provided in methods, 10 out of the 14 studies conducted with a light intensity set at 60 lux or less succeeded in demonstrating pain-induced anxiety-like behaviours (Hasnie et al., 2007a; Suzuki et al., 2007; Wallace et al., 2007a; Wallace et al., 2007b; Wallace et al., 2007c; Avila-Martin et al., 2015; Galan-Arriero et al., 2015; Missig et al., 2017; Zhang et al., 2017; Gong et al., 2018), while the 4 studies using an intensity equal or higher than 100 lux failed (Kontinen et al., 1999; Kodama et al., 2011; Urban et al., 2011; Chen et al., 2018). These data suggest that too high light intensity might induce anxiety strong enough in controls to mask the difference between experimental groups, and that milder light setting should perhaps be preferred for better discrimination between groups. Finally, it has been shown that even when the test conditions are strictly controlled, a strong variability between different laboratories can still be present (Robinson et al., 2018). Regarding these results, it seems that the OF should not be the only test used to assess anxiety in pain condition, and indeed several groups rather employ a battery of behavioural tests to depict rodent emotional state (Suzuki et al., 2007; Leite-Almeida et al., 2009; Wang et al., 2015b; Descalzi et al., 2017) and often use the OF as a marker of locomotor activity rather than an aniety test (Goncalves et al., 2008; Lyons et al., 2015; Wu et al., 2016; Pan et al., 2018).

\subsubsection{Light/dark box test}

Another test aiming at assessing anxiety-like behaviour is the light/dark box test (LDB) developed by Crawley and Goodwin who also showed the sensitivity of this test to benzodiazepines (Crawley

\& Goodwin, 1980). Several other groups reproduced the results obtained by Crawley and Goodwin with various benzodiazepines, as well as with drugs acting on the serotonergic neurotransmission system (for an extensive review see (Bourin \& Hascoet, 2003)). The LDB is formed by two communicating chambers, one dimly lit with black walls and one brightly lit (100- 
500 lux) with white (Narita et al., 2006a) or transparent (Gambeta et al., 2018) walls. Animals are placed in the dark compartment and let free to explore the apparatus for 5-10 minutes. Entries and time spent in the light box are recorded, and latency to enter in the light box and rearing can also be considered among parameters (Lyons et al., 2015). Since the bright compartment represents an aversive environment for rodents, a decrease in the time spent/or number of entries in this zone is defined as an anxiety-like behaviour.

As for the previously described tests, when LDB is performed in neuropathic pain models anxiety-like behaviours can be observed 4 (Narita et al., 2006a; Narita et al., 2006b; MatsuzawaYanagida et al., 2008; Yalcin et al., 2011; Chen et al., 2013; Sieberg et al., 2018; Guimaraes et al., 2019) to 8 weeks post-surgery (Suzuki et al., 2007; Yalcin et al., 2011; Lyons et al., 2015; Barthas et al., 2017; Lyons et al., 2018; Sellmeijer et al., 2018), except for the SCI model in which no decrease in time spent in light box was detected (Boadas-Vaello et al., 2018) (Table 1, Figure 2 \& 3). Three studies also demonstrated a decrease in the time spent in the light box already detectable at 2 weeks after neuropathic pain induction (Mutso et al., 2012; Gambeta et al., 2018; Chen et al., 2019). Again difficulties to show anxiety-like behaviours can generally be explained by the testing time point being too early (Kontinen et al., 1999; Pitzer et al., 2019) or too late (Pitzer et al., 2019). When done in inflammatory condition, anxiety-like behaviour was observed in the LDB from 1 day to 28 days after induction (Narita et al., 2006a; Narita et al., 2006b; Parent et al., 2012; do Nascimento \& Leite-Panissi, 2014; Omorogbe et al., 2018) (Table 2).

\subsubsection{Social interaction}

The social interaction test (SI) was first developed to enable a measure of anxiety based on ethological behaviours and to replace tests including electric shock or food deprivation used so far (File \& Seth, 2003). This test was shown to be sensitive to anxiogenic (yohimbine, benzodiazepine receptor antagonists, picrotoxin) and anxiolytic drugs (lorazepam, diazepam, buspirone), as well as to stress-related hormones like the corticotropin-releasing factor and the adrenocorticotropic hormone (File \& Seth, 2003). Originally, animals were isolated for several days prior to testing, but recent studies only used an isolation of 5 to 120 minutes (Gregoire et al., 2012; HisaokaNakashima et al., 2019). After this isolation period, a juvenile congener is introduced in the cage and the amount of time spent in interaction (sniffing, following, grooming, licking) is recorded during 5 min (Hisaoka-Nakashima et al., 2019). For a more global recording of rodent social spontaneous behaviours, Benbouzid and collaborators did a video monitoring in home cage during 
6 hours (Benbouzid et al., 2008). In this case the SI was performed with littermates instead of a juvenile congener.

The number of studies using the SI as a measure of anxiety-like behaviours in pain conditions is quite limited. Yet, when conducted in neuropathic pain models, a decrease in SI has been observed at 4 (Benbouzid et al., 2008) and 6 (Hisaoka-Nakashima et al., 2019) weeks postsurgery (Table 1, Figure 4). The studies conducted by Maldonado-Bouchard (MaldonadoBouchard et al., 2016) or Gregoire (Gregoire et al., 2012) only tested animals before 3 weeks postsurgery, which might explain the absence of decrease in SI (Table 1, Figure 4). Indeed, the work conducted by Benbouzid and collaborators even report an increase in time dedicated to social contact at 2 post-operative weeks (Benbouzid et al., 2008). Regarding the sole study conducted in an inflammatory model (Gregoire et al., 2014), a decrease in SI was observed 2-3 weeks after CFA injection.

\subsubsection{Marble burying test}

Originally used to assess anxiety-like behaviours because of its sensitivity to anxiolytic drugs such as diazepam or buspirone (Njung'e \& Handley, 1991), the marble burying test (MB) is now thought to also be a potential test for the detection of compulsive behaviours (Thomas et al., 2009; Angoa-Perez et al., 2013). MB is performed in cages (same dimension as the home cages) containing 3-5 cm of fine sawdust. Twelve to 25 glass marbles $(1 \mathrm{~cm}$ diameter) are evenly spaced on top of the sawdust. Animals are placed individually into the cages and left undisturbed for 1530 min. After this period animals are removed, and buried marbles are counted. Marbles are considered buried if two thirds or more of their surface is covered by sawdust. The number of buried marbles is considered as a measure of animal anxiety and/or compulsive behaviour (Jimenez-Gomez et al., 2011).

When used in neuropathic pain models, the MB highlights compulsive/anxiety-like behaviours at time-points between 28 to 46 days post-surgery (Benbouzid et al., 2008; Yalcin et al., 2011; Guida et al., 2015; Aguilar-Avila et al., 2019) (Table 1, Figure 4). According to D'Aniello and collaborators, the changes seen in burying behaviours, at least in the SNI model, can last up to 1 year (D'Aniello et al., 2017) (Table 1, Figure 4). In an inflammatory pain model induced by intraplantar CFA injection, the increase in buried marbles occurred within 5 weeks post CFA injection (Urban et al., 2011).

\subsubsection{Hole-board test}


While the hole-board test (HB) can also give an insight into anxiety-like behaviours, it is less commonly used in the study of pain and mood disorder comorbidity. The HB device consists of a square plate (around 40x40 cm dimension) surrounded by walls and containing 9 (Sieberg et al., 2018) or 16 holes (Montserrat-de la Paz et al., 2015), around $3 \mathrm{~cm}$ diameter each, equally spaced on 3 to 4 rows. Animals are placed in the periphery (Sieberg et al., 2018) or in the centre (Montserrat-de la Paz et al., 2015) of the arena, and let free to explore the apparatus for 5 to 15 minutes (Montserrat-de la Paz et al., 2015; Sieberg et al., 2018). The number of nose-pokes, recorded by infrared photocells in the hole, is used as a measure of anxiety-like behavior since diazepam or chlordiazepoxide administration increase nosepoke numbers while anxiogenic compounds (FG7142, beta-CCM; inverse agonists of the benzodiazepine site of GABAa receptors) decrease it (Takeda et al., 1998). A decrease in the number of nose-pokes then reflects anxiogenic condition. Besides, the time spent in the centre of the HB is also recorded as a measure of anxiety (like in the OF), and the total distance travelled is an indicator of locomotor activity and thus serves as an internal control for motor function (Sieberg et al., 2018).

In a neuropathic pain model, a decrease in nose-poke activity has been observed at 4-6 postoperative weeks (Sieberg et al., 2018). In a fibromyalgia model, this effect is already present at 3 post-induction days (Montserrat-de la Paz et al., 2015).

\subsubsection{Burrowing test}

This test was first introduced by Deacon and collaborators in 2001, and relies on the natural burrowing behaviour of rodents (Deacon et al., 2001; Deacon, 2012). The burrowing test (BT) was proposed as a measurement of laboratory animals well-being since burrowing deficit are among the first behaviours to be detectable when rodents undergo stressful condition (Jirkof, 2014). The testing takes place in new cages similar to animal's home cages. Hollow plastic tubes $(32 \mathrm{~cm}$ long, $10 \mathrm{~cm}$ diameter for rats) sealed at one end and opened at the other end, are filled with gravel and disposed $6 \mathrm{~cm}$ above the ground to avoid loss of gravel (Andrews et al., 2012; Huang et al., 2013). Test sessions are usually 2 hours long and latency to start burrowing and the amount of gravel displaced are recorded. In the BT, an increase in latency to burrow and a decreased amount of material displaced suggests the development of anxiety-like behaviours. Interestingly BT can be repeated on the same animals over time and thus gives the opportunity to conduct longitudinal studies. Note that several other protocols exist for burrowing assessment in rodent, and notably some using food pellet instead of gravel (for a review see (Jirkof, 2014)).

This article is protected by copyright. All rights reserved 
In a model of inflammatory pain, burrowing behaviour deficits were seen at 10 postinduction days (Andrews et al., 2012). Regarding neuropathic pain models, a decrease in burrowing has been observed at 10 post-operative days in SNL and PSNL (Andrews et al., 2012) and between 21 (Huang et al., 2013) and 77 days (Andrews et al., 2012) in TNT (Table 1, Figure 4). Notably, a standardization of the procedure and a comparison across laboratories have been recently done (Muralidharan et al., 2016; Wodarski et al., 2016), making this test particularly interesting and reinforcing its validity for studying pain-related deficits.

\subsection{Depression-like behaviours}

\subsubsection{Novelty-suppressed feeding test}

The novelty-suppressed feeding (NSF) test can be used to assess both anxiety- and depressive-like behaviours, as demonstrated by its sensitivity to both anxiolytic (lorazepam, buspirone) and antidepressant drugs (imipramine, fluoxetine, amitriptyline) (Dulawa \& Hen, 2005). The NSF consists in a 40x40x30 cm plastic box with the floor covered with $2 \mathrm{~cm}$ of sawdust. Animals are usually food-restricted for twenty-four hours prior to the test. At the time of testing, a single pellet of food is placed on a paper in the centre of the box. An animal is then placed facing a corner of the box and the latency to first contact and onset of eating the pellet is recorded within a 5 minutes period. This test induces a conflict between the drive to eat the pellet and the fear of venturing in the centre of the box. The increase in the latency to eat suggests anxiodepressive-like behaviours.

In each neuropathic pain model used so far, an increase in the latency to feed has been observed, mainly between 2 to 9 weeks post-surgery (Yalcin et al., 2011; Mutso et al., 2012; Barthas et al., 2015; Barthas et al., 2017; Jiang et al., 2018; Poupon et al., 2018; Sellmeijer et al., 2018; Hisaoka-Nakashima et al., 2019; Jiang et al., 2019) (Table 1, Figure 5 \& 6). In a model of chemotherapy-induced neuropathy, Hache and collaborators showed an earlier onset of anxiodepressive-like behaviours compared to traumatic models (Hache et al., 2015) (Table 1,

Figure $5 \&$ 6). In the biogenic amine depletion model of fibromyalgia, an increase in the latency to feed was seen 4 to 5 post-induction days (Blasco-Serra et al., 2015).

\subsubsection{Forced swim test}

A more common test to assess depressive-like behaviours in rodents is the forced swim test (FST), initially developed by Porsolt and collaborators in rats (Porsolt et al., 1977b) and mice (Porsolt et al., 1977a) in order to rapidly screen antidepressant drugs. Indeed, it was shown that immobility in 
the FST was decreased by tricyclic antidepressants, such as imipramine or amitriptyline (Porsolt et al., 1977b). From this initial validation and use as a simple drug-screening test, the FST has since been more widely used to also study depressive-like behaviours. In rats, a pre-test phase is required. Animals are gently lowered in an inescapable cylinder (height $50 \mathrm{~cm}$, diameter $20 \mathrm{~cm}$ ) containing $30 \mathrm{~cm}$ of water $\left(23-25^{\circ} \mathrm{C}\right)$ for 15 minutes. The following day the rat is placed once again in the same apparatus and the duration of immobility phase is scored during 5 minutes (Alba-Delgado et al., 2013). For mice, there is no need to expose them to the pre-test, so animals are directly lowered into an inescapable cylinder (height 20-46 cm, diameter 10-25 cm) containing 14-20 cm of water $\left(21-25^{\circ} \mathrm{C}\right.$ ) (Dimitrov et al., 2014; Gai et al., 2014; Descalzi et al., 2017; Yang et al., 2019a). Here the test duration is 6 minutes, and since little immobility is generally observed during the first 2 minutes, the duration of immobility is quantified over the last 4 minutes of the 6 minutes test (Yalcin et al., 2011). The animals are considered immobile when they float in the water, in an upright position, and made only small movements to keep their head above water. In this paradigm, the impossibility to escape an aversive situation creates a despair state in the animals, reflected by immobility time, thus an increase in immobility time is considered as a depressive-like behaviour. Besides immobility time, differentiating active behaviours between climbing, defined as forepaw vigorous upward movements in and out of the water, and swimming can also be recorded (Hu et al., 2009; Alba-Delgado et al., 2013). This distinction will then allow a finest assessment of despair behaviour since it has been shown that climbing behaviour was increased by norepinephrine-targeting antidepressant drugs, while swimming was modified by serotonin-targeted antidepressant drugs (Detke \& Lucki, 1996).

For most of the studies using FST to assess neuropathic pain-induced depression, an increased immobility time was observed at 4 weeks (Hu et al., 2010; Gai et al., 2014; Bruning et al., 2015; Wang et al., 2015b; Chung et al., 2017; Wang et al., 2017; Poupon et al., 2018) and 8 weeks (Suzuki et al., 2007; Goncalves et al., 2008; Descalzi et al., 2017; Boadas-Vaello et al., 2018; Hisaoka-Nakashima et al., 2019) post-surgery (Table 1, Figure 5 \& 6). Interestingly, in the SNI and CCI models a shift to an earlier development of depressive-like behaviours can be observed. Indeed, over the 15 studies reporting an increase in immobility time in CCI, 8 showed it at or even before 2 weeks post-surgery (Fukuhara et al., 2012; Li et al., 2014; Garg et al., 2017; Li et al., 2019) (see also Table 1, Figure 5 \& 6). For the SNI, among the 17 studies presenting depressive-like behaviour, 11 observed the development of deficits in active behaviour in this test before 2 weeks post-surgery (Stratinaki et al., 2013; Zhou et al., 2015; Laumet et al., 2017; Xu et 
al., 2017; Pan et al., 2018; Yang et al., 2019b) (see also Table 1, Figure 5 \& 6). This timing could however be related to the severity of the model(s), and the fact that pain related to paw might by itself also affect motor (swimming) capacity, thus interfering with FST. In the CCI model, fluctuation in the time-dependency of depressive-like behaviours could also be explained by the inter-individual variability in pain induction that may be present in this model. Similarly, in a chemotherapy-induced neuropathy an early onset of depressive-like behaviour has been reported (Redivo et al., 2016; Toma et al., 2017). Regarding inflammatory pain models, increased immobility time in FST has been detected between 7 and 35 post-induction days in CFA injected animals (Urban et al., 2011; Kim et al., 2012; Maciel et al., 2013; Borges et al., 2014; Le et al., 2014; Hamann et al., 2016; Zhang et al., 2016) and at 4 post-induction weeks in kaolin/carrageenan injected animals (Amorim et al., 2014). Finally, when conducted in an acid injection-induced model of fibromyalgia, a decrease in immobility time was observed after 19-20 post-operative days (Liu et al., 2014), after 10-14 days in an intermittent cold stress model (Nasu et al., 2019), and within few days in biogenic amine depletion models (Nagakura et al., 2009; Arora \& Chopra, 2013; de Souza et al., 2014; Klein et al., 2014; Siemian et al., 2019).

\subsubsection{Tail-suspension test}

A variant of the FST, also developed for antidepressant drug screening (Steru et al., 1985) and based on behavioural despair, is the tail suspension test (TST) in mice. It is sensitive to desipramine and amitriptyline (Steru et al., 1985). In TST, mice are suspended by the tail from a bar, $50 \mathrm{~cm}$ above the floor using an adhesive tape (1-2 $\mathrm{cm}$ from the proximal tail tip) (D'Aniello et al., 2017; Jiang et al., 2018). The test duration is 6 minutes and the immobility is measured during the whole test. Mice are considered as immobile when they hung down motionless (Gai et al., 2014). An increase immobility time is thought to represent depressive-like behaviour.

As for the FST, when the TST is used in CCI or SNI an early development of depressivelike behaviour (around 1 to 2 weeks) is observed (Zhao et al., 2014a; Zhao et al., 2014b; Jiang et al., 2018; Yang et al., 2019a). Similar results were found when using a chemotherapy-induced neuropathic pain model (Hache et al., 2015). For other neuropathic pain models, increased in immobility time was observed between 4 weeks and 2 months (Gai et al., 2014; Wu et al., 2014; Guida et al., 2015; Ferreira-Chamorro et al., 2018; Aguilar-Avila et al., 2019; Zhang et al., 2019) (Table 1, Figure 5 \& 6). For inflammatory pain models, depressive-like behaviours have been highlighted by the TST 7 to 14 days after CFA injection (Kim et al., 2012; Maciel et al., 2013; 
Omorogbe et al., 2018) and at 41 weeks in an osteoarthritis model (Griffin et al., 2010). Finally, in a fibromyalgia model, an increase in immobility time was observed within 3 post-induction days (Klein et al., 2014).

\subsubsection{Sucrose preference test}

The sucrose or saccharine preference test (SPT) was first described by Katz in 1982 (Katz, 1982), and pharmacologically validated five years later by Willner and collaborators using the tricyclic antidepressant desipramine (Willner et al., 1987). The purpose of this test is to assess in animals the decrease ability to feel pleasure, also called anhedonia, often reported in patients suffering from depression. Animals are individually housed for the duration of the test and are free to choose between water and sweet solution. An index of sweet solution preference is then calculated as the ratio of the sweet solution intake over total liquid intake. A decrease in this index suggests depressive-like behaviour (Dellarole et al., 2014; Xie et al., 2017). Today, a multitude of protocols are used to assess anhedonia in rodents. The sweet solution is mainly obtained using sucrose at a concentration varying from $0.5 \%$ (Gambeta et al., 2018) to 20\% (Liu et al., 2014), but concentrations of $1 \%$ or $2 \%$ are the most used (Bura et al., 2013; Wang et al., 2015b; La Porta et al., 2016; Zhu et al., 2017; Martinez-Navarro et al., 2019). To avoid a potential bias due to sucrose caloric value, it can be replaced by saccharine; the concentrations used are then comprised between 0.25 and $0.3 \%$ (Wu et al., 2014; Refsgaard et al., 2016). Usually, a period of habituation is required prior testing. During this period, from $2 \mathrm{~h}$ (Zong et al., 2018) to 10 days (Wang et al., 2011), the bottles of water and sweet solution are often interchanged to prevent any side preference. Before the test session, a water deprivation is sometimes done with a duration varying between 2 (Bura et al., 2013) to 24 hours (Yang et al., 2019a). Finally, when considering the test duration, it varies from 15 minutes (Liu et al., 2014; Ji et al., 2017) to 48 hours (Urban et al., 2011; Wu et al., 2014), but test sessions of 24 hours were the most commonly used (La Porta et al., 2016; Li et al., 2017; Xie et al., 2017; Gong et al., 2018; Pan et al., 2018; Wu et al., 2018; Martinez-Navarro et al., 2019).

Despite all these protocol variations, the majority of reported studies could asses a presence of anhedonia between one week (Goffer et al., 2013; Xu et al., 2017; Zhu et al., 2017; Wu et al., 2018; Fang et al., 2019b; Martinez-Navarro et al., 2019) to 10-11 weeks (Wu et al., 2014; Fu et

al., 2018; Thompson et al., 2018; Fang et al., 2019a) after neuropathic pain induction (see also

Figure $5 \& 6$ and Table 1). However, this time window depends on the considered model. 
Regarding the CCI model, anhedonia tends to arise at 4 post-surgery weeks (Dellarole et al., 2014; Li et al., 2017; Wang et al., 2019). Thus the lack of such behavioural deficit in the Gregoire and collaborator study could result from the fact that the test was performed at an earlier time point (Gregoire et al., 2012). Furthermore, two studies conducted in the SNI model showed the presence of individual differences (in pro-inflammatory cytokines or in gut microbiota) between animals that are resilient or sensitive to chronic pain induced-depression (Xie et al., 2017; Yang et al., 2019a). These inter-individual differences might explain that effect in the SPT is sometimes cohort-dependant. In inflammatory pain models, a decrease in sucrose consumption was observed at 2 days post-induction (Refsgaard et al., 2016) and lasted at least for 4 weeks (Amorim et al., 2014). Finally, in a fibromyalgia model, Liu and collaborators observed anhedonia-like behaviour at 19-20 post-induction days (Liu et al., 2014).

\subsubsection{Nesting test}

Nesting is an innate behaviour in rodents, which allows them to shelter from environment, maintain a certain heat and reproduce (Jirkof, 2014). As for the burrowing test described before, a deficit in nesting is an early sign of decreased well-being that can be rescued with chronic fluoxetine treatment (Farooq et al., 2018). In the study of Toma and collaborators, mice were individually housed with all the previous nesting material removed from the cage and placed in a dark room for an acclimation period of 30 minutes. Then, a compressed cotton nestlet was weighted and cut into 6 pieces placed on the top of the wire cage lid, evenly spaced. After 120 minutes the nestlet pieces remaining on the cage lid were weighted and a score given to the nest constructed. A score of 0 was given if no nest was formed, a score of 1 if the mice build a partial nest and a score of 2 if the nest was completely constructed. A poor nest score and a high amount of remaining nestlet on the cage lid are thought to indicate depressive-like behaviours. With this nesting protocol, no nesting deficit was found in a paclitaxel-induced neuropathic pain model (Toma et al., 2017).

If one wants to assess the nesting behaviour more precisely, other protocols have been used in mood disorder-related studies (see (Jirkof, 2014) for a review); the most common protocol being the one described by Deacon in 2003, with a score from 0 (no nest formed) to 4 (established nest). This protocol also takes into account the shape of the nest (flat or dome shaped), the position in the cage (in the centre or at a corner) and is performed overnight (Deacon, 2006a; Deacon, 2012). When using the nest test to assess depressive-like behaviour it is essential to make sure that 
the chosen protocol fits with the strain and sex of the animals used in the study. Indeed, differences in nest quality have been reported between males and females and between mice strains (Gaskill et al., 2012) or even between sub-strains (Sluyter et al., 1999).

\subsubsection{Splash Test}

The splash test (ST) is based on grooming, which is an important aspect of rodent behaviour and is often altered in animal models of depression (Santarelli et al., 2003; Yalcin et al., 2011). Animals are placed in a new cage with $1 \mathrm{~cm}$ of sawdust and a solution of $10 \%$ sucrose is sprayed on their back. The time spent for grooming as well as the grooming location (head or body) are measured for 5 minutes. A grooming deficit in this test is thought to be related to the loss of interest in performing self-oriented minor tasks, thus indicating the development of depressive-like behaviours. Moreover, the administration of antidepressant drugs, such as imipramine, desipramine, fluoxetine or maprotiline, rescued the grooming deficits in the unpredictable chronic mild stress mouse model of depression (Yalcin et al., 2008). When studied in a neuropathic pain model, more particularly in the cuff model, grooming deficits were reported between 6 and 9 postoperative weeks (Yalcin et al., 2011; Barthas et al., 2015; Sellmeijer et al., 2018) (Table 1, Figure 5 \& 6). Interestingly, Sellmeijer and collaborators studied the long term effect of neuropathic pain on affective behaviours and found that grooming deficits were still present at 14 post-operative weeks but no more at 16 weeks. In this study the extinction of depressive-like behaviours seemed to follow the recovery of ongoing pain.

\section{Discussion}

For this review, we found and analysed 144 articles related to the study of anxiodepressive-like disorders induced by chronic pain. The first articles on the topic were published shortly before the 2000 s, but there has been a sharp increase in the number of scientific publications in the recent years, pointing out the growing interest in the comorbidity between pain and anxiety and depression. While most published studies demonstrated the possibility to model anxiodepressivelike consequences of chronic pain in animals (and potentially highlighted the essential role of time in the development of these symptoms), contradictory results can still be observed. Beside the time factor, these differences between studies may be due to the chosen animal models and tests, as well as to the protocols used to perform the tests. Rather than relying on a single parameter in animal models, it may thus be important to prefer strategies that would include behavioural 
profiling based on performing several tests evaluating anxiety and depression (Yalcin et al., 2011; Sellmeijer et al., 2018). In this respect, choosing the appropriate tests and control condition is one of the critical steps to assess the affective consequences of chronic pain. For example, most of the tests measuring anxiety and depression in rodent depend on motor activity of animals (exploration of a novel environment, swimming), which might be altered by pain models and lead to bias in interpreting the results. It is thus critical to take into consideration the limit of each test. For instance FST is one of the most common paradigm used to detect depressive-like behaviours, despite the fact that besides antidepressants most psychostimulants could also decrease the immobility time (Bogdanova et al., 2013). Similarly when using the NSF, nesting, burrowing and marble burying tests, it should be kept in mind that these tests can in fact reflect various behavioural alterations at the same time, such as anxiety- or depressive-like behaviours for NSF (Dulawa \& Hen, 2005), as well as obsessive compulsive- and autism-like behaviours for marble burying (Deacon, 2006b; Angoa-Perez et al., 2013). Furthermore, the experimenter should be careful with the order of tests when using several tests on the same animals. Indeed, some tests are anxiogenic per se, like the FST or TST, and should preferably be performed at the end of the experiments to avoid risks of interactions with other tests. In addition, tests based on the fear generated by novelty can often only be done once (EPM, NSF, EZM). On the other hand, tests based on ethologically relevant rodent behaviours, such as grooming, nesting or burrowing assessment, are potentially less anxiogenic. These tests, together with social interaction and the sucrose preference test, have the advantage to be repeatable and thus useful for a longitudinal follow-up of the animals (Thomas et al., 2009; Kaidanovich-Beilin et al., 2011). For chronic pain studies, such longitudinal testing strategy allows evaluating emotional state before pain induction and at various time points afterwards, thus using the animal as its own control. However, the development of new devices, such as PhenoWorld, can reinforce the possibility of testing animals in their habitual environment in automatic fashion, with limited interaction with the experimenter and on long term periods (Castelhano-Carlos et al., 2014). In addition, apparatuses combining multiple tests (EPM, LDB and OF) in one testing paradigm (Ramos, 2008) can also be a good alternative.

In this issue, we aimed at describing anxiodepressive tests that are already used for studying the comorbidity of chronic pain and mood disorders, but it is worth to mention that other paradigms such as intracranial self-stimulation (ICSS), sexual behaviours, electroencephalography or 
circadian rhythm analysis (Castagne et al., 2009) can also be used to address motivation, anhedonia and sleep pattern which are frequently altered in chronic pain.

The diversity of tests has already enable notable breakthrough in the understanding of mood disorders and chronic pain comorbidity in animal models. However, in order to homogenize and increase the reproducibility of results, it is critical that the description of the parameters used for the testing is detailed in articles' methods. Indeed, important information such as handling and housing conditions or habituation to the testing room are often missing and thus prevent to conclude on the best practices to adopt. For example, as already mentioned previously light setting in tests like OF, EPM, or EZM are rarely specified although the use of a too bright light can induces anxiety-like behaviours even in control animals. Indeed, creating more relevant procedures and standardization of some of the most variable procedures (such as OF and SPT) among laboratories would be of great interest for the field. NIMH proposed a Research Domain Criteria system (RDoC) defining the good practices when evaluating psychopathologies in animal models that might be of great use for achieving this goal (Anderzhanova et al., 2017). Moreover, an effort is still needed in developing new methods to measure pain that are not based on nociceptive reflex response. Indeed, no study so far could show a correlation between the degree of nociceptive hypersensitivity and the anxiodepressive-like consequences. Thus, animals with or without anxiety- and/or depression-like phenotype can show similar mechanical or thermal withdrawal thresholds in animal models of pain (Gui et al., 2016; Xie et al., 2017; Yang et al., 2019a). Conversely, a recent study showed that rats that do not develop mechanical allodynia after SNI can still develop anxiodepressive-like behaviours similarly to painful rats (Guimaraes et al., 2019). There is thus no correlation in rodent models of chronic pain between the nociceptive response and the development of anxiodepressive disorders, which is similar to clinical reports (Dickens et al., 2002; Jensen et al., 2010; Keltner et al., 2012; Bagnato et al., 2015).

The above results may apparently question the causality relation between pain and emotional/cognitive disturbances. However, a causal link between pain and anxiodepressive consequences should not necessarily imply direct correlation between the intensity of nociceptive and anxiodepressive symptoms. Some observations suggest a temporal dissociation and partly independent mechanisms between these aspects of chronic pain (Zhou et al., 2015; Gui et al., 2016; Guimaraes et al., 2019). As example, in a model of sciatic nerve compression, mechanical hypersensitivity is no longer present 2 to 3 months after the surgery, while anxiodepressive-like behaviours can persist after the recovery of hypersensivity (Dimitrov et al., 2014; Sellmeijer et al., 
2018). Interestingly, one of these studies showed that ongoing pain can also persist beyond the recovery of nociceptive hypersensitivity (Sellmeijer et al., 2018), suggesting that reflex responses might not always be the best marker of pain.

Another limitation in the field relates to the fact that most published data used trauma models of neuropathic pain. While the cause of neuropathic pain is peripheral in a large set of patients, recent studies on anxiodepressive consequences of pain showed the potential involvement of distinct mechanisms with different neuropathic pain aetiologies, i.e. diabetic vs. trauma (AlbaDelgado et al., 2016). For mechanistic aspects, it will thus be necessary to study these comorbidities in the context of the considered aetiologies, and in particular distinguish neuropathy, inflammation and fibromyalgia; and within neuropathic pain also consider metabolic diseases or neurotoxicity beyond the mostly used lesion models. Indeed, only three preclinical articles so far focused on the anxiodepressive-like aspects in chemotherapy-induced murine models of neuropathic pain (Hache et al., 2015; Toma et al., 2017; Poupon et al., 2018). Similarly, models mimicking neuropathic pain following viral infection (HIV or varicella zoster virus) have been poorly studied in regard to anxiodepressive-like symptoms. The study of central neuropathic pain also requires improvements. Indeed, preclinical studies using spinal cord injury either failed in showing anxiodepressive phenotype or reported a lack of reproducibility, whereas the comorbidity is clinically well established (Haythornthwaite \& Benrud-Larson, 2000; Attal et al., 2011; Lim et al., 2017). Studies testing similar mechanistic hypotheses in models relying on different aetiologies would likely be important in the field in order to identify shared mechanistic features (which may illustrate core or converging mechanisms of anxiety or of depression) and distinct mechanistic features (which may be relevant to individualised medicine).

Despite their imperfections, animal models have proved to be useful in dissecting the mechanisms underlying the comorbidity between chronic pain and mood disorders. Thus, the involvement of several brain structures, such as the prefrontal cortex (PFC) including the anterior cingulate cortex, the hippocampus, the amygdala, the nucleus accumbens (NAc), the lateral habenula, the ventral tegmental area, or the locus coeruleus (LC) has been shown (Yalcin et al., 2014; Doan et al., 2015; Humo et al., 2019). Not only morphological, structural and functional modifications have been observed in these brain structures, but the implication of several neurotransmitter systems was also identified. For example, there is an increase in glutamatergic transmission in PFC, NAc, LC and amygdala (Goffer et al., 2013; Gonzalez-Sepulveda et al., 2016; Llorca-Torralba et al., 2018; Martinez-Navarro et al., 2019) leading to hyperactivities in 
these brain structures. Besides the glutamatergic system, the implication of the endocannabinoid system (Hasnie et al., 2007a; Wallace et al., 2007c; Jiang et al., 2019), and of serotoninergic, noradrenergic and opioidergic transmissions have also been identified in structures such as the LC, the amygdala, the striatum or the anterior cingulate cortex (ACC) (Narita et al., 2006b; Ji et al., 2017; Alba-Delgado et al., 2018; Sang et al., 2018; Thompson et al., 2018).

Beyond these anatomical and neurotransmitter-related information, animal studies on neuropathic pain also reported an implication of inflammatory mechanisms such as microglia activation (Galan-Arriero et al., 2014; Sawada et al., 2014; Wu et al., 2014; Galan-Arriero et al., 2015; Xu et al., 2017; Ferreira-Chamorro et al., 2018) and/or pro-inflammatory cytokine production (Norman et al., 2010; Dellarole et al., 2014; Gonzalez-Sepulveda et al., 2016) in mood disorders accompanying chronic pain. At intracellular level, changes in the mitogen-activated protein kinases (MAPK) and indoleamine 2, 3-dioxygenase 1 (IDO1) were also reported (Sawada et al., 2014; Zhou et al., 2015; Barthas et al., 2017). Looking at the mechanisms down to epigenetic level, the animal models and tests also allowed showing the recruitment of histone deacetylases (HDAC) (Descalzi et al., 2017) and of dimethyl-3-transferase (DM3T) (Wang et al., 2019). From anatomy to neural transmission and cellular, molecular and epigenetic changes, the animal models and tests thus provided major contributions to our understanding of the mechanisms linking pain and mood (for review: (Yalcin \& Barrot, 2014; Yalcin et al., 2014; Leite-Almeida et al., 2015; Humo et al., 2019).

In conclusion, despite their drawbacks that are highlighted in this review, preclinical models so far allowed exploring the anxiodepressive-like consequences of chronic pain. However, translational studies combining animal models and human condition, as well as side by side comparison of different animal models, should help us further improving the existing tests and guide us in developing new approaches to model this comorbidity in animals. Moreover, not all the patients suffering from chronic pain develop mood disorders. To better understand the mechanisms underlying the comorbidity between pain and mood disorders, it would thus also be critical to develop studies on such resiliency/susceptibility in animal models. In parallel, an effort is still needed in developing other measurements than the behavioural testing, such as the neuroimaging or biochemical biomarkers, in order to better characterize the anxiodepressive consequences of chronic pain. 


\section{References}

Aguilar-Avila, D.S., Flores-Soto, M.E., Tapia-Vazquez, C., Pastor-Zarandona, O.A., Lopez-Roa, R.I. \& Viveros-Paredes, J.M. (2019) beta-Caryophyllene, a Natural Sesquiterpene, Attenuates Neuropathic Pain and Depressive-Like Behavior in Experimental Diabetic Mice. J Med Food, 22, 460-468.

Alba-Delgado, C., Cebada-Aleu, A., Mico, J.A. \& Berrocoso, E. (2016) Comorbid anxiety-like behavior and locus coeruleus impairment in diabetic peripheral neuropathy: A comparative study with the chronic constriction injury model. Prog Neuropsychopharmacol Biol Psychiatry, 71, 45-56.

Alba-Delgado, C., Llorca-Torralba, M., Horrillo, I., Ortega, J.E., Mico, J.A., Sanchez-Blazquez, P., Meana, J.J. \& Berrocoso, E. (2013) Chronic pain leads to concomitant noradrenergic impairment and mood disorders. Biol Psychiatry, 73, 54-62.

Alba-Delgado, C., Llorca-Torralba, M., Mico, J.A. \& Berrocoso, E. (2018) The onset of treatment with the antidepressant desipramine is critical for the emotional consequences of neuropathic pain. Pain, 159, 2606-2619.

Amorim, D., David-Pereira, A., Pertovaara, A., Almeida, A. \& Pinto-Ribeiro, F. (2014) Amitriptyline reverses hyperalgesia and improves associated mood-like disorders in a model of experimental monoarthritis. Behavioural brain research, 265, 12-21.

Anderzhanova, E., Kirmeier, T. \& Wotjak, C.T. (2017) Animal models in psychiatric research: The RDoC system as a new framework for endophenotype-oriented translational neuroscience. Neurobiology of stress, 7, 47-56.

Andrews, N., Legg, E., Lisak, D., Issop, Y., Richardson, D., Harper, S., Pheby, T., Huang, W., Burgess, G., Machin, I. \& Rice, A.S. (2012) Spontaneous burrowing behaviour in the rat is reduced by peripheral nerve injury or inflammation associated pain. Eur J Pain, 16, 485-495.

Angoa-Perez, M., Kane, M.J., Briggs, D.I., Francescutti, D.M. \& Kuhn, D.M. (2013) Marble burying and nestlet shredding as tests of repetitive, compulsive-like behaviors in mice. Journal of visualized experiments : JoVE, 50978 .

Apkarian, A.V. \& Reckziegel, D. (2019) Peripheral and central viewpoints of chronic pain, and translational implications. Neurosci Lett, 702, 3-5.

This article is protected by copyright. All rights reserved 
Arora, V. \& Chopra, K. (2013) Possible involvement of oxido-nitrosative stress induced neuroinflammatory cascade and monoaminergic pathway: underpinning the correlation between nociceptive and depressive behaviour in a rodent model. $J$ Affect Disord, 151, 1041-1052.

Attal, N., Fermanian, C., Fermanian, J., Lanteri-Minet, M., Alchaar, H. \& Bouhassira, D. (2008) Neuropathic pain: are there distinct subtypes depending on the aetiology or anatomical lesion? Pain, 138, 343-353.

Attal, N., Lanteri-Minet, M., Laurent, B., Fermanian, J. \& Bouhassira, D. (2011) The specific disease burden of neuropathic pain: results of a French nationwide survey. Pain, 152, 2836-2843.

Avila-Martin, G., Galan-Arriero, I., Ferrer-Donato, A., Busquets, X., Gomez-Soriano, J., Escriba, P.V. \& Taylor, J. (2015) Oral 2-hydroxyoleic acid inhibits reflex hypersensitivity and open-field-induced anxiety after spared nerve injury. Eur J Pain, 19, 111-122.

Bagnato, G., De Andres, I., Sorbara, S., Verduci, E., Corallo, G., Ferrera, A., Morgante, S., Roberts, W.N., Jr. \& Bagnato, G. (2015) Pain threshold and intensity in rheumatic patients: correlations with the Hamilton Depression Rating scale. Clin Rheumatol, 34, 555-561.

Bair, M.J., Robinson, R.L., Katon, W. \& Kroenke, K. (2003) Depression and pain comorbidity: a literature review. Arch Intern Med, 163, 2433-2445.

Baliki, M.N. \& Apkarian, A.V. (2015) Nociception, Pain, Negative Moods, and Behavior Selection. Neuron, 87, 474-491.

Barrot, M. (2012) Tests and models of nociception and pain in rodents. Neuroscience, 211, 39-50.

Barthas, F., Humo, M., Gilsbach, R., Waltisperger, E., Karatas, M., Leman, S., Hein, L., Belzung, C., Boutillier, A.L., Barrot, M. \& Yalcin, I. (2017) Cingulate Overexpression of Mitogen-Activated Protein Kinase Phosphatase-1 as a Key Factor for Depression. Biol Psychiatry, 82, 370-379.

Barthas, F., Sellmeijer, J., Hugel, S., Waltisperger, E., Barrot, M. \& Yalcin, I. (2015) The anterior cingulate cortex is a critical hub for pain-induced depression. Biol Psychiatry, 77, 236-245.

Basbaum, A.I., and Jessell, T. (2000) The perception of pain. E.R. Kandel, J. Schwartz, and T. Jessell, eds. (New York: Appleton and Lange).

Basbaum, A.I., Bautista, D.M., Scherrer, G. \& Julius, D. (2009) Cellular and molecular mechanisms of pain. Cell, 139, 267-284. 
Behrmann, D.L., Bresnahan, J.C., Beattie, M.S. \& Shah, B.R. (1992) Spinal cord injury produced by consistent mechanical displacement of the cord in rats: behavioral and histologic analysis. $J$ Neurotrauma, 9, 197-217.

Benbouzid, M., Pallage, V., Rajalu, M., Waltisperger, E., Doridot, S., Poisbeau, P., Freund-Mercier, M.J. \& Barrot, M. (2008) Sciatic nerve cuffing in mice: a model of sustained neuropathic pain. Eur J Pain, 12, 591-599.

Bennett, G.J. \& Xie, Y.K. (1988) A peripheral mononeuropathy in rat that produces disorders of pain sensation like those seen in man. Pain, 33, 87-107.

Birmann, P.T., Sousa, F.S.S., Domingues, M., Bruning, C.A., Vieira, B.M., Lenardao, E.J. \& Savegnago, L. (2019) 3-(4-Chlorophenylselanyl)-1-methyl-1H-indole promotes recovery of neuropathic pain and depressive-like behavior induced by partial constriction of the sciatic nerve in mice. $J$ Trace Elem Med Biol, 54, 126-133.

Blasco-Serra, A., Escrihuela-Vidal, F., Gonzalez-Soler, E.M., Martinez-Exposito, F., Blasco-Ausina, M.C., Martinez-Bellver, S., Cervera-Ferri, A., Teruel-Marti, V. \& Valverde-Navarro, A.A. (2015) Depressive-like symptoms in a reserpine-induced model of fibromyalgia in rats. Physiology \& behavior, 151, 456-462.

Boadas-Vaello, P., Homs, J., Portero-Tresserra, M., Alvarez-Perez, B., Deulofeu, M. \& Verdu, E. (2018) Graded photochemical spinal cord injury results in chronic hyperalgesia and depression-like behaviour but no anxiety exacerbation in female BALB/c mice. Neurosci Lett, 664, 98-106.

Bogdanova, O.V., Kanekar, S., D'Anci, K.E. \& Renshaw, P.F. (2013) Factors influencing behavior in the forced swim test. Physiology \& behavior, 118, 227-239.

Borges, G., Neto, F., Mico, J.A. \& Berrocoso, E. (2014) Reversal of monoarthritis-induced affective disorders by diclofenac in rats. Anesthesiology, 120, 1476-1490.

Bourin, M. \& Hascoet, M. (2003) The mouse light/dark box test. European journal of pharmacology, 463, $55-65$.

Breivik, H., Collett, B., Ventafridda, V., Cohen, R. \& Gallacher, D. (2006) Survey of chronic pain in Europe: prevalence, impact on daily life, and treatment. Eur J Pain, 10, 287-333.

Bromet, E., Andrade, L.H., Hwang, I., Sampson, N.A., Alonso, J., de Girolamo, G., de Graaf, R., Demyttenaere, K., Hu, C., Iwata, N., Karam, A.N., Kaur, J., Kostyuchenko, S., Lepine, J.P., Levinson, D., Matschinger, H., Mora, M.E., Browne, M.O., Posada-Villa, J., Viana, M.C., 
Williams, D.R. \& Kessler, R.C. (2011) Cross-national epidemiology of DSM-IV major depressive episode. BMC Med, 9, 90.

Bruning, C.A., Martini, F., Soares, S.M., Sampaio, T.B., Gai, B.M., Duarte, M.M. \& Nogueira, C.W. (2015) m-Trifluoromethyl-diphenyl diselenide, a multi-target selenium compound, prevented mechanical allodynia and depressive-like behavior in a mouse comorbid pain and depression model. Prog Neuropsychopharmacol Biol Psychiatry, 63, 35-46.

Bura, A.S., Guegan, T., Zamanillo, D., Vela, J.M. \& Maldonado, R. (2013) Operant self-administration of a sigma ligand improves nociceptive and emotional manifestations of neuropathic pain. Eur J Pain, 17, 832-843.

Butler, S.H., Godefroy, F., Besson, J.M. \& Weil-Fugazza, J. (1992) A limited arthritic model for chronic pain studies in the rat. Pain, 48, 73-81.

Cabo-Meseguer, A., Cerda-Olmedo, G. \& Trillo-Mata, J.L. (2017) Fibromyalgia: Prevalence, epidemiologic profiles and economic costs. Med Clin (Barc), 149, 441-448.

Calvino, B., Besson, J.M., Boehrer, A. \& Depaulis, A. (1996) Ultrasonic vocalization (22-28 kHz) in a model of chronic pain, the arthritic rat: effects of analgesic drugs. Neuroreport, 7, 581-584.

Caspani, O., Reitz, M.C., Ceci, A., Kremer, A. \& Treede, R.D. (2014) Tramadol reduces anxiety-related and depression-associated behaviors presumably induced by pain in the chronic constriction injury model of neuropathic pain in rats. Pharmacology, biochemistry, and behavior, 124, 290-296.

Castagne, V., Moser, P. \& Porsolt, R.D. (2009) Behavioral Assessment of Antidepressant Activity in Rodents Methods of Behavior Analysis in Neuroscience. Taylor \& Francis Group, LLC., Boca Raton FL.

Castelhano-Carlos, M., Costa, P.S., Russig, H. \& Sousa, N. (2014) PhenoWorld: a new paradigm to screen rodent behavior. Translational psychiatry, 4, e399.

Cavaletti, G., Tredici, G., Braga, M. \& Tazzari, S. (1995) Experimental peripheral neuropathy induced in adult rats by repeated intraperitoneal administration of taxol. Exp Neurol, 133, 64-72.

Cavaletti, G., Tredici, G., Petruccioli, M.G., Donde, E., Tredici, P., Marmiroli, P., Minoia, C., Ronchi, A., Bayssas, M. \& Etienne, G.G. (2001) Effects of different schedules of oxaliplatin treatment on the peripheral nervous system of the rat. Eur J Cancer, 37, 2457-2463.

This article is protected by copyright. All rights reserved 
Chen, J., Song, Y., Yang, J., Zhang, Y., Zhao, P., Zhu, X.J. \& Su, H.C. (2013) The contribution of TNFalpha in the amygdala to anxiety in mice with persistent inflammatory pain. Neurosci Lett, 541, 275-280.

Chen, Z., Wei, H., Pertovaara, A., Wang, J. \& Carlson, S. (2018) Anxiety- and activity-related effects of paracetamol on healthy and neuropathic rats. Pharmacol Res Perspect, 6.

Chen, Z., Wei, H., Sagalajev, B., Koivisto, A. \& Pertovaara, A. (2019) Amygdaloid administration of tetrapentylammonium attenuates development of pain and anxiety-like behavior following peripheral nerve injury. Pharmacol Rep, 71, 54-60.

Choi, Y., Yoon, Y.W., Na, H.S., Kim, S.H. \& Chung, J.M. (1994) Behavioral signs of ongoing pain and cold allodynia in a rat model of neuropathic pain. Pain, 59, 369-376.

Choleris, E., Thomas, A.W., Kavaliers, M. \& Prato, F.S. (2001) A detailed ethological analysis of the mouse open field test: effects of diazepam, chlordiazepoxide and an extremely low frequency pulsed magnetic field. Neuroscience and biobehavioral reviews, 25, 235-260.

Chung, G., Kim, C.Y., Yun, Y.C., Yoon, S.H., Kim, M.H., Kim, Y.K. \& Kim, S.J. (2017) Upregulation of prefrontal metabotropic glutamate receptor 5 mediates neuropathic pain and negative mood symptoms after spinal nerve injury in rats. Sci Rep, 7, 9743.

Clauw, D.J. (2014) Fibromyalgia: a clinical review. JAMA, 311, 1547-1555.

Colleoni, M. \& Sacerdote, P. (2010) Murine models of human neuropathic pain. Biochim Biophys Acta, 1802, 924-933.

Colloca, L., Ludman, T., Bouhassira, D., Baron, R., Dickenson, A.H., Yarnitsky, D., Freeman, R., Truini, A., Attal, N., Finnerup, N.B., Eccleston, C., Kalso, E., Bennett, D.L., Dworkin, R.H. \& Raja, S.N. (2017) Neuropathic pain. Nat Rev Dis Primers, 3, 17002.

Cook, C.D. \& Moore, K.I. (2006) Effects of sex, hindpaw injection site and stimulus modality on nociceptive sensitivity in arthritic rats. Physiology \& behavior, 87, 552-562.

Crawley, J. \& Goodwin, F.K. (1980) Preliminary report of a simple animal behavior model for the anxiolytic effects of benzodiazepines. Pharmacology, biochemistry, and behavior, 13, 167-170.

D'Amour, F.E. \& Smith, D.L. (1941) A method for determining loss of pain sensation. J Pharmacol Exp Ther, 72, 74-79. 
D'Aniello, A., Luongo, L., Romano, R., Iannotta, M., Marabese, I., Boccella, S., Belardo, C., de Novellis, V., Arra, C., Barbieri, A., D'Aniello, B., Scandurra, A., Magliozzi, L., Fisher, G., Guida, F. \& Maione, S. (2017) d-Aspartic acid ameliorates painful and neuropsychiatric changes and reduces beta-amyloid Abeta1-42 peptide in a long lasting model of neuropathic pain. Neurosci Lett, 651, 151-158.

de Souza, A.H., da Costa Lopes, A.M., Castro, C.J., Jr., Pereira, E.M., Klein, C.P., da Silva, C.A., Jr., da Silva, J.F., Ferreira, J. \& Gomez, M.V. (2014) The effects of Phalphal beta, a spider toxin, calcium channel blocker, in a mouse fibromyalgia model. Toxicon, $\mathbf{8 1}, 37-42$.

Deacon, R. (2012) Assessing burrowing, nest construction, and hoarding in mice. Journal of visualized experiments : JoVE, e2607.

Deacon, R.M. (2006a) Assessing nest building in mice. Nature protocols, 1, 1117-1119.

Deacon, R.M. (2006b) Digging and marble burying in mice: simple methods for in vivo identification of biological impacts. Nature protocols, 1, 122-124.

Deacon, R.M., Raley, J.M., Perry, V.H. \& Rawlins, J.N. (2001) Burrowing into prion disease. Neuroreport, 12, 2053-2057.

Decosterd, I. \& Woolf, C.J. (2000) Spared nerve injury: an animal model of persistent peripheral neuropathic pain. Pain, 87, 149-158.

Dellarole, A., Morton, P., Brambilla, R., Walters, W., Summers, S., Bernardes, D., Grilli, M. \& Bethea, J.R. (2014) Neuropathic pain-induced depressive-like behavior and hippocampal neurogenesis and plasticity are dependent on TNFR1 signaling. Brain Behav Immun, 41, 65-81.

Descalzi, G., Mitsi, V., Purushothaman, I., Gaspari, S., Avrampou, K., Loh, Y.E., Shen, L. \& Zachariou, V. (2017) Neuropathic pain promotes adaptive changes in gene expression in brain networks involved in stress and depression. Sci Signal, 10.

Detke, M.J. \& Lucki, I. (1996) Detection of serotonergic and noradrenergic antidepressants in the rat forced swimming test: the effects of water depth. Behavioural brain research, 73, 43-46.

Deuis, J.R., Dvorakova, L.S. \& Vetter, I. (2017) Methods Used to Evaluate Pain Behaviors in Rodents. Front Mol Neurosci, 10, 284.

Di Paola, R. \& Cuzzocrea, S. (2008) Predictivity and sensitivity of animal models of arthritis. Autoimmun Rev, 8, 73-75. 
Dickens, C., Jayson, M. \& Creed, F. (2002) Psychological correlates of pain behavior in patients with chronic low back pain. Psychosomatics, 43, 42-48.

Dimitrov, E.L., Tsuda, M.C., Cameron, H.A. \& Usdin, T.B. (2014) Anxiety- and depression-like behavior and impaired neurogenesis evoked by peripheral neuropathy persist following resolution of prolonged tactile hypersensitivity. $J$ Neurosci, 34, 12304-12312.

do Nascimento, G.C. \& Leite-Panissi, C.R. (2014) Time-dependent analysis of nociception and anxiety-like behavior in rats submitted to persistent inflammation of the temporomandibular joint. Physiology \& behavior, 125, 1-7.

Doan, L., Manders, T. \& Wang, J. (2015) Neuroplasticity underlying the comorbidity of pain and depression. Neural Plast, 2015, 504691.

Dulawa, S.C. \& Hen, R. (2005) Recent advances in animal models of chronic antidepressant effects: the novelty-induced hypophagia test. Neuroscience and biobehavioral reviews, 29, 771-783.

Fang, X., Xu, X., Lin, X. \& Liu, R. (2019a) Downregulated spinal IRF8 and BDNF in NAC are involved in neuropathic pain-induced depression relief via pulsed radiofrequency on dorsal root ganglion in rat SNI model. Brain Res Bull, 146, 192-200.

Fang, X., Zhan, G., Zhang, J., Xu, H., Zhu, B., Hu, Y., Yang, C. \& Luo, A. (2019b) Abnormalities in Inflammatory Cytokines Confer Susceptible to Chronic Neuropathic Pain-related Anhedonia in a Rat Model of Spared Nerve Injury. Clin Psychopharmacol Neurosci, 17, 189-199.

Farooq, R.K., Tanti, A., Ainouche, S., Roger, S., Belzung, C. \& Camus, V. (2018) A P2X7 receptor antagonist reverses behavioural alterations, microglial activation and neuroendocrine dysregulation in an unpredictable chronic mild stress (UCMS) model of depression in mice. Psychoneuroendocrinology, 97, 120-130.

Fasick, V., Spengler, R.N., Samankan, S., Nader, N.D. \& Ignatowski, T.A. (2015) The hippocampus and TNF: Common links between chronic pain and depression. Neuroscience and biobehavioral reviews, 53, 139-159.

Fehrenbacher, J.C., Vasko, M.R. \& Duarte, D.B. (2012) Models of inflammation: Carrageenan- or complete Freund's Adjuvant (CFA)-induced edema and hypersensitivity in the rat. Curr Protoc Pharmacol, Chapter 5, Unit5 4.

Fernandez-Guasti, A., Reyes, R., Martinez-Mota, L. \& Lopez-Munoz, F.J. (2005) Influence of inflammatory nociception on the anxiolytic-like effect of diazepam and buspirone in rats. Psychopharmacology, 180, 399-407. 
Ferreira-Chamorro, P., Redondo, A., Riego, G., Leanez, S. \& Pol, O. (2018) Sulforaphane Inhibited the Nociceptive Responses, Anxiety- and Depressive-Like Behaviors Associated With Neuropathic Pain and Improved the Anti-allodynic Effects of Morphine in Mice. Front Pharmacol, 9, 1332.

Fiest, K.M., Hitchon, C.A., Bernstein, C.N., Peschken, C.A., Walker, J.R., Graff, L.A., Zarychanski, R., Abou-Setta, A., Patten, S.B., Sareen, J., Bolton, J., Marrie, R.A., Burden, C.T.D.t. \& Managing the Effects of Psychiatric Comorbidity in Chronic Immunoinflammatory, D. (2017) Systematic Review and Meta-analysis of Interventions for Depression and Anxiety in Persons With Rheumatoid Arthritis. J Clin Rheumatol, 23, 425-434.

Fietta, P., Fietta, P. \& Manganelli, P. (2007) Fibromyalgia and psychiatric disorders. Acta Biomed, 78, 8895.

File, S.E. \& Seth, P. (2003) A review of 25 years of the social interaction test. European journal of pharmacology, 463, 35-53.

Fischer, B.D., Adeyemo, A., O'Leary, M.E. \& Bottaro, A. (2017) Animal models of rheumatoid pain: experimental systems and insights. Arthritis Res Ther, 19, 146.

Fu, B., Wen, S.N., Wang, B., Wang, K., Zhang, J.Y., Weng, X.C. \& Liu, S.J. (2018) Gabapentin regulates dopaminergic neuron firing and theta oscillation in the ventral tegmental area to reverse depression-like behavior in chronic neuropathic pain state. J Pain Res, 11, 2247-2256.

Fuchs, P.N. \& McNabb, C.T. (2012) The place escape/avoidance paradigm: a novel method to assess nociceptive processing. J Integr Neurosci, 11, 61-72.

Fukuhara, K., Ishikawa, K., Yasuda, S., Kishishita, Y., Kim, H.K., Kakeda, T., Yamamoto, M., Norii, T. \& Ishikawa, T. (2012) Intracerebroventricular 4-methylcatechol (4-MC) ameliorates chronic pain associated with depression-like behavior via induction of brain-derived neurotrophic factor (BDNF). Cell Mol Neurobiol, 32, 971-977.

Gai, B.M., Bortolatto, C.F., Bruning, C.A., Zborowski, V.A., Stein, A.L., Zeni, G. \& Nogueira, C.W. (2014) Depression-related behavior and mechanical allodynia are blocked by 3-(4fluorophenylselenyl)-2,5-diphenylselenophene in a mouse model of neuropathic pain induced by partial sciatic nerve ligation. Neuropharmacology, 79, 580-589.

Galan-Arriero, I., Avila-Martin, G., Ferrer-Donato, A., Gomez-Soriano, J., Bravo-Esteban, E. \& Taylor, J. (2014) Oral administration of the p38alpha MAPK inhibitor, UR13870, inhibits affective pain behavior after spinal cord injury. Pain, 155, 2188-2198.

This article is protected by copyright. All rights reserved 
Galan-Arriero, I., Avila-Martin, G., Ferrer-Donato, A., Gomez-Soriano, J., Piazza, S. \& Taylor, J. (2015) Early treatment with UR13870, a novel inhibitor of p38alpha mitogenous activated protein kinase, prevents hyperreflexia and anxiety behaviors, in the spared nerve injury model of neuropathic pain. Neurosci Lett, 604, 69-74.

Gambeta, E., Batista, M.A., Maschio, G.P., Turnes, J.M., Araya, E.I. \& Chichorro, J.G. (2018) Anxietybut not depressive-like behaviors are related to facial hyperalgesia in a model of trigeminal neuropathic pain in rats. Physiology \& behavior, 191, 131-137.

Garg, S., Deshmukh, V.R. \& Prasoon, P. (2017) Possible modulation of PPAR-gamma cascade against depression caused by neuropathic pain in rats. J Basic Clin Physiol Pharmacol, 28, 593-600.

Gaskill, B.N., Gordon, C.J., Pajor, E.A., Lucas, J.R., Davis, J.K. \& Garner, J.P. (2012) Heat or insulation: behavioral titration of mouse preference for warmth or access to a nest. PLoS One, 7, e32799.

Georgiev, T. \& Angelov, A.K. (2019) Modifiable risk factors in knee osteoarthritis: treatment implications. Rheumatol Int.

Goffer, Y., Xu, D., Eberle, S.E., D'Amour, J., Lee, M., Tukey, D., Froemke, R.C., Ziff, E.B. \& Wang, J. (2013) Calcium-permeable AMPA receptors in the nucleus accumbens regulate depression-like behaviors in the chronic neuropathic pain state. J Neurosci, 33, 19034-19044.

Goncalves, L., Silva, R., Pinto-Ribeiro, F., Pego, J.M., Bessa, J.M., Pertovaara, A., Sousa, N. \& Almeida, A. (2008) Neuropathic pain is associated with depressive behaviour and induces neuroplasticity in the amygdala of the rat. Exp Neurol, 213, 48-56.

Gong, X., Chen, Y., Chang, J., Huang, Y., Cai, M. \& Zhang, M. (2018) Environmental enrichment reduces adolescent anxiety- and depression-like behaviors of rats subjected to infant nerve injury. $J$ Neuroinflammation, 15, 262.

Gonzalez-Sepulveda, M., Pozo, O.J., Marcos, J. \& Valverde, O. (2016) Chronic pain causes a persistent anxiety state leading to increased ethanol intake in CD1 mice. $J$ Psychopharmacol, 30, 188-203.

Green, P.G., Alvarez, P., Gear, R.W., Mendoza, D. \& Levine, J.D. (2011) Further validation of a model of fibromyalgia syndrome in the rat. J Pain, 12, 811-818.

Gregoire, S., Michaud, V., Chapuy, E., Eschalier, A. \& Ardid, D. (2012) Study of emotional and cognitive impairments in mononeuropathic rats: effect of duloxetine and gabapentin. Pain, 153, 1657-1663.

This article is protected by copyright. All rights reserved 
Gregoire, S., Wattiez, A.S., Etienne, M., Marchand, F. \& Ardid, D. (2014) Monoarthritis-induced emotional and cognitive impairments in rats are sensitive to low systemic doses or intra-amygdala injections of morphine. European journal of pharmacology, 735, 1-9.

Griffin, T.M., Fermor, B., Huebner, J.L., Kraus, V.B., Rodriguiz, R.M., Wetsel, W.C., Cao, L., Setton, L.A. \& Guilak, F. (2010) Diet-induced obesity differentially regulates behavioral, biomechanical, and molecular risk factors for osteoarthritis in mice. Arthritis Res Ther, 12, R130.

Gui, W.S., Wei, X., Mai, C.L., Murugan, M., Wu, L.J., Xin, W.J., Zhou, L.J. \& Liu, X.G. (2016) Interleukin-1beta overproduction is a common cause for neuropathic pain, memory deficit, and depression following peripheral nerve injury in rodents. Mol Pain, 12.

Guida, F., Luongo, L., Marmo, F., Romano, R., Iannotta, M., Napolitano, F., Belardo, C., Marabese, I., D'Aniello, A., De Gregorio, D., Rossi, F., Piscitelli, F., Lattanzi, R., de Bartolomeis, A., Usiello, A., Di Marzo, V., de Novellis, V. \& Maione, S. (2015) Palmitoylethanolamide reduces pain-related behaviors and restores glutamatergic synapses homeostasis in the medial prefrontal cortex of neuropathic mice. Mol Brain, 8, 47.

Guimaraes, M.R., Soares, A.R., Cunha, A.M., Esteves, M., Borges, S., Magalhaes, R., Moreira, P.S., Rodrigues, A.J., Sousa, N., Almeida, A. \& Leite-Almeida, H. (2019) Evidence for lack of direct causality between pain and affective disturbances in a rat peripheral neuropathy model. Genes Brain Behav, 18, e12542.

Guo, H.L., Xiao, Y., Tian, Z., Li, X.B., Wang, D.S., Wang, X.S., Zhang, Z.W., Zhao, M.G. \& Liu, S.B. (2016) Anxiolytic effects of sesamin in mice with chronic inflammatory pain. Nutr Neurosci, 19, 231-236.

Gustorff, B., Dorner, T., Likar, R., Grisold, W., Lawrence, K., Schwarz, F. \& Rieder, A. (2008) Prevalence of self-reported neuropathic pain and impact on quality of life: a prospective representative survey. Acta Anaesthesiol Scand, 52, 132-136.

Haanpaa, M., Attal, N., Backonja, M., Baron, R., Bennett, M., Bouhassira, D., Cruccu, G., Hansson, P., Haythornthwaite, J.A., Iannetti, G.D., Jensen, T.S., Kauppila, T., Nurmikko, T.J., Rice, A.S., Rowbotham, M., Serra, J., Sommer, C., Smith, B.H. \& Treede, R.D. (2011) NeuPSIG guidelines on neuropathic pain assessment. Pain, 152, 14-27.

Hache, G., Guiard, B.P., Nguyen, T.H., Quesseveur, G., Gardier, A.M., Peters, D., Munro, G. \& Coudore, F. (2015) Antinociceptive activity of the new triple reuptake inhibitor NS18283 in a mouse model of chemotherapy-induced neuropathic pain. Eur J Pain, 19, 322-333.

This article is protected by copyright. All rights reserved 
Hamann, F.R., Zago, A.M., Rossato, M.F., Beck, V.R., Mello, C.F., de Brum, T.F., de Carvalho, L.M., Faccin, H., Oliveira, S.M. \& Rubin, M.A. (2016) Antinociceptive and antidepressant-like effects of the crude extract of Vitex megapotamica in rats. $J$ Ethnopharmacol, 192, 210-216.

Han, J.S., Bird, G.C., Li, W., Jones, J. \& Neugebauer, V. (2005) Computerized analysis of audible and ultrasonic vocalizations of rats as a standardized measure of pain-related behavior. $J$ Neurosci Methods, 141, 261-269.

Hargreaves, K., Dubner, R., Brown, F., Flores, C. \& Joris, J. (1988) A new and sensitive method for measuring thermal nociception in cutaneous hyperalgesia. Pain, 32, 77-88.

Harper, R.P., Kerins, C.A., McIntosh, J.E., Spears, R. \& Bellinger, L.L. (2001) Modulation of the inflammatory response in the rat TMJ with increasing doses of complete Freund's adjuvant. Osteoarthritis Cartilage, 9, 619-624.

Hasnie, F.S., Breuer, J., Parker, S., Wallace, V., Blackbeard, J., Lever, I., Kinchington, P.R., Dickenson, A.H., Pheby, T. \& Rice, A.S. (2007a) Further characterization of a rat model of varicella zoster virus-associated pain: Relationship between mechanical hypersensitivity and anxiety-related behavior, and the influence of analgesic drugs. Neuroscience, 144, 1495-1508.

Hasnie, F.S., Wallace, V.C., Hefner, K., Holmes, A. \& Rice, A.S. (2007b) Mechanical and cold hypersensitivity in nerve-injured $\mathrm{C} 57 \mathrm{BL} / 6 \mathrm{~J}$ mice is not associated with fear-avoidance- and depression-related behaviour. Br J Anaesth, 98, 816-822.

Hauser, W., Ablin, J., Fitzcharles, M.A., Littlejohn, G., Luciano, J.V., Usui, C. \& Walitt, B. (2015) Fibromyalgia. Nat Rev Dis Primers, 1, 15022.

Haythornthwaite, J.A. \& Benrud-Larson, L.M. (2000) Psychological aspects of neuropathic pain. Clin J Pain, 16, S101-105.

Hisaoka-Nakashima, K., Tomimura, Y., Yoshii, T., Ohata, K., Takada, N., Zhang, F.F., Nakamura, Y., Liu, K., Wake, H., Nishibori, M., Nakata, Y. \& Morioka, N. (2019) High-mobility group box 1mediated microglial activation induces anxiodepressive-like behaviors in mice with neuropathic pain. Prog Neuropsychopharmacol Biol Psychiatry, 92, 347-362.

Hooten, W.M. (2016) Chronic Pain and Mental Health Disorders: Shared Neural Mechanisms, Epidemiology, and Treatment. Mayo Clinic proceedings, 91, 955-970.

Hsu, W.H., Lee, C.H., Chao, Y.M., Kuo, C.H., Ku, W.C., Chen, C.C. \& Lin, Y.L. (2019) ASIC3-dependent metabolomics profiling of serum and urine in a mouse model of fibromyalgia. Sci Rep, 9, 12123.

This article is protected by copyright. All rights reserved 
Hu, B., Doods, H., Treede, R.D. \& Ceci, A. (2009) Depression-like behaviour in rats with mononeuropathy is reduced by the CB2-selective agonist GW405833. Pain, 143, 206-212.

Hu, Y., Yang, J., Hu, Y., Wang, Y. \& Li, W. (2010) Amitriptyline rather than lornoxicam ameliorates neuropathic pain-induced deficits in abilities of spatial learning and memory. Eur J Anaesthesiol, 27, 162-168.

Huang, W., Calvo, M., Karu, K., Olausen, H.R., Bathgate, G., Okuse, K., Bennett, D.L. \& Rice, A.S. (2013) A clinically relevant rodent model of the HIV antiretroviral drug stavudine induced painful peripheral neuropathy. Pain, 154, 560-575.

Hubbard, C.S., Khan, S.A., Xu, S., Cha, M., Masri, R. \& Seminowicz, D.A. (2015) Behavioral, metabolic and functional brain changes in a rat model of chronic neuropathic pain: a longitudinal MRI study. Neuroimage, 107, 333-344.

Humo, M., Lu, H. \& Yalcin, I. (2019) The molecular neurobiology of chronic pain-induced depression. Cell Tissue Res, 377, 21-43.

Imboden, J.B. (2009) The immunopathogenesis of rheumatoid arthritis. Annu Rev Pathol, 4, 417-434.

Jaggi, A.S., Jain, V. \& Singh, N. (2011) Animal models of neuropathic pain. Fundam Clin Pharmacol, 25, $1-28$.

Jensen, K.B., Petzke, F., Carville, S., Fransson, P., Marcus, H., Williams, S.C., Choy, E., Mainguy, Y., Gracely, R., Ingvar, M. \& Kosek, E. (2010) Anxiety and depressive symptoms in fibromyalgia are related to poor perception of health but not to pain sensitivity or cerebral processing of pain. Arthritis Rheum, 62, 3488-3495.

Ji, G., Fu, Y., Ruppert, K.A. \& Neugebauer, V. (2007) Pain-related anxiety-like behavior requires CRF1 receptors in the amygdala. Mol Pain, $\mathbf{3}, 13$.

Ji, G., Yakhnitsa, V., Kiritoshi, T., Presto, P. \& Neugebauer, V. (2018) Fear extinction learning ability predicts neuropathic pain behaviors and amygdala activity in male rats. Mol Pain, 14, 1744806918804441.

Ji, G., Zhang, W., Mahimainathan, L., Narasimhan, M., Kiritoshi, T., Fan, X., Wang, J., Green, T.A. \& Neugebauer, V. (2017) 5-HT2C Receptor Knockdown in the Amygdala Inhibits Neuropathic-PainRelated Plasticity and Behaviors. J Neurosci, 37, 1378-1393.

This article is protected by copyright. All rights reserved 
Jiang, H., Fang, D., Kong, L.Y., Jin, Z.R., Cai, J., Kang, X.J., Wan, Y. \& Xing, G.G. (2014) Sensitization of neurons in the central nucleus of the amygdala via the decreased GABAergic inhibition contributes to the development of neuropathic pain-related anxiety-like behaviors in rats. $\mathrm{Mol}$ Brain, 7, 72.

Jiang, H.X., Ke, B.W., Liu, J., Ma, G., Hai, K.R., Gong, D.Y., Yang, Z. \& Zhou, C. (2019) Inhibition of Fatty Acid Amide Hydrolase Improves Depressive-Like Behaviors Independent of Its Peripheral Antinociceptive Effects in a Rat Model of Neuropathic Pain. Anesthesia and analgesia, 129, 587597.

Jiang, X., Yan, Q., Liu, F., Jing, C., Ding, L., Zhang, L. \& Pang, C. (2018) Chronic trans-astaxanthin treatment exerts antihyperalgesic effect and corrects co-morbid depressive like behaviors in mice with chronic pain. Neurosci Lett, 662, 36-43.

Jimenez-Gomez, C., Osentoski, A. \& Woods, J.H. (2011) Pharmacological evaluation of the adequacy of marble burying as an animal model of compulsion and/or anxiety. Behavioural pharmacology, 22, 711-713.

Jirkof, P. (2014) Burrowing and nest building behavior as indicators of well-being in mice. $J$ Neurosci Methods, 234, 139-146.

Jolivalt, C.G., Frizzi, K.E., Guernsey, L., Marquez, A., Ochoa, J., Rodriguez, M. \& Calcutt, N.A. (2016) Peripheral Neuropathy in Mouse Models of Diabetes. Curr Protoc Mouse Biol, 6, 223-255.

Joseph, E.K., Chen, X., Khasar, S.G. \& Levine, J.D. (2004) Novel mechanism of enhanced nociception in a model of AIDS therapy-induced painful peripheral neuropathy in the rat. Pain, 107, 147-158.

Jourdan, D., Ardid, D. \& Eschalier, A. (2002) Analysis of ultrasonic vocalisation does not allow chronic pain to be evaluated in rats. Pain, 95, 165-173.

Kaidanovich-Beilin, O., Lipina, T., Vukobradovic, I., Roder, J. \& Woodgett, J.R. (2011) Assessment of social interaction behaviors. Journal of visualized experiments : JoVE.

Katz, R.J. (1982) Animal model of depression: pharmacological sensitivity of a hedonic deficit. Pharmacology, biochemistry, and behavior, 16, 965-968.

Kayser, V., Basbaum, A.I. \& Guilbaud, G. (1990) Deafferentation in the rat increases mechanical nociceptive threshold in the innervated limbs. Brain Res, 508, 329-332.

Keltner, J.R., Vaida, F., Ellis, R.J., Moeller-Bertram, T., Fitzsimmons, C., Duarte, N.A., Robinson-Papp, J., Dworkin, R.H., Clifford, D.B., McArthur, J.C., Simpson, D.M., Collier, A.C., Marra, C.M., 
Atkinson, J.H., Grant, I. \& Group, C. (2012) Health-related quality of life 'well-being' in HIV distal neuropathic pain is more strongly associated with depression severity than with pain intensity. Psychosomatics, 53, 380-386.

Kessler, R.C., Berglund, P., Demler, O., Jin, R., Koretz, D., Merikangas, K.R., Rush, A.J., Walters, E.E., Wang, P.S. \& National Comorbidity Survey, R. (2003) The epidemiology of major depressive disorder: results from the National Comorbidity Survey Replication (NCS-R). JAMA, 289, 30953105 .

Khasar, S.G., Burkham, J., Dina, O.A., Brown, A.S., Bogen, O., Alessandri-Haber, N., Green, P.G., Reichling, D.B. \& Levine, J.D. (2008) Stress induces a switch of intracellular signaling in sensory neurons in a model of generalized pain. $J$ Neurosci, 28, 5721-5730.

Kidd, B.L. \& Urban, L.A. (2001) Mechanisms of inflammatory pain. Br J Anaesth, 87, 3-11.

Kim, H., Chen, L., Lim, G., Sung, B., Wang, S., McCabe, M.F., Rusanescu, G., Yang, L., Tian, Y. \& Mao, J. (2012) Brain indoleamine 2,3-dioxygenase contributes to the comorbidity of pain and depression. J Clin Invest, 122, 2940-2954.

Kim, S.H. \& Chung, J.M. (1992) An experimental model for peripheral neuropathy produced by segmental spinal nerve ligation in the rat. Pain, 50, 355-363.

King, T., Vera-Portocarrero, L., Gutierrez, T., Vanderah, T.W., Dussor, G., Lai, J., Fields, H.L. \& Porreca, F. (2009) Unmasking the tonic-aversive state in neuropathic pain. Nat Neurosci, 12, 1364-1366.

Klein, C.P., Sperotto, N.D., Maciel, I.S., Leite, C.E., Souza, A.H. \& Campos, M.M. (2014) Effects of Dseries resolvins on behavioral and neurochemical changes in a fibromyalgia-like model in mice. Neuropharmacology, 86, 57-66.

Kodama, D., Ono, H. \& Tanabe, M. (2011) Increased hippocampal glycine uptake and cognitive dysfunction after peripheral nerve injury. Pain, 152, 809-817.

Kontinen, V.K., Kauppila, T., Paananen, S., Pertovaara, A. \& Kalso, E. (1999) Behavioural measures of depression and anxiety in rats with spinal nerve ligation-induced neuropathy. Pain, 80, 341-346.

Kulkarni, S.K., Singh, K. \& Bishnoi, M. (2007) Elevated zero maze: a paradigm to evaluate antianxiety effects of drugs. Methods Find Exp Clin Pharmacol, 29, 343-348.

Kumar, A., Kaur, H. \& Singh, A. (2018) Neuropathic Pain models caused by damage to central or peripheral nervous system. Pharmacol Rep, 70, 206-216. 
Kurejova, M., Nattenmuller, U., Hildebrandt, U., Selvaraj, D., Stosser, S. \& Kuner, R. (2010) An improved behavioural assay demonstrates that ultrasound vocalizations constitute a reliable indicator of chronic cancer pain and neuropathic pain. Mol Pain, 6, 18.

Kuyinu, E.L., Narayanan, G., Nair, L.S. \& Laurencin, C.T. (2016) Animal models of osteoarthritis: classification, update, and measurement of outcomes. J Orthop Surg Res, 11, 19.

La Porta, C., Lara-Mayorga, I.M., Negrete, R. \& Maldonado, R. (2016) Effects of pregabalin on the nociceptive, emotional and cognitive manifestations of neuropathic pain in mice. Eur J Pain, 20, 1454-1466.

LaBuda, C.J. \& Fuchs, P.N. (2000) A behavioral test paradigm to measure the aversive quality of inflammatory and neuropathic pain in rats. Exp Neurol, 163, 490-494.

LaBuda, C.J. \& Little, P.J. (2005) Pharmacological evaluation of the selective spinal nerve ligation model of neuropathic pain in the rat. $J$ Neurosci Methods, 144, 175-181.

Langford, D.J., Bailey, A.L., Chanda, M.L., Clarke, S.E., Drummond, T.E., Echols, S., Glick, S., Ingrao, J., Klassen-Ross, T., Lacroix-Fralish, M.L., Matsumiya, L., Sorge, R.E., Sotocinal, S.G., Tabaka, J.M., Wong, D., van den Maagdenberg, A.M., Ferrari, M.D., Craig, K.D. \& Mogil, J.S. (2010) Coding of facial expressions of pain in the laboratory mouse. Nat Methods, 7, 447-449.

Laumet, G., Zhou, W., Dantzer, R., Edralin, J.D., Huo, X., Budac, D.P., O'Connor, J.C., Lee, A.W., Heijnen, C.J. \& Kavelaars, A. (2017) Upregulation of neuronal kynurenine 3-monooxygenase mediates depression-like behavior in a mouse model of neuropathic pain. Brain Behav Immun, 66, 94-102.

Le, A.M., Lee, M., Su, C., Zou, A. \& Wang, J. (2014) AMPAkines have novel analgesic properties in rat models of persistent neuropathic and inflammatory pain. Anesthesiology, 121, 1080-1090.

Le Bars, D., Gozariu, M. \& Cadden, S.W. (2001) Animal models of nociception. Pharmacol Rev, 53, 597652.

Leite-Almeida, H., Almeida-Torres, L., Mesquita, A.R., Pertovaara, A., Sousa, N., Cerqueira, J.J. \& Almeida, A. (2009) The impact of age on emotional and cognitive behaviours triggered by experimental neuropathy in rats. Pain, 144, 57-65.

Leite-Almeida, H., Cerqueira, J.J., Wei, H., Ribeiro-Costa, N., Anjos-Martins, H., Sousa, N., Pertovaara, A. \& Almeida, A. (2012) Differential effects of left/right neuropathy on rats' anxiety and cognitive behavior. Pain, 153, 2218-2225.

This article is protected by copyright. All rights reserved 
Leite-Almeida, H., Pinto-Ribeiro, F. \& Almeida, A. (2015) Animal Models for the Study of Comorbid Pain and Psychiatric Disorders. Mod Trends Pharmacopsychiatry, 30, 1-21.

Lenzen, S. (2008) The mechanisms of alloxan- and streptozotocin-induced diabetes. Diabetologia, 51, 216226.

Li, Q., Yue, N., Liu, S.B., Wang, Z.F., Mi, W.L., Jiang, J.W., Wu, G.C., Yu, J. \& Wang, Y.Q. (2014) Effects of chronic electroacupuncture on depression- and anxiety-like behaviors in rats with chronic neuropathic pain. Evid Based Complement Alternat Med, 2014, 158987.

Li, Y., Chen, C., Li, S. \& Jiang, C. (2019) Ginsenoside Rf relieves mechanical hypersensitivity, depressionlike behavior, and inflammatory reactions in chronic constriction injury rats. Phytother Res, 33, 1095-1103.

Li, Y., Wang, Y., Xuan, C., Li, Y., Piao, L., Li, J. \& Zhao, H. (2017) Role of the Lateral Habenula in PainAssociated Depression. Front Behav Neurosci, 11, 31.

Lim, S.W., Shiue, Y.L., Ho, C.H., Yu, S.C., Kao, P.H., Wang, J.J. \& Kuo, J.R. (2017) Anxiety and Depression in Patients with Traumatic Spinal Cord Injury: A Nationwide Population-Based Cohort Study. PLoS One, 12, e0169623.

Lipnik-Stangelj, M. (2013) Mediators of inflammation as targets for chronic pain treatment. Mediators Inflamm, 2013, 783235.

Lister, R.G. (1987) The use of a plus-maze to measure anxiety in the mouse. Psychopharmacology, 92, 180-185.

Liu, M.G. \& Chen, J. (2014) Preclinical research on pain comorbidity with affective disorders and cognitive deficits: Challenges and perspectives. Prog Neurobiol, 116, 13-32.

Liu, R.T. \& Alloy, L.B. (2010) Stress generation in depression: A systematic review of the empirical literature and recommendations for future study. Clin Psychol Rev, 30, 582-593.

Liu, S.S., Pickens, S., Burma, N.E., Ibarra-Lecue, I., Yang, H., Xue, L., Cook, C., Hakimian, J.K., Severino, A.L., Lueptow, L., Komarek, K., Taylor, A.M.W., Olmstead, M.C., Carroll, F.I., Bass, C.E., Andrews, A.M., Walwyn, W., Trang, T., Evans, C.J., Leslie, F.M. \& Cahill, C.M. (2019) Kappa Opioid Receptors Drive a Tonic Aversive Component of Chronic Pain. J Neurosci, 39, 4162-4178.

Liu, Y.T., Shao, Y.W., Yen, C.T. \& Shaw, F.Z. (2014) Acid-induced hyperalgesia and anxio-depressive comorbidity in rats. Physiology \& behavior, 131, 105-110. 
Llorca-Torralba, M., Mico, J.A. \& Berrocoso, E. (2018) Behavioral effects of combined morphine and MK-801 administration to the locus coeruleus of a rat neuropathic pain model. Prog Neuropsychopharmacol Biol Psychiatry, 84, 257-266.

Loeser, J.D. \& Melzack, R. (1999) Pain: an overview. Lancet, 353, 1607-1609.

Lopez-Munoz, F.J. \& Salazar, L.A. (1993) Analgesic effects of multiple combinations of morphine and aspirin in the rat. Proc West Pharmacol Soc, 36, 263-266.

Lyons, D.N., Kniffin, T.C., Zhang, L.P., Danaher, R.J., Miller, C.S., Bocanegra, J.L., Carlson, C.R. \& Westlund, K.N. (2015) Trigeminal Inflammatory Compression (TIC) injury induces chronic facial pain and susceptibility to anxiety-related behaviors. Neuroscience, 295, 126-138.

Lyons, D.N., Zhang, L., Pandya, J.D., Danaher, R.J., Ma, F., Miller, C.S., Sullivan, P.G., Sirbu, C. \& Westlund, K.N. (2018) Combination Drug Therapy of Pioglitazone and D-cycloserine Attenuates Chronic Orofacial Neuropathic Pain and Anxiety by Improving Mitochondrial Function Following Trigeminal Nerve Injury. Clin J Pain, 34, 168-177.

Ma, F., Zhang, L., Lyons, D. \& Westlund, K.N. (2012) Orofacial neuropathic pain mouse model induced by Trigeminal Inflammatory Compression (TIC) of the infraorbital nerve. Mol Brain, 5, 44.

Maciel, I.S., Silva, R.B., Morrone, F.B., Calixto, J.B. \& Campos, M.M. (2013) Synergistic effects of celecoxib and bupropion in a model of chronic inflammation-related depression in mice. PLoS One, 8, e77227.

Maldonado-Bouchard, S., Peters, K., Woller, S.A., Madahian, B., Faghihi, U., Patel, S., Bake, S. \& Hook, M.A. (2016) Inflammation is increased with anxiety- and depression-like signs in a rat model of spinal cord injury. Brain Behav Immun, 51, 176-195.

Maletic, V. \& Raison, C.L. (2009) Neurobiology of depression, fibromyalgia and neuropathic pain. Front Biosci (Landmark Ed), 14, 5291-5338.

Martinez-Navarro, M., Lara-Mayorga, I.M., Negrete, R., Bilecki, W., Wawrzczak-Bargiela, A., Goncalves, L., Dickenson, A.H., Przewlocki, R., Banos, J.E. \& Maldonado, R. (2019) Influence of behavioral traits in the inter-individual variability of nociceptive, emotional and cognitive manifestations of neuropathic pain. Neuropharmacology, 148, 291-304.

Matsuzawa-Yanagida, K., Narita, M., Nakajima, M., Kuzumaki, N., Niikura, K., Nozaki, H., Takagi, T., Tamai, E., Hareyama, N., Terada, M., Yamazaki, M. \& Suzuki, T. (2008) Usefulness of 
antidepressants for improving the neuropathic pain-like state and pain-induced anxiety through actions at different brain sites. Neuropsychopharmacology, 33, 1952-1965.

McWilliams, L.A., Goodwin, R.D. \& Cox, B.J. (2004) Depression and anxiety associated with three pain conditions: results from a nationally representative sample. Pain, 111, 77-83.

Menard, C., Hodes, G.E. \& Russo, S.J. (2016) Pathogenesis of depression: Insights from human and rodent studies. Neuroscience, 321, 138-162.

Mert, T., Ocal, I., Cinar, E., Yalcin, M.S. \& Gunay, I. (2014) Pain-relieving effects of pulsed magnetic fields in a rat model of carrageenan-induced hindpaw inflammation. Int J Radiat Biol, 90, 95-103.

Missig, G., Mei, L., Vizzard, M.A., Braas, K.M., Waschek, J.A., Ressler, K.J., Hammack, S.E. \& May, V. (2017) Parabrachial Pituitary Adenylate Cyclase-Activating Polypeptide Activation of Amygdala Endosomal Extracellular Signal-Regulated Kinase Signaling Regulates the Emotional Component of Pain. Biol Psychiatry, 81, 671-682.

Mogil, J.S. (2009) Animal models of pain: progress and challenges. Nat Rev Neurosci, 10, 283-294.

Montserrat-de la Paz, S., Garcia-Gimenez, M.D., Angel-Martin, M. \& Fernandez-Arche, A. (2015) Validation and additional support for an experimental animal model of fibromyalgia. Mod Rheumatol, 25, 116-122.

Moqrich, A., Hwang, S.W., Earley, T.J., Petrus, M.J., Murray, A.N., Spencer, K.S., Andahazy, M., Story, G.M. \& Patapoutian, A. (2005) Impaired thermosensation in mice lacking TRPV3, a heat and camphor sensor in the skin. Science, 307, 1468-1472.

Morrison, I., Perini, I. \& Dunham, J. (2013) Facets and mechanisms of adaptive pain behavior: predictive regulation and action. Front Hum Neurosci, 7, 755.

Mosconi, T. \& Kruger, L. (1996) Fixed-diameter polyethylene cuffs applied to the rat sciatic nerve induce a painful neuropathy: ultrastructural morphometric analysis of axonal alterations. Pain, 64, 37-57.

Muley, M.M., Krustev, E. \& McDougall, J.J. (2016) Preclinical Assessment of Inflammatory Pain. CNS Neurosci Ther, 22, 88-101.

Muralidharan, A., Kuo, A., Jacob, M., Lourdesamy, J.S., Carvalho, L.M., Nicholson, J.R., Corradini, L. \& Smith, M.T. (2016) Comparison of Burrowing and Stimuli-Evoked Pain Behaviors as End-Points in Rat Models of Inflammatory Pain and Peripheral Neuropathic Pain. Front Behav Neurosci, 10, 88. 
Mutso, A.A., Radzicki, D., Baliki, M.N., Huang, L., Banisadr, G., Centeno, M.V., Radulovic, J., Martina, M., Miller, R.J. \& Apkarian, A.V. (2012) Abnormalities in hippocampal functioning with persistent pain. $J$ Neurosci, 32, 5747-5756.

Nagakura, Y., Oe, T., Aoki, T. \& Matsuoka, N. (2009) Biogenic amine depletion causes chronic muscular pain and tactile allodynia accompanied by depression: A putative animal model of fibromyalgia. Pain, 146, 26-33.

Narita, M., Kaneko, C., Miyoshi, K., Nagumo, Y., Kuzumaki, N., Nakajima, M., Nanjo, K., Matsuzawa, K., Yamazaki, M. \& Suzuki, T. (2006a) Chronic pain induces anxiety with concomitant changes in opioidergic function in the amygdala. Neuropsychopharmacology, 31, 739-750.

Narita, M., Kuzumaki, N., Narita, M., Kaneko, C., Hareyama, N., Miyatake, M., Shindo, K., Miyoshi, K., Nakajima, M., Nagumo, Y., Sato, F., Wachi, H., Seyama, Y. \& Suzuki, T. (2006b) Chronic paininduced emotional dysfunction is associated with astrogliosis due to cortical delta-opioid receptor dysfunction. $J$ Neurochem, 97, 1369-1378.

Nasu, T., Kubo, A., Queme, L.F. \& Mizumura, K. (2019) A single administration of Neurotropin reduced the elongated immobility time in the forced swimming test of rats exposed to repeated cold stress. Behavioural pharmacology.

Navratilova, E., Xie, J.Y., King, T. \& Porreca, F. (2013) Evaluation of reward from pain relief. Ann N Y Acad Sci, 1282, 1-11.

Nazeri, M., Zarei, M.R., Pourzare, A.R., Ghahreh-Chahi, H.R., Abareghi, F. \& Shabani, M. (2018) Evidence of Altered Trigeminal Nociception in an Animal Model of Fibromyalgia. Pain Med, 19, 328-335.

Nerurkar, L., Siebert, S., McInnes, I.B. \& Cavanagh, J. (2019) Rheumatoid arthritis and depression: an inflammatory perspective. Lancet Psychiatry, 6, 164-173.

Nishiyori, M. \& Ueda, H. (2008) Prolonged gabapentin analgesia in an experimental mouse model of fibromyalgia. Mol Pain, 4, 52.

Njung'e, K. \& Handley, S.L. (1991) Evaluation of marble-burying behavior as a model of anxiety. Pharmacology, biochemistry, and behavior, 38, 63-67.

Norman, G.J., Karelina, K., Zhang, N., Walton, J.C., Morris, J.S. \& Devries, A.C. (2010) Stress and IL1 beta contribute to the development of depressive-like behavior following peripheral nerve injury. Mol Psychiatry, 15, 404-414. 
O'Callaghan, J.P. \& Holtzman, S.G. (1975) Quantification of the analgesic activity of narcotic antagonists by a modified hot-plate procedure. J Pharmacol Exp Ther, 192, 497-505.

Olesen, J., Gustavsson, A., Svensson, M., Wittchen, H.U., Jonsson, B., group, C.s. \& European Brain, C. (2012) The economic cost of brain disorders in Europe. Eur J Neurol, 19, 155-162.

Omorogbe, O., Ajayi, A.M., Ben-Azu, B., Oghwere, E.E., Adebesin, A., Aderibigbe, A.O., Okubena, O. \& Umukoro, S. (2018) Jobelyn((R)) attenuates inflammatory responses and neurobehavioural deficits associated with complete Freund-adjuvant-induced arthritis in mice. Biomed Pharmacother, 98, 585-593.

Pan, W., Zhang, G.F., Li, H.H., Ji, M.H., Zhou, Z.Q., Li, K.Y. \& Yang, J.J. (2018) Ketamine differentially restores diverse alterations of neuroligins in brain regions in a rat model of neuropathic paininduced depression. Neuroreport, 29, 863-869.

Parent, A.J., Beaudet, N., Beaudry, H., Bergeron, J., Berube, P., Drolet, G., Sarret, P. \& Gendron, L. (2012) Increased anxiety-like behaviors in rats experiencing chronic inflammatory pain. Behavioural brain research, 229, 160-167.

Pellow, S., Chopin, P., File, S.E. \& Briley, M. (1985) Validation of open:closed arm entries in an elevated plus-maze as a measure of anxiety in the rat. J Neurosci Methods, 14, 149-167.

Pitzer, C., La Porta, C., Treede, R.D. \& Tappe-Theodor, A. (2019) Inflammatory and neuropathic pain conditions do not primarily evoke anxiety-like behaviours in C57BL/6 mice. Eur J Pain, 23, 285306.

Porsolt, R.D., Bertin, A. \& Jalfre, M. (1977a) Behavioral despair in mice: a primary screening test for antidepressants. Arch Int Pharmacodyn Ther, 229, 327-336.

Porsolt, R.D., Le Pichon, M. \& Jalfre, M. (1977b) Depression: a new animal model sensitive to antidepressant treatments. Nature, 266, 730-732.

Poupon, L., Lamoine, S., Pereira, V., Barriere, D.A., Lolignier, S., Giraudet, F., Aissouni, Y., Meleine, M., Prival, L., Richard, D., Kerckhove, N., Authier, N., Balayssac, D., Eschalier, A., Lazdunski, M. \& Busserolles, J. (2018) Targeting the TREK-1 potassium channel via riluzole to eliminate the neuropathic and depressive-like effects of oxaliplatin. Neuropharmacology, 140, 43-61.

Price, D.D. (2000) Psychological and neural mechanisms of the affective dimension of pain. Science, 288, 1769-1772. 
Radat, F., Margot-Duclot, A. \& Attal, N. (2013) Psychiatric co-morbidities in patients with chronic peripheral neuropathic pain: a multicentre cohort study. Eur J Pain, 17, 1547-1557.

Radhakrishnan, R., Moore, S.A. \& Sluka, K.A. (2003) Unilateral carrageenan injection into muscle or joint induces chronic bilateral hyperalgesia in rats. Pain, 104, 567-577.

Ramos, A. (2008) Animal models of anxiety: do I need multiple tests? Trends in pharmacological sciences, 29, 493-498.

Randall, L.O. \& Selitto, J.J. (1957) A method for measurement of analgesic activity on inflamed tissue. Arch Int Pharmacodyn Ther, 111, 409-419.

Redivo, D.D., Schreiber, A.K., Adami, E.R., Ribeiro, D.E., Joca, S.R., Zanoveli, J.M. \& Cunha, J.M. (2016) Effect of omega-3 polyunsaturated fatty acid treatment over mechanical allodynia and depressive-like behavior associated with experimental diabetes. Behavioural brain research, 298, $57-64$.

Refsgaard, L.K., Hoffmann-Petersen, J., Sahlholt, M., Pickering, D.S. \& Andreasen, J.T. (2016) Modelling affective pain in mice: Effects of inflammatory hypersensitivity on place escape/avoidance behaviour, anxiety and hedonic state. J Neurosci Methods, 262, 85-92.

Robinson, L., Spruijt, B. \& Riedel, G. (2018) Between and within laboratory reliability of mouse behaviour recorded in home-cage and open-field. J Neurosci Methods, 300, 10-19.

Roeska, K., Ceci, A., Treede, R.D. \& Doods, H. (2009) Effect of high trait anxiety on mechanical hypersensitivity in male rats. Neurosci Lett, 464, 160-164.

Roeska, K., Doods, H., Arndt, K., Treede, R.D. \& Ceci, A. (2008) Anxiety-like behaviour in rats with mononeuropathy is reduced by the analgesic drugs morphine and gabapentin. Pain, 139, 349-357.

Ryabkova, V.A., Churilov, L.P. \& Shoenfeld, Y. (2019) Neuroimmunology: What Role for Autoimmunity, Neuroinflammation, and Small Fiber Neuropathy in Fibromyalgia, Chronic Fatigue Syndrome, and Adverse Events after Human Papillomavirus Vaccination? Int J Mol Sci, 20.

Sang, K., Bao, C., Xin, Y., Hu, S., Gao, X., Wang, Y., Bodner, M., Zhou, Y.D. \& Dong, X.W. (2018) Plastic change of prefrontal cortex mediates anxiety-like behaviors associated with chronic pain in neuropathic rats. Mol Pain, 14, 1744806918783931.

Santarelli, L., Saxe, M., Gross, C., Surget, A., Battaglia, F., Dulawa, S., Weisstaub, N., Lee, J., Duman, R., Arancio, O., Belzung, C. \& Hen, R. (2003) Requirement of hippocampal neurogenesis for the behavioral effects of antidepressants. Science, 301, 805-809.

This article is protected by copyright. All rights reserved 
Sawada, A., Niiyama, Y., Ataka, K., Nagaishi, K., Yamakage, M. \& Fujimiya, M. (2014) Suppression of bone marrow-derived microglia in the amygdala improves anxiety-like behavior induced by chronic partial sciatic nerve ligation in mice. Pain, 155, 1762-1772.

Schmidt-Wilcke, T. \& Clauw, D.J. (2011) Fibromyalgia: from pathophysiology to therapy. Nat Rev Rheumatol, 7, 518-527.

Scholz, J., Finnerup, N.B., Attal, N., Aziz, Q., Baron, R., Bennett, M.I., Benoliel, R., Cohen, M., Cruccu, G., Davis, K.D., Evers, S., First, M., Giamberardino, M.A., Hansson, P., Kaasa, S., Korwisi, B., Kosek, E., Lavand'homme, P., Nicholas, M., Nurmikko, T., Perrot, S., Raja, S.N., Rice, A.S.C., Rowbotham, M.C., Schug, S., Simpson, D.M., Smith, B.H., Svensson, P., Vlaeyen, J.W.S., Wang, S.J., Barke, A., Rief, W., Treede, R.D. \& Classification Committee of the Neuropathic Pain Special Interest, G. (2019) The IASP classification of chronic pain for ICD-11: chronic neuropathic pain. Pain, 160, 53-59.

Scholz, J. \& Woolf, C.J. (2002) Can we conquer pain? Nat Neurosci, 5 Suppl, 1062-1067.

Scott, D.L., Wolfe, F. \& Huizinga, T.W. (2010) Rheumatoid arthritis. Lancet, 376, 1094-1108.

Sellmeijer, J., Mathis, V., Hugel, S., Li, X.H., Song, Q., Chen, Q.Y., Barthas, F., Lutz, P.E., Karatas, M., Luthi, A., Veinante, P., Aertsen, A., Barrot, M., Zhuo, M. \& Yalcin, I. (2018) Hyperactivity of Anterior Cingulate Cortex Areas 24a/24b Drives Chronic Pain-Induced Anxiodepressive-like Consequences. $J$ Neurosci, 38, 3102-3115.

Seltzer, Z., Dubner, R. \& Shir, Y. (1990) A novel behavioral model of neuropathic pain disorders produced in rats by partial sciatic nerve injury. Pain, 43, 205-218.

Seminowicz, D.A., Laferriere, A.L., Millecamps, M., Yu, J.S., Coderre, T.J. \& Bushnell, M.C. (2009) MRI structural brain changes associated with sensory and emotional function in a rat model of long-term neuropathic pain. Neuroimage, 47, 1007-1014.

Shepherd, J.K., Grewal, S.S., Fletcher, A., Bill, D.J. \& Dourish, C.T. (1994) Behavioural and pharmacological characterisation of the elevated "zero-maze" as an animal model of anxiety. Psychopharmacology, 116, 56-64.

Sieberg, C.B., Taras, C., Gomaa, A., Nickerson, C., Wong, C., Ward, C., Baskozos, G., Bennett, D.L.H., Ramirez, J.D., Themistocleous, A.C., Rice, A.S.C., Shillo, P.R., Tesfaye, S., Edwards, R.R., Andrews, N.A., Berde, C. \& Costigan, M. (2018) Neuropathic pain drives anxiety behavior in mice, results consistent with anxiety levels in diabetic neuropathy patients. Pain Rep, 3, e651.

This article is protected by copyright. All rights reserved 
Siemian, J.N., Shang, L., Seaman, R.W., Jr., Zhu, Q., Zhang, Y. \& Li, J.X. (2019) Effects of imidazoline I2 receptor agonists on reserpine-induced hyperalgesia and depressive-like behavior in rats. Behavioural pharmacology, 30, 429-434.

Silberberg, M. \& Silberberg, R. (1950) Effects of a high fat diet on the joints of aging mice. AMA Arch Pathol, 50, 828-846.

Sluka, K.A. \& Clauw, D.J. (2016) Neurobiology of fibromyalgia and chronic widespread pain. Neuroscience, 338, 114-129.

Sluyter, F., Marican, C.C. \& Crusio, W.E. (1999) Further phenotypical characterisation of two substrains of C57BL/6J inbred mice differing by a spontaneous single-gene mutation. Behavioural brain research, 98, 39-43.

Sorkin, L.S. \& Yaksh, T.L. (2009) Behavioral models of pain states evoked by physical injury to the peripheral nerve. Neurotherapeutics, 6, 609-619.

Sotocinal, S.G., Sorge, R.E., Zaloum, A., Tuttle, A.H., Martin, L.J., Wieskopf, J.S., Mapplebeck, J.C., Wei, P., Zhan, S., Zhang, S., McDougall, J.J., King, O.D. \& Mogil, J.S. (2011) The Rat Grimace Scale: a partially automated method for quantifying pain in the laboratory rat via facial expressions. Mol Pain, 7, 55.

Steru, L., Chermat, R., Thierry, B. \& Simon, P. (1985) The tail suspension test: a new method for screening antidepressants in mice. Psychopharmacology, 85, 367-370.

Stratinaki, M., Varidaki, A., Mitsi, V., Ghose, S., Magida, J., Dias, C., Russo, S.J., Vialou, V., Caldarone, B.J., Tamminga, C.A., Nestler, E.J. \& Zachariou, V. (2013) Regulator of G protein signaling 4 [corrected] is a crucial modulator of antidepressant drug action in depression and neuropathic pain models. Proc Natl Acad Sci U S A, 110, 8254-8259.

Sufka, K.J. (1994) Conditioned place preference paradigm: a novel approach for analgesic drug assessment against chronic pain. Pain, 58, 355-366.

Sun, T., Wang, J., Li, X., Li, Y.J., Feng, D., Shi, W.L., Zhao, M.G., Wang, J.B. \& Wu, Y.M. (2016) Gastrodin relieved complete Freund's adjuvant-induced spontaneous pain by inhibiting inflammatory response. Int Immunopharmacol, 41, 66-73.

Suzuki, T., Amata, M., Sakaue, G., Nishimura, S., Inoue, T., Shibata, M. \& Mashimo, T. (2007) Experimental neuropathy in mice is associated with delayed behavioral changes related to anxiety and depression. Anesthesia and analgesia, 104, 1570-1577, table of contents. 
Takeda, H., Tsuji, M. \& Matsumiya, T. (1998) Changes in head-dipping behavior in the hole-board test reflect the anxiogenic and/or anxiolytic state in mice. European journal of pharmacology, 350, 2129.

Thomas, A., Burant, A., Bui, N., Graham, D., Yuva-Paylor, L.A. \& Paylor, R. (2009) Marble burying reflects a repetitive and perseverative behavior more than novelty-induced anxiety. Psychopharmacology, 204, 361-373.

Thompson, S.J., Pitcher, M.H., Stone, L.S., Tarum, F., Niu, G., Chen, X., Kiesewetter, D.O., Schweinhardt, P. \& Bushnell, M.C. (2018) Chronic neuropathic pain reduces opioid receptor availability with associated anhedonia in rat. Pain, 159, 1856-1866.

Tian, J., Tian, Z., Qin, S.L., Zhao, P.Y., Jiang, X. \& Tian, Z. (2017) Anxiolytic-like effects of alphaasarone in a mouse model of chronic pain. Metab Brain Dis, 32, 2119-2129.

Toma, W., Kyte, S.L., Bagdas, D., Alkhlaif, Y., Alsharari, S.D., Lichtman, A.H., Chen, Z.J., Del Fabbro, E., Bigbee, J.W., Gewirtz, D.A. \& Damaj, M.I. (2017) Effects of paclitaxel on the development of neuropathy and affective behaviors in the mouse. Neuropharmacology, 117, 305-315.

Treede, R.D., Jensen, T.S., Campbell, J.N., Cruccu, G., Dostrovsky, J.O., Griffin, J.W., Hansson, P., Hughes, R., Nurmikko, T. \& Serra, J. (2008) Neuropathic pain: redefinition and a grading system for clinical and research purposes. Neurology, 70, 1630-1635.

Tucker, L.B. \& McCabe, J.T. (2017) Behavior of Male and Female C57BL/6J Mice Is More Consistent with Repeated Trials in the Elevated Zero Maze than in the Elevated Plus Maze. Front Behav Neurosci, 11, 13.

Urban, R., Scherrer, G., Goulding, E.H., Tecott, L.H. \& Basbaum, A.I. (2011) Behavioral indices of ongoing pain are largely unchanged in male mice with tissue or nerve injury-induced mechanical hypersensitivity. Pain, 152, 990-1000.

Verdu, E., Garcia-Alias, G., Fores, J., Vela, J.M., Cuadras, J., Lopez-Vales, R. \& Navarro, X. (2003) Morphological characterization of photochemical graded spinal cord injury in the rat. $J$ Neurotrauma, 20, 483-499.

Vos, B.P., Strassman, A.M. \& Maciewicz, R.J. (1994) Behavioral evidence of trigeminal neuropathic pain following chronic constriction injury to the rat's infraorbital nerve. J Neurosci, 14, 2708-2723.

Wallace, V.C., Blackbeard, J., Pheby, T., Segerdahl, A.R., Davies, M., Hasnie, F., Hall, S., McMahon, S.B. \& Rice, A.S. (2007a) Pharmacological, behavioural and mechanistic analysis of HIV-1 gp120 induced painful neuropathy. Pain, 133, 47-63.

This article is protected by copyright. All rights reserved 
Wallace, V.C., Blackbeard, J., Segerdahl, A.R., Hasnie, F., Pheby, T., McMahon, S.B. \& Rice, A.S. (2007b) Characterization of rodent models of HIV-gp120 and anti-retroviral-associated neuropathic pain. Brain, 130, 2688-2702.

Wallace, V.C., Norbury, T.A. \& Rice, A.S. (2005) Ultrasound vocalisation by rodents does not correlate with behavioural measures of persistent pain. Eur J Pain, 9, 445-452.

Wallace, V.C., Segerdahl, A.R., Lambert, D.M., Vandevoorde, S., Blackbeard, J., Pheby, T., Hasnie, F. \& Rice, A.S. (2007c) The effect of the palmitoylethanolamide analogue, palmitoylallylamide (L-29) on pain behaviour in rodent models of neuropathy. Br J Pharmacol, 151, 1117-1128.

Wang, D.S., Tian, Z., Guo, Y.Y., Guo, H.L., Kang, W.B., Li, S., Den, Y.T., Li, X.B., Feng, B., Feng, D., Zhao, J.N., Liu, G. \& Zhao, M.G. (2015a) Anxiolytic-like effects of translocator protein (TSPO) ligand ZBD-2 in an animal model of chronic pain. Mol Pain, 11, 16.

Wang, J., Goffer, Y., Xu, D., Tukey, D.S., Shamir, D.B., Eberle, S.E., Zou, A.H., Blanck, T.J. \& Ziff, E.B. (2011) A single subanesthetic dose of ketamine relieves depression-like behaviors induced by neuropathic pain in rats. Anesthesiology, 115, 812-821.

Wang, W., Li, C., Cai, Y. \& Pan, Z.Z. (2017) Pain vulnerability and DNA methyltransferase 3a involved in the affective dimension of chronic pain. Mol Pain, 13, 1744806917726713.

Wang, X.M., Zhang, G.F., Jia, M., Xie, Z.M., Yang, J.J., Shen, J.C. \& Zhou, Z.Q. (2019) Environmental enrichment improves pain sensitivity, depression-like phenotype, and memory deficit in mice with neuropathic pain: role of NPAS4. Psychopharmacology, 236, 1999-2014.

Wang, X.Q., Zhong, X.L., Li, Z.B., Wang, H.T., Zhang, J., Li, F., Zhang, J.Y., Dai, R.P., Xin-Fu, Z., Li, C.Q., Li, Z.Y. \& Bi, F.F. (2015b) Differential roles of hippocampal glutamatergic receptors in neuropathic anxiety-like behavior after partial sciatic nerve ligation in rats. BMC Neurosci, 16, 14.

Willner, P., Towell, A., Sampson, D., Sophokleous, S. \& Muscat, R. (1987) Reduction of sucrose preference by chronic unpredictable mild stress, and its restoration by a tricyclic antidepressant. Psychopharmacology, 93, 358-364.

Wodarski, R., Delaney, A., Ultenius, C., Morland, R., Andrews, N., Baastrup, C., Bryden, L.A., Caspani, O., Christoph, T., Gardiner, N.J., Huang, W., Kennedy, J.D., Koyama, S., Li, D., Ligocki, M., Lindsten, A., Machin, I., Pekcec, A., Robens, A., Rotariu, S.M., Vo, B.S., Segerdahl, M., Stenfors, C., Svensson, C.I., Treede, R.D., Uto, K., Yamamoto, K., Rutten, K. \& Rice, A.S. (2016) Crosscentre replication of suppressed burrowing behaviour as an ethologically relevant pain outcome measure in the rat: a prospective multicentre study. Pain, 157, 2350-2365.

This article is protected by copyright. All rights reserved 
Woolfe, G. \& MacDonald, A.L. (1944) The evaluation of the analgesic action of pethidine hydrochloride (Demerol). J Pharmacol Exp Ther, 80, 300-307.

Wu, J., Zhao, Z., Sabirzhanov, B., Stoica, B.A., Kumar, A., Luo, T., Skovira, J. \& Faden, A.I. (2014) Spinal cord injury causes brain inflammation associated with cognitive and affective changes: role of cell cycle pathways. $J$ Neurosci, 34, 10989-11006.

Wu, S., Marie Lutz, B., Miao, X., Liang, L., Mo, K., Chang, Y.J., Du, P., Soteropoulos, P., Tian, B., Kaufman, A.G., Bekker, A., Hu, Y. \& Tao, Y.X. (2016) Dorsal root ganglion transcriptome analysis following peripheral nerve injury in mice. Mol Pain, 12, 1744806916629048.

Wu, X.B., Jing, P.B., Zhang, Z.J., Cao, D.L., Gao, M.H., Jiang, B.C. \& Gao, Y.J. (2018) Chemokine receptor CCR2 contributes to neuropathic pain and the associated depression via increasing NR2Bmediated currents in both D1 and D2 dopamine receptor-containing medium spiny neurons in the nucleus accumbens shell. Neuropsychopharmacology, 43, 2320-2330.

Wu, Y.Y., Jiang, Y.L., He, X.F., Zhao, X.Y., Shao, X.M., Sun, J., Shen, Z., Shou, S.Y., Wei, J.J., Ye, J.Y., Yan, S.S. \& Fang, J.Q. (2017) 5-HT in the dorsal raphe nucleus is involved in the effects of $100-\mathrm{Hz}$ electro-acupuncture on the pain-depression dyad in rats. Exp Ther Med, 14, 107-114.

Xie, Z.M., Wang, X.M., Xu, N., Wang, J., Pan, W., Tang, X.H., Zhou, Z.Q., Hashimoto, K. \& Yang, J.J. (2017) Alterations in the inflammatory cytokines and brain-derived neurotrophic factor contribute to depression-like phenotype after spared nerve injury: improvement by ketamine. Sci Rep, 7, 3124 .

Xu, N., Tang, X.H., Pan, W., Xie, Z.M., Zhang, G.F., Ji, M.H., Yang, J.J., Zhou, M.T. \& Zhou, Z.Q. (2017) Spared Nerve Injury Increases the Expression of Microglia M1 Markers in the Prefrontal Cortex of Rats and Provokes Depression-Like Behaviors. Front Neurosci, 11, 209.

Yalcin, I. \& Barrot, M. (2014) The anxiodepressive comorbidity in chronic pain. Curr Opin Anaesthesiol, 27, 520-527.

Yalcin, I., Barthas, F. \& Barrot, M. (2014) Emotional consequences of neuropathic pain: insight from preclinical studies. Neuroscience and biobehavioral reviews, 47, 154-164.

Yalcin, I., Belzung, C. \& Surget, A. (2008) Mouse strain differences in the unpredictable chronic mild stress: a four-antidepressant survey. Behavioural brain research, 193, 140-143.

Yalcin, I., Bohren, Y., Waltisperger, E., Sage-Ciocca, D., Yin, J.C., Freund-Mercier, M.J. \& Barrot, M. (2011) A time-dependent history of mood disorders in a murine model of neuropathic pain. Biol Psychiatry, 70, 946-953.

This article is protected by copyright. All rights reserved 
Yang, C., Fang, X., Zhan, G., Huang, N., Li, S., Bi, J., Jiang, R., Yang, L., Miao, L., Zhu, B., Luo, A. \& Hashimoto, K. (2019a) Key role of gut microbiota in anhedonia-like phenotype in rodents with neuropathic pain. Translational psychiatry, 9, 57.

Yang, L., Liu, X., Yao, K., Sun, Y., Jiang, F., Yan, H., Mao, P., Fan, S., Wei, X., Liu, Y., Yuan, W. \& Zhang, S. (2019b) HCN channel antagonist ZD7288 ameliorates neuropathic pain and associated depression. Brain Res, 1717, 204-213.

Yue, J., Wang, X.S., Guo, Y.Y., Zheng, K.Y., Liu, H.Y., Hu, L.N., Zhao, M.G. \& Liu, S.B. (2018) Anxiolytic effect of CPEB1 knockdown on the amygdala of a mouse model of inflammatory pain. Brain Res Bull, 137, 156-165.

Zeng, Q., Wang, S., Lim, G., Yang, L., Mao, J., Sung, B., Chang, Y., Lim, J.A., Guo, G. \& Mao, J. (2008) Exacerbated mechanical allodynia in rats with depression-like behavior. Brain Res, 1200, 27-38.

Zhang, G.F., Wang, J., Han, J.F., Guo, J., Xie, Z.M., Pan, W., Yang, J.J. \& Sun, K.J. (2016) Acute single dose of ketamine relieves mechanical allodynia and consequent depression-like behaviors in a rat model. Neurosci Lett, 631, 7-12.

Zhang, X.M., Wang, L.Z., He, B., Xiang, Y.K., Fan, L.X., Wang, Q. \& Tao, L. (2019) The gap junction inhibitor INI-0602 attenuates mechanical allodynia and depression-like behaviors induced by spared nerve injury in rats. Neuroreport, 30, 369-377.

Zhang, Z.J., Jiang, B.C. \& Gao, Y.J. (2017) Chemokines in neuron-glial cell interaction and pathogenesis of neuropathic pain. Cell Mol Life Sci.

Zhao, X., Wang, C., Zhang, J.F., Liu, L., Liu, A.M., Ma, Q., Zhou, W.H. \& Xu, Y. (2014a) Chronic curcumin treatment normalizes depression-like behaviors in mice with mononeuropathy: involvement of supraspinal serotonergic system and GABAA receptor. Psychopharmacology, 231, 2171-2187.

Zhao, X., Yu, C., Wang, C., Zhang, J.F., Zhou, W.H., Cui, W.G., Ye, F. \& Xu, Y. (2014b) Chronic resveratrol treatment exerts antihyperalgesic effect and corrects co-morbid depressive like behaviors in mice with mononeuropathy: involvement of serotonergic system. Neuropharmacology, 85, 131-141.

Zhou, W., Dantzer, R., Budac, D.P., Walker, A.K., Mao-Ying, Q.L., Lee, A.W., Heijnen, C.J. \& Kavelaars, A. (2015) Peripheral indoleamine 2,3-dioxygenase 1 is required for comorbid depression-like behavior but does not contribute to neuropathic pain in mice. Brain Behav Immun, 46, 147-153. 
Zhou, W., Jin, Y., Meng, Q., Zhu, X., Bai, T., Tian, Y., Mao, Y., Wang, L., Xie, W., Zhong, H., Zhang, N., Luo, M.H., Tao, W., Wang, H., Li, J., Li, J., Qiu, B.S., Zhou, J.N., Li, X., Xu, H., Wang, K., Zhang, X., Liu, Y., Richter-Levin, G., Xu, L. \& Zhang, Z. (2019) A neural circuit for comorbid depressive symptoms in chronic pain. Nat Neurosci, 22, 1649-1658.

Zhu, C., Xu, Q., Wang, C., Mao, Z. \& Lin, N. (2017) Evidence that CA3 is Underling the Comorbidity Between Pain and Depression and the Co-curation by Wu-Tou decoction in Neuropathic Pain. Sci Rep, 7, 11935.

Zilliox, L.A. (2017) Neuropathic Pain. Continuum (Minneap Minn), 23, 512-532.

Zis, P., Daskalaki, A., Bountouni, I., Sykioti, P., Varrassi, G. \& Paladini, A. (2017) Depression and chronic pain in the elderly: links and management challenges. Clin Interv Aging, 12, 709-720.

Zong, J., Liao, X., Ren, B. \& Wang, Z. (2018) The antidepressant effects of rosiglitazone on rats with depression induced by neuropathic pain. Life Sci, 203, 315-322.

This article is protected by copyright. All rights reserved 


\begin{tabular}{|c|c|c|c|c|}
\hline Pain model & Species & $\begin{array}{c}\text { Behavioural } \\
\text { Test }\end{array}$ & Results & References \\
\hline PSNL & Mouse & EPM; LD & ALB at PO day 28 & $\begin{array}{l}\text { (Narita et al., 2006a; } \\
\text { Narita et al., 2006b) }\end{array}$ \\
\hline PSNL & Rat & $\mathrm{OF}$ & No ALB at PO day 14 & (Hasnie et al., 2007a) \\
\hline PSNL & Mouse & $\begin{array}{l}\text { EPM;OF; } \\
\text { TST }\end{array}$ & $\begin{array}{l}\text { No ALB at PO days } 7,14,28 \\
\text { No DLB at PO days } 8,15,29\end{array}$ & (Hasnie et al., 2007b) \\
\hline PSNL & Rat & OF & ALB at PO day 14 & (Wallace et al., 2007c) \\
\hline PSNL & Mouse & EPM; LD & ALB at PO day 27 & $\begin{array}{l}\text { (Matsuzawa-Yanagida } \\
\text { et al., 2008) }\end{array}$ \\
\hline PSNL & Rat & EPM & No ALB at PO week 4 & (Roeska et al., 2008) \\
\hline PSNL & Mouse & $\mathrm{OF}$ & No ALB at PO day 10 & (Kodama et al., 2011) \\
\hline PSNL & Rat & BT & $\begin{array}{l}\text { Burrowing behaviour deficits at PO } \\
\text { day } 14\end{array}$ & (Andrews et al., 2012) \\
\hline PSNL & Mouse & SPT & DLB at PO day 16 & (Bura et al., 2013) \\
\hline PSNL & Mouse & EPM & ALB at $\mathrm{PO}$ day 28 & (Sawada et al., 2014) \\
\hline PSNL & Mouse & FST; TST & DLB at PO week 4 & (Gai et al., 2014) \\
\hline PSNL & Rat & $\begin{array}{l}\text { EPM; OF; } \\
\text { FST; SPT }\end{array}$ & $\begin{array}{l}\text { ALB at PO day } 28 ; \text { No DLB at PO } \\
\text { day } 28\end{array}$ & (Wang et al., 2015b) \\
\hline PSNL & Mouse & FST & DLB at PO week 4 & (Bruning et al., 2015) \\
\hline PSNL & Mouse & $\begin{array}{c}\text { EPM } \\
\text { TST; MB }\end{array}$ & $\begin{array}{l}\text { ALB at PO days } 5 \text { to } 47 \text {; DLB at } \\
\text { post-surgery days } 20 \text { to } 62\end{array}$ & $\begin{array}{l}\text { (Gonzalez-Sepulveda } e t \\
\text { al., 2016) }\end{array}$ \\
\hline PSNL & Mouse & $\begin{array}{c}\text { EPM; } \\
\text { FST; SPT }\end{array}$ & $\begin{array}{l}\text { ALB at PO weeks 1, 3; DLB at PO } \\
\text { week } 3\end{array}$ & (La Porta et al., 2016) \\
\hline PSNL & Mouse & $\begin{array}{l}\text { EPM; OF } \\
\text { FST }\end{array}$ & ALB and DLB at PO day 30 & (Wang et al., 2017) \\
\hline PSNL & Mouse & $\begin{array}{l}\text { EPM } \\
\text { SPT }\end{array}$ & $\begin{array}{l}\text { ALB at PO day } 15 ; \text { DLB at PO day } \\
10\end{array}$ & $\begin{array}{l}\text { (Martinez-Navarro et } \\
\text { al., 2019) }\end{array}$ \\
\hline PSNL & Mouse & $\begin{array}{c}\text { SI } \\
\text { FST; NSF }\end{array}$ & $\begin{array}{l}\text { ALB at PO week 6; DLB at PO } \\
\text { week } 8\end{array}$ & $\begin{array}{l}\text { (Hisaoka-Nakashima } \text { et } \\
\text { al., 2019) }\end{array}$ \\
\hline PSNL & Mouse & FST; ST & DLB at PO day 28 & (Birmann et al., 2019) \\
\hline SNL & Rat & $\begin{array}{l}\text { EPM; OF; } \\
\quad \text { LD }\end{array}$ & No ALB at PO day 14 & (Kontinen et al., 1999) \\
\hline $\mathrm{SNL}$ & Mouse & $\begin{array}{l}\text { EPM; OF; } \\
\text { LD; FST }\end{array}$ & $\begin{array}{l}\text { ALB at PO days } 30,56 ; \text { DLB at PO } \\
\text { days } 15,30,56\end{array}$ & (Suzuki et al., 2007) \\
\hline SNL & Rat & $\mathrm{OF}$ & ALB at PO day 14 & (Hasnie et al., 2007a) \\
\hline SNL & Rat & FST & DLB at PO day 29 & (Hu et al., 2010) \\
\hline
\end{tabular}

This article is protected by copyright. All rights reserved 


\begin{tabular}{|c|c|c|c|c|}
\hline SNL & Rat & BT & $\begin{array}{l}\text { Burrowing behaviour deficits at PO } \\
\text { day } 14\end{array}$ & (Andrews et al., 2012) \\
\hline SNL & Rat & EPM; OF & ALB at PO day 10 & (Jiang et al., 2014) \\
\hline SNL & Rat & OF; FST & $\begin{array}{l}\text { No ALB at PO day } 20 \\
\text { DLB at PO day } 23\end{array}$ & (Chung et al., 2017) \\
\hline SNL & Rat & EPM; SPT & ALB and DLB at PO week 4 & (Ji et al., 2017) \\
\hline SNL & Mouse & $\begin{array}{c}\text { OF; } \\
\text { FST; SPT }\end{array}$ & $\begin{array}{l}\text { ALB at PO day } 7,14 ; \text { DLB at PO } \\
\text { day } 7,14,21\end{array}$ & (Zhu et al., 2017) \\
\hline SNL & Rat & EPM; FST & ALB and DLB at PO week 4 & (Ji et al., 2018) \\
\hline SNL & Mouse & FST; SPT & DLB at PO day 14 & (Wu et al., 2018) \\
\hline SNL & Rat & $\begin{array}{l}\text { FST; TST; } \\
\text { SPT }\end{array}$ & DLB at PO day 15 & (Zong et al., 2018) \\
\hline $\mathrm{CCI}$ & Rat & FST; HST & DLB at PO days 3,7 & (Zeng et al., 2008) \\
\hline $\mathrm{CCI}$ & Rat & EPM & ALB at PO week 4 & (Roeska et al., 2008) \\
\hline $\mathrm{CCI}$ & Rat & EPM & ALB at PO day 36 & (Roeska et al., 2009) \\
\hline CCI & Rat & FST & DLB at PO days 21-28 & (Hu et al., 2009) \\
\hline $\mathrm{CCI}$ & Mouse & $\begin{array}{l}\text { EPM; OF; } \\
\text { MB }\end{array}$ & No ALB at PO day 3 to week 7 & (Urban et al., 2011) \\
\hline CCI & Rat & FST & DLB at PO days $14-21$ & (Fukuhara et al., 2012) \\
\hline $\mathrm{CCI}$ & Rat & $\begin{array}{l}\text { EPM; OF; } \\
\text { SI; SPT }\end{array}$ & $\begin{array}{l}\text { No ALB and no DLB at PO days 14- } \\
21\end{array}$ & (Gregoire et al., 2012) \\
\hline $\mathrm{CCI}$ & Rat & EZM; FST & ALB and DLB at PO day 28 & $\begin{array}{l}\text { (Alba-Delgado et al., } \\
\text { 2013) }\end{array}$ \\
\hline $\mathrm{CCI}$ & Rat & EPM; FST & $\begin{array}{l}\text { ALB at PO day 25; DLB at PO day } \\
32\end{array}$ & (Caspani et al., 2014) \\
\hline $\mathrm{CCI}$ & Rat & EPM; FST & ALB and DLB at PO days 7, 21 & (Li et al., 2014) \\
\hline $\mathrm{CCI}$ & Mouse & FST; TST & DLB at PO weeks 2, 4, 6 & (Zhao et al., 2014a) \\
\hline CCI & Mouse & FST & DLB at PO weeks 2-5 & (Zhao et al., 2014b) \\
\hline $\mathrm{CCI}$ & Mouse & SPT & DLB at PO weeks 4-10 & (Dellarole et al., 2014) \\
\hline $\mathrm{CCI}$ & Rat & OF; EZM & ALB at PO week 4 & $\begin{array}{l}\text { (Alba-Delgado et al., } \\
\text { 2016) }\end{array}$ \\
\hline $\mathrm{CCI}$ & Rat & BT & $\begin{array}{l}\text { Burrowing behaviour at PO days 3- } \\
14\end{array}$ & $\begin{array}{l}\text { (Muralidharan et al., } \\
\text { 2016) }\end{array}$ \\
\hline $\mathrm{CCI}$ & Mouse & OF & ALB at $\mathrm{PO}$ week 2 & (Missig et al., 2017) \\
\hline $\mathrm{CCI}$ & Rat & FST & DLB at $\mathrm{PO}$ days $7,14,21,28$ & (Garg et al., 2017) \\
\hline CCI & Rat & FST; SPT & DLB at PO day 28 & (Li et al., 2017) \\
\hline CCI & Mouse & FST; TST & DLB at PO days 7-34 & (Jiang et al., 2018) \\
\hline
\end{tabular}

This article is protected by copyright. All rights reserved 


\begin{tabular}{|c|c|c|c|c|}
\hline $\mathrm{CCI}$ & Rat & EZM; FST & ALB and DLB at PO weeks 4, 6 & $\begin{array}{l}\text { (Alba-Delgado et al., } \\
\text { 2018) }\end{array}$ \\
\hline CCI & Mouse & EPM; TST & ALB and DLB at PO day 28 & $\begin{array}{l}\text { (Ferreira-Chamorro et } \\
\text { al., 2018) }\end{array}$ \\
\hline $\mathrm{CCI}$ & Rat & EZM & ALB at PO week 4 & $\begin{array}{l}\text { (Llorca-Torralba et al., } \\
\text { 2018) }\end{array}$ \\
\hline CCI & Rat & FST; NSF & DLB at PO day 29 & (Jiang et al., 2019) \\
\hline $\mathrm{CCI}$ & Mouse & FST; SPT & DLB at PO days $35-42$ & (Wang et al., 2019) \\
\hline CCI & Rat & FST & DLB at PO week 2 & (Li et al., 2019) \\
\hline SNI & Rat & $\begin{array}{l}\text { EPM; OF; } \\
\text { FST }\end{array}$ & $\begin{array}{l}\text { No ALB at PO week 7; DLB at PO } \\
\text { week } 7\end{array}$ & (Goncalves et al., 2008) \\
\hline SNI & Rat & $\begin{array}{l}\text { EPM; OF; } \\
\text { FST }\end{array}$ & ALB and DLB at PO day 28 & $\begin{array}{l}\text { (Leite-Almeida et al., } \\
\text { 2009) }\end{array}$ \\
\hline SNI & Rat & EPM & ALB at PO weeks 19, 24 & $\begin{array}{l}\text { (Seminowicz et al., } \\
2009)\end{array}$ \\
\hline SNI & Mouse & OF; FST & $\begin{array}{l}\text { No ALB at PO day } 6 ; \text { DLB at PO } \\
\text { day } 7\end{array}$ & (Norman et al., 2010) \\
\hline SNI & Rat & FST; SPT & DLB at PO day 14,56 & (Wang et al., 2011) \\
\hline SNI & Mouse & $\begin{array}{l}\text { OF; EZM; } \\
\text { SI; MB; } \\
\text { FST; SPT }\end{array}$ & $\begin{array}{l}\text { No ALB and DLB at PO day } 3 \text { to } \\
\text { week } 7\end{array}$ & (Urban et al., 2011) \\
\hline SNI & Rat & EPM & ALB cohort-dependent at PO day 28 & $\begin{array}{l}\text { (Leite-Almeida et al., } \\
\text { 2012) }\end{array}$ \\
\hline SNI & Mouse & LD; NSF & ALB at PO day 12 & (Mutso et al., 2012) \\
\hline SNI & Rat & FST; SPT & DLB at PO day 14 & (Goffer et al., 2013) \\
\hline SNI & Mouse & FST & DLB at PO day 15 & (Stratinaki et al., 2013) \\
\hline SNI & Rat & FST & DLB at PO day 14 & (Le et al., 2014) \\
\hline SNI & Rat & $\mathrm{OF}$ & ALB at PO day 21 & $\begin{array}{l}\text { (Avila-Martin et al., } \\
\text { 2015) }\end{array}$ \\
\hline SNI & Mouse & TST; MB & DLB at PO day 30 & (Guida et al., 2015) \\
\hline SNI & Rat & $\mathrm{OF}$ & ALB at PO 21 & $\begin{array}{l}\text { (Galan-Arriero et al., } \\
\text { 2015) }\end{array}$ \\
\hline SNI & Mice & FST & DLB at PO day 7 & (Zhou et al., 2015) \\
\hline SNI & Rat & EPM; OF & No ALB at PO weeks $2,5,9,14,19$ & (Hubbard et al., 2015) \\
\hline SNI & Mouse & $\begin{array}{l}\text { EPM; OF; } \\
\text { FST; SPT }\end{array}$ & $\begin{array}{l}\text { ALB at PO month } 2 \\
\text { DLB at PO week } 9\end{array}$ & (Descalzi et al., 2017) \\
\hline SNI & Mouse & EPM; OF & ALB at PO day 28 & (Zhang et al., 2017) \\
\hline
\end{tabular}

This article is protected by copyright. All rights reserved 


\begin{tabular}{|c|c|c|c|c|}
\hline SNI & Mouse & FST & DLB at PO day 7 & (Laumet et al., 2017) \\
\hline SNI & Rat & FST; SPT & $\begin{array}{l}\text { DLB cohort-dependent at PO days } \\
14,21\end{array}$ & (Xie et al., 2017) \\
\hline SNI & Mouse & TST; MB & DLB at PO year 1 & (D'Aniello et al., 2017) \\
\hline SNI & Rat & FST; SPT & DLB at PO day 14 & (Xu et al., 2017) \\
\hline SNI & Rat & $\begin{array}{l}\text { EPM; OF; } \\
\text { SPT }\end{array}$ & $\begin{array}{l}\text { ALB at PO days } 20-40 \\
\text { DLB at PO day } 45\end{array}$ & (Gong et al., 2018) \\
\hline SNI & Rat & EPM; OF & ALB at PO weeks 4,8 & (Sang et al., 2018) \\
\hline SNI & Rat & $\begin{array}{l}\text { EPM; OF; } \\
\text { LD; SPT }\end{array}$ & $\begin{array}{l}\text { ALB at PO week } 3 \\
\text { No DLB at PO week } 3\end{array}$ & (Chen et al., 2018) \\
\hline SNI & Mouse & $\begin{array}{l}\text { EPM; LD; } \\
\text { HB }\end{array}$ & ALB at PO weeks 4-6 & (Sieberg et al., 2018) \\
\hline SNI & Rat & SPT & DLB at PO week 11 & (Thompson et al., 2018) \\
\hline SNI & Rat & $\begin{array}{l}\text { OF; FST; } \\
\text { SPT }\end{array}$ & DLB at $\mathrm{PO}$ days 14,18 & (Pan et al., 2018) \\
\hline SNI & Rat & FST; SPT & DLB at PO days 42,56 & (Fu et al., 2018) \\
\hline SNI & Mouse & $\begin{array}{l}\text { EPM; LD; } \\
\text { FST }\end{array}$ & No ALB and DLB at PO days 3-97 & (Pitzer et al., 2019) \\
\hline SNI & Rat & LD & ALB at $\mathrm{PO}$ day 14 & (Chen et al., 2019) \\
\hline NI & Rat & $\begin{array}{l}\text { FST; TST; } \\
\text { SPT }\end{array}$ & DLB at PO day 25 & (Zhang et al., 2019) \\
\hline SNI & Mouse & SPT & $\begin{array}{l}\text { Anhedonia cohort-dependent at } \mathrm{PO} \\
\text { days } 5,12,19\end{array}$ & (Yang et al., 2019a) \\
\hline SNI & Rat & FST & DLB at PO day 14 & (Yang et al., 2019b) \\
\hline SNI & Rat & FST; SPT & DLB at $\mathrm{PO}$ day 42 & (Fang et al., 2019a) \\
\hline SNI & Rat & SPT & $\begin{array}{l}\text { DLB cohort-dependent at PO day } \\
12,19\end{array}$ & (Fang et al., 2019b) \\
\hline SNI & Mouse & $\begin{array}{l}\text { OF; EPM; } \\
\text { TST; SPT }\end{array}$ & ALB and DLB at PO week 6 & (Zhou et al., 2019) \\
\hline Cuff & Mouse & $\begin{array}{l}\text { EPM; SI; } \\
\text { MB; TST }\end{array}$ & $\begin{array}{l}\text { ALB at PO days } 30,41 \\
\text { No DLB at PO days } 23,35\end{array}$ & (Benbouzid et al., 2008) \\
\hline Cuff & Mouse & $\begin{array}{l}\text { LD; MB; } \\
\text { FST; NSF; } \\
\text { ST }\end{array}$ & $\begin{array}{l}\text { ALB at } \mathrm{PO} \text { weeks } 4-9 \text {; DLB at PO } \\
\text { weeks 6-9 }\end{array}$ & (Yalcin et al., 2011) \\
\hline Cuff & Mouse & $\begin{array}{l}\text { OF; EZM; } \\
\text { FST }\end{array}$ & $\begin{array}{l}\text { ALB at PO day 35; DLB at PO day } \\
40\end{array}$ & (Dimitrov et al., 2014) \\
\hline Cuff & Mouse & FST; NSF; & DLB at PO weeks 6-8 & (Barthas et al., 2015) \\
\hline
\end{tabular}

This article is protected by copyright. All rights reserved 


\begin{tabular}{|c|c|c|c|c|}
\hline & & ST & & \\
\hline Cuff & Mouse & $\begin{array}{l}\text { LD; FST; } \\
\text { NSF; ST }\end{array}$ & $\begin{array}{l}\text { ALB at PO week 8; DLB at PO } \\
\text { weeks } 8-17\end{array}$ & (Barthas et al., 2017) \\
\hline Cuff & Mouse & $\begin{array}{l}\text { LD; FST; } \\
\text { NSF; ST }\end{array}$ & $\begin{array}{l}\text { ALB at PO week 8; DLB at PO } \\
\text { weeks } 7,8\end{array}$ & (Sellmeijer et al., 2018) \\
\hline Cuff & Mouse & LD; FST & $\begin{array}{l}\text { ALB at PO week 8; DLB at PO } \\
\text { week } 8\end{array}$ & (Liu et al., 2019) \\
\hline TNT & Rat & BT & $\begin{array}{l}\text { Burrowing behaviour deficits at PO } \\
\text { days } 56-77\end{array}$ & (Andrews et al., 2012) \\
\hline $\mathrm{SCI}$ & Rat & $\mathrm{OF}$ & No ALB at PO day 42 & $\begin{array}{l}\text { (Galan-Arriero et al., } \\
\text { 2014) }\end{array}$ \\
\hline $\mathrm{SCI}$ & Mouse & TST; SPT & DLB at PO week 10 & (Wu et al., 2014) \\
\hline SCI & Rat & $\begin{array}{c}\text { OF; SI; FST; } \\
\text { SPT }\end{array}$ & $\begin{array}{l}\text { ALB and DLB cohort dependent at } \\
\text { PO } 10,21\end{array}$ & $\begin{array}{l}\text { (Maldonado-Bouchard } \\
\text { et al., 2016) }\end{array}$ \\
\hline SCI & Mouse & OF; LD; FST & $\begin{array}{l}\text { No ALB at PO weeks } 1,4,8 ; \text { DLB } \\
\text { at PO week } 8\end{array}$ & $\begin{array}{l}\text { (Boadas-Vaello et al., } \\
\text { 2018) }\end{array}$ \\
\hline Oxaliplatin & Mouse & TST; NSF & ALB and DLB at PI day 7 & (Hache et al., 2015) \\
\hline Oxaliplatin & Mouse & FST; NSF & DLB at PI day 28 & (Poupon et al., 2018) \\
\hline Paclitaxel & Mouse & $\begin{array}{l}\text { FST; SPT; } \\
\text { NSF; Nest } \\
\text { test }\end{array}$ & $\begin{array}{l}\text { ALB at PI weeks 3-9; DLB at PI } \\
\text { weeks } 2,3\end{array}$ & (Toma et al., 2017) \\
\hline Streptozotocin & Rat & OF; EZM & ALB at PI week 4 & $\begin{array}{l}\text { (Alba-Delgado et al., } \\
\text { 2016) }\end{array}$ \\
\hline Streptozotocin & Rat & FST & DLB at PI weeks 2,4 & (Redivo et al., 2016) \\
\hline Streptozotocin & Mouse & $\begin{array}{c}\text { FST; TST; } \\
\text { MB }\end{array}$ & DLB at PI day 46 & $\begin{array}{l}\text { (Aguilar-Avila et al., } \\
\text { 2019) }\end{array}$ \\
\hline CION & Rat & $\begin{array}{l}\text { EPM; LD; } \\
\text { FST; SPT }\end{array}$ & $\begin{array}{l}\text { ALB at PO day 15; } \\
\text { No DLB at PO day } 14-46\end{array}$ & (Gambeta et al., 2018) \\
\hline TIC & Mouse & $\begin{array}{l}\text { EPM; OF; } \\
\text { LD }\end{array}$ & ALB at PO week 8 & (Lyons et al., 2015) \\
\hline TIC & Mouse & LD & ALB at PO week 8 & (Lyons et al., 2018) \\
\hline Antiretroviral & Rat & BT & Burrowing behaviour at PI day 21 & (Huang et al., 2013) \\
\hline gp120 & Rat & $\mathrm{OF}$ & ALB at PI 14 & $\begin{array}{l}\text { (Wallace et al., 2007a; } \\
\text { Wallace } \text { et al., 2007b) }\end{array}$ \\
\hline $\mathrm{VZV}$ & Rat & $\mathrm{OF}$ & ALB at PI day 14 & (Hasnie et al., 2007a) \\
\hline
\end{tabular}

Table 1. Summary of studies on the affective consequences of neuropathic pain. 
ALB, anxiety-like behaviour; BT, burrowing test; CCI, chronic constriction injury; CION, infraorbital nerve constriction; DLB, depression-like behaviour; EPM, elevated-plus maze; EZM, elevated zero maze; FST, forced swimming test; gp120, immunodeficiency virus type 1 envelope glycoprotein 120; HB, hole-board test; HST, horizontal suspension test; LD, light-dark test, MB, marble burying test; NSF, novelty-suppressed feeding; OF, open field; PI, post-induction; PO, post-operative; PSNL, partial sciatic nerve ligation; SCI, spinal cord injury; SI, social interaction; SNI, spared nerve injury; SNL, sciatic nerve ligation; SPT, sucrose or saccharin preference test; ST, splash test; TIC, trigeminal inflammatory compression; TNT, tibial nerve transection; TST, tail suspension test; VZV, varicella zoster virus. 


\begin{tabular}{|c|c|c|c|c|}
\hline Pain model & Species & $\begin{array}{c}\text { Behavioural } \\
\text { Test }\end{array}$ & Results & References \\
\hline CFA & Mouse & EPM; LD & ALB at PI day 28 & $\begin{array}{l}\text { (Narita et al., 2006a; } \\
\text { Narita } \text { et al., 2006b) }\end{array}$ \\
\hline CFA & Mouse & $\begin{array}{c}\text { OF; EZM; } \\
\text { MB; SI; } \\
\text { FST; SPT }\end{array}$ & No ALB and DLB at PI days 7-35 & (Urban et al., 2011) \\
\hline CFA & Rat & $\begin{array}{l}\text { OF; FST; } \\
\text { TST; SPT }\end{array}$ & $\begin{array}{l}\text { ALB at PI days } 7,14 ; \text { DLB at PI day } \\
14\end{array}$ & (Kim et al., 2012) \\
\hline CFA & Rat & $\begin{array}{l}\text { EPM; OF; } \\
\text { LD; SPT }\end{array}$ & ALB at PI day 28 & (Parent et al., 2012) \\
\hline $\mathrm{CFA}$ & Rat & BT & Burrowing behaviour at PI day 10 & (Andrews et al., 2012) \\
\hline CFA & Mouse & EPM; OF & ALB at PI days 3,7 & (Chen et al., 2013) \\
\hline CFA & Mouse & FST; TST & DLB at PI days 7-21 & (Maciel et al., 2013) \\
\hline CFA & Rat & EPM; LD & ALB at PI days $1,3,10$ & $\begin{array}{l}\text { (do Nascimento \& } \\
\text { Leite-Panissi, 2014) }\end{array}$ \\
\hline CFA & Rat & EPM; FST & ALB and DLB at PI day 28 & (Borges et al., 2014) \\
\hline CFA & Rat & OF; SI; SPT & ALB and DLB at PI weeks 2-3 & (Gregoire et al., 2014) \\
\hline CFA & Rat & FST & DLB at PI day 7 & (Le et al., 2014) \\
\hline CFA & Mouse & EPM & ALB at PI day 21 & (Wang et al., 2015a) \\
\hline CFA & Rat & FST & DLB at PI day 7 & (Hamann et al., 2016) \\
\hline CFA & Rat & FST; SPT & DLB at PI days 7-14 & (Zhang et al., 2016) \\
\hline CFA & Mouse & EPM; OF & ALB at day 21 & (Guo et al., 2016) \\
\hline CFA & Mouse & EZM; SPT & ALB at PI day 1; DLB at PI day 2 & (Refsgaard et al., 2016) \\
\hline CFA & Mouse & EPM; OF & ALB at PI day 21 & (Sun et al., 2016) \\
\hline CFA & Rat & BT & Burrowing behaviour at PI days 2-10 & $\begin{array}{l}\text { (Muralidharan et al., } \\
\text { 2016) }\end{array}$ \\
\hline CFA & Mouse & EPM; OF & ALB at PI week 2 & (Tian et al., 2017) \\
\hline CFA & Mouse & LD; TST & ALB and DLB at PI day 14 & (Omorogbe et al., 2018) \\
\hline CFA & Mouse & EPM; OF & ALB at PI week 1 & (Yue et al., 2018) \\
\hline CFA & Mouse & $\begin{array}{l}\text { EPM; OF; } \\
\text { LD; FST }\end{array}$ & No ALB and DLB at PI days 1-22 & (Pitzer et al., 2019) \\
\hline CFA & Mouse & $\begin{array}{l}\text { OF; EPM; } \\
\text { TST; SPT }\end{array}$ & ALB and DLB at PO week 3 & (Zhou et al., 2019) \\
\hline $\mathrm{K} / \mathrm{C}$ & Rat & EPM & ALB at PI hours 5-6 & (Ji et al., 2007) \\
\hline $\mathrm{K} / \mathrm{C}$ & Rat & $\begin{array}{l}\text { EPM; OF; } \\
\text { FST; SPT }\end{array}$ & ALB and DLB at PI week 4 & (Amorim et al., 2014) \\
\hline
\end{tabular}

This article is protected by copyright. All rights reserved 


\begin{tabular}{|c|c|c|l|l|}
\hline Uric acid & Rat & EPM; MB & ALB at PI hour 3 & $\begin{array}{l}\text { (Fernandez-Guasti } \text { et } \\
\text { al., 2005) }\end{array}$ \\
\hline Osteoarthritis & Mouse & EZM; TST & ALB and DLB at PI week 41 & (Griffin et al., 2010) \\
\hline
\end{tabular}

Table 2. Summary of studies on the affective consequences of inflammatory pain.

ALB, anxiety-like behaviour; BT, burrowing test; CFA, complete Freund's adjuvant; DLB, depression-like behaviour; EPM, elevated-plus maze; EZM, elevated zero maze; FST, forced swimming test; HB, hole-board test; K/C, kaolin/carrageenan; LD, light-dark test; MB, marble burying test; NSF, novelty-suppressed feeding; OF, open field; PI, post-induction; SI, social interaction; SPT, sucrose or saccharin preference test; ST, splash test; TST, tail suspension test. 


\begin{tabular}{|c|c|c|c|c|}
\hline Pain model & Species & $\begin{array}{c}\text { Behavioural } \\
\text { Test }\end{array}$ & Results & References \\
\hline USS & Rat & EPM & ALB at PI day 14 & (Green et al., 2011) \\
\hline BAD & Rat & FST & DLB at PI day 5 & (Nagakura et al., 2009) \\
\hline BAD & Rat & FST & DLB at PI day 2 & (Arora \& Chopra, 2013) \\
\hline $\mathrm{BAD}$ & Mouse & FST; TST & DLB at PI day 3 & (Klein et al., 2014) \\
\hline $\mathrm{BAD}$ & Mouse & FST & DLB at PI day 4 & (de Souza et al., 2014) \\
\hline BAD & Rat & NSF & DLB at PI days 4-5 & (Blasco-Serra et al., 2015) \\
\hline BAD & Rat & OF; EZM & ALB at PI day 5 & (Wu et al., 2017) \\
\hline BAD & Rat & FST & DLB at PI day 3 & (Siemian et al., 2019) \\
\hline $\begin{array}{l}\text { Acid-induced } \\
\text { hyperalgesia }\end{array}$ & Rat & $\begin{array}{l}\text { OF; EPM } \\
\text { FST; SPT }\end{array}$ & $\begin{array}{l}\text { ALB at PI day 13; } \\
\text { DLB at PI days 19- } \\
20\end{array}$ & (Liu et al., 2014) \\
\hline ICS & Mouse & HB & DLB at PI day 3 & (Montserrat-de la Paz et al., 2015) \\
\hline $\mathrm{RCS}$ & Rat & FST & $\begin{array}{l}\text { DLB at PI days 10- } \\
14\end{array}$ & (Nasu et al., 2019) \\
\hline SSS & Rat & EPM & ALB at PI week 1 & (Nazeri et al., 2018) \\
\hline
\end{tabular}

Table 3. Summary of studies on the affective consequences of fibromyalgia.

ALB, anxiety-like behaviour; BAD, biogenic amine depletion; DLB, depression-like behaviour; EPM, elevated-plus maze; FST, forced swimming test; HB, hole-board test; ICS, intermittent cold stress; NSF, novelty-suppressed feeding; OF, open field; PI, post-induction day; RCS, repeated cold stress; SPT, sucrose preference test; SSS, subchronic swim stress; TST, tail suspension test; USS, unpredictable sound stress. 
Pain

Allodynia

Analgesia

Arthritis

Dysesthesia

Fibromylagia

Hyperalgesia

Hyperpathia

Hypoalgesia

Inflammatory pain

Monoarthritis

Neuropathic pain

Nociception

Nociceptive pain

Nociceptive stimulus

Nociceptor

\section{Osteoarthritis}

An unpleasant sensory and emotional experience associated with actual or potential tissue damage, or described in terms of such damage. (IASP)

Pain due to a stimulus that does not normally provoke pain. (IASP)

Absence of pain in response to stimulation which would normally be painful. (IASP)

An informal way of referring to joint pain or joint disease. (COFER)

An unpleasant abnormal sensation, whether spontaneous or evoked. (IASP)

Syndrome characterized by chronic widespread pain at multiple tender points, joint stiffness, and systemic symptoms (e.g. mood disorders, fatigue, cognitive dysfunction and insomnia) without a well-defined underlying organic disease.

(ICD)

Increased pain from a stimulus that normally provokes pain. (IASP)

A painful syndrome characterized by an abnormally painful reaction to a stimulus, especially a repetitive stimulus, as well as an increased threshold. (IASP)

Diminished pain in response to a normally painful stimulus. (IASP)

Inflammatory nociceptive pain is associated with tissue damage and the resulting inflammatory process. (COFER)

Inflammation of one joint (arthritis) at a time (ICD)

Pain caused by a lesion or disease of the somatosensory nervous system. (IASP)

The neural process of encoding noxious stimuli. (IASP)

Pain that arises from actual or threatened damage to non-neural tissue and is due to the activation of nociceptors. (IASP)

An actually or potentially tissue-damaging event transduced and encoded by nociceptors. (IASP)

A high-threshold sensory receptor of the peripheral somatosensory nervous system that is capable of transducing and encoding noxious stimuli. (IASP)

Group of distinct, but overlapping diseases, which may have different etiologies, but similar biological, morphological, and clinical outcomes affecting the articular cartilage, subchondral bone, ligaments, joint capsule, synovial membrane and periarticular muscles. (ICD) 
Pain threshold

Paraesthesia

Rheumatoid arthritis

Sensitization
The minimum intensity of a stimulus that is perceived as painful. (IASP)

An abnormal sensation, whether spontaneous or evoked. (IASP)

Persistent and/or erosive disease that is defined as the confirmed presence of synovitis in at least 1 joint, absence of an alternative diagnosis that better explains the synovitis, and achievement of a total score of 6 or greater (of a possible 10) from the individual scores in 4 domains: number and site of involved joints, serologic abnormality, elevated acute-phase response, and symptom duration. (ICD)

Increased responsiveness of nociceptive neurons to their normal input, and/or recruitment of a response to normally subthreshold inputs. (IASP)

Box1. Definition and assessment of sensory symptoms or signs in pain.

COFER, Collège français des enseignants en rhumatologie; IASP, international association for the study of pain; ICD, international classification of diseases. 


\section{Figure legends}

Figure 1. Experimental traumatic models of neuropathic pain.

(1) Partial sciatic nerve ligation (PSNL; Seltzer et al., 1990); (2) Sciatic nerve ligation (SNL; Kim and Chung, 1992); (3) L5 spinal nerve ligation (variant of the SNL model; LaBuda and Little, 2005); (4) Tibial nerve transection (TNT; Lee and al., 2000); (5) Chronic constriction injury (CCI; Bennett and Xie, 1988);

(6) Sciatic nerve cuffing (Cuff; Mosconi and Kruger, 1996; Benbouzid et al., 2008); (7) Spared nerve injury (SNI; Decosterd and Woolf, 2000); (8) Spinal cord injury (SCI; Behrmann et al., 1992). The level of insertion of the nerve roots and therefore the associated dorsal root ganglia may vary according to the animals' strain hence the double level numbering on the dorsal root ganglia.

Figure 2. Anxiety-like behaviours in animal models of neuropathic pain.

"n" displayed in the figure corresponds to the number of publications relative to the test (see Table $\mathbf{1}$ for more details and references). EPM, elevated-plus maze; EZM, elevated zero maze.

Figure 3. The impact of time on the anxiety-like behaviour in animal models of neuropathic pain. "n" displayed in the figure corresponds to the number of publications relative to the test (see Table $\mathbf{1}$ for more details and references). EPM, elevated-plus maze; EZM, elevated zero maze; LD, light-dark test; OF, open field.

Figure 4. The impact of time on well-being in animal models of neuropathic pain.

"n" displayed in the figure corresponds to the number of publications relative to the test (see Table $\mathbf{1}$ for more details and references). SI, social interaction.

Figure 5. Depressive-like behaviours in animal models of neuropathic pain.

"n" displayed in the figure corresponds to the number of publications relative to the test (see Table $\mathbf{1}$ for more details and references). FST, forced swimming test; HST, horizontal suspension test; NSF, noveltysuppressed feeding; TST, tail suspension test.

Figure 6. The impact of time on depressive-like behaviour in animal models of neuropathic pain.

" $n$ " displayed in the figure corresponds to the number of publications relative to the test (see Table $\mathbf{1}$ for more details and references). FST, forced swimming test; NSF, novelty-suppressed feeding; TST, tail suspension test.

This article is protected by copyright. All rights reserved 

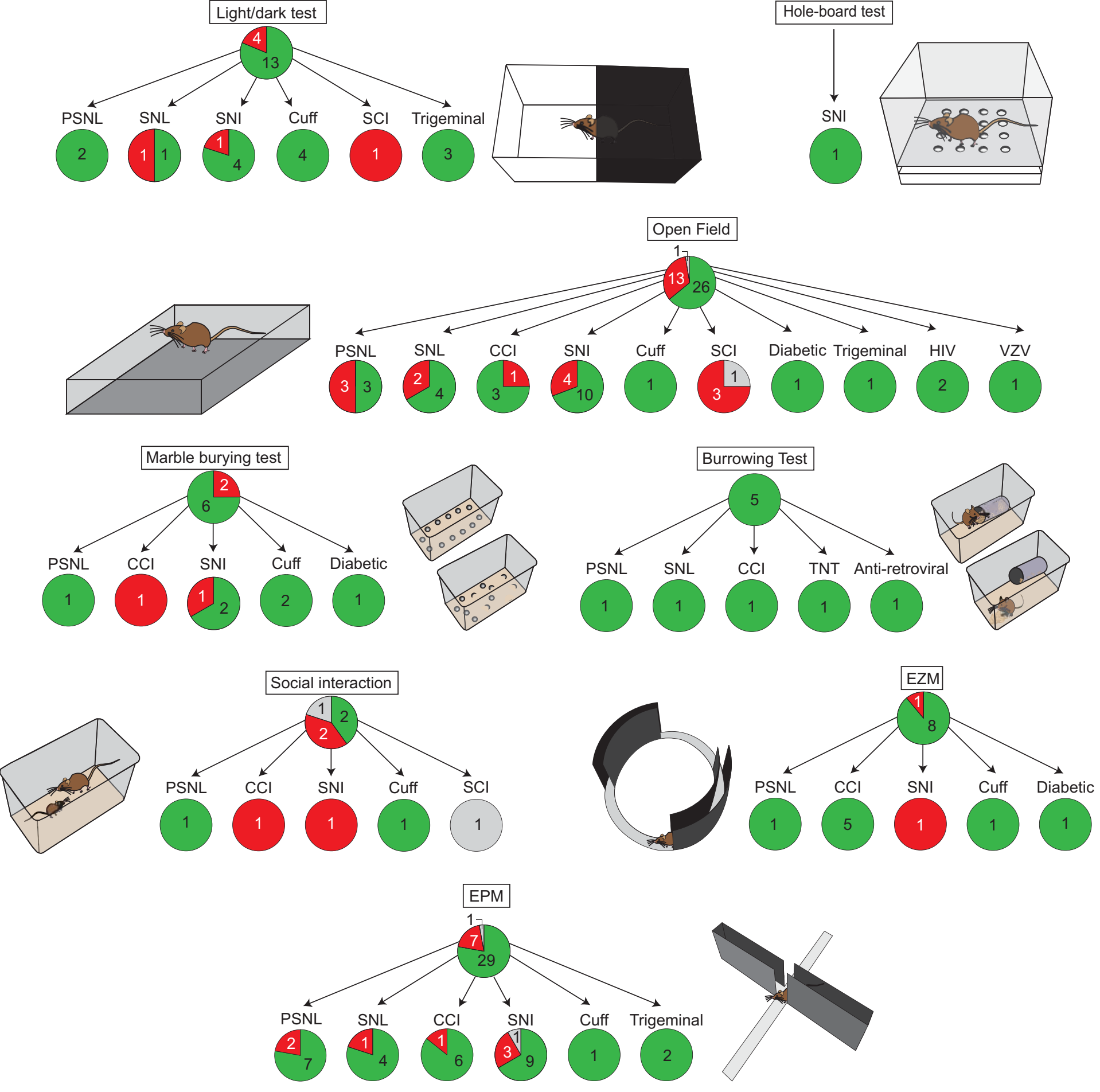

anxiety-like behaviour

cohort-dependent

no anxiety-like behaviour

Figure 2. 


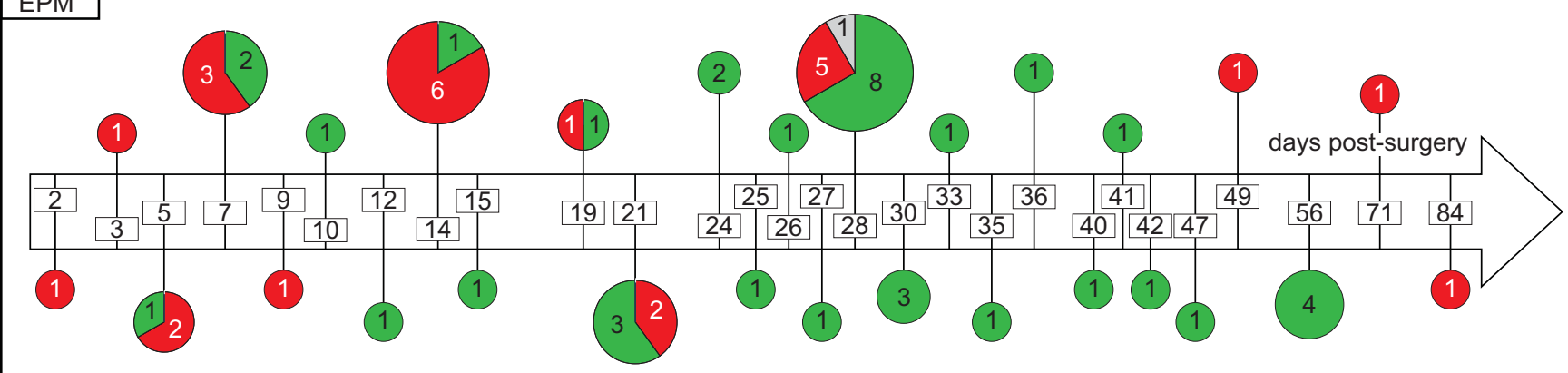

\section{EZM}

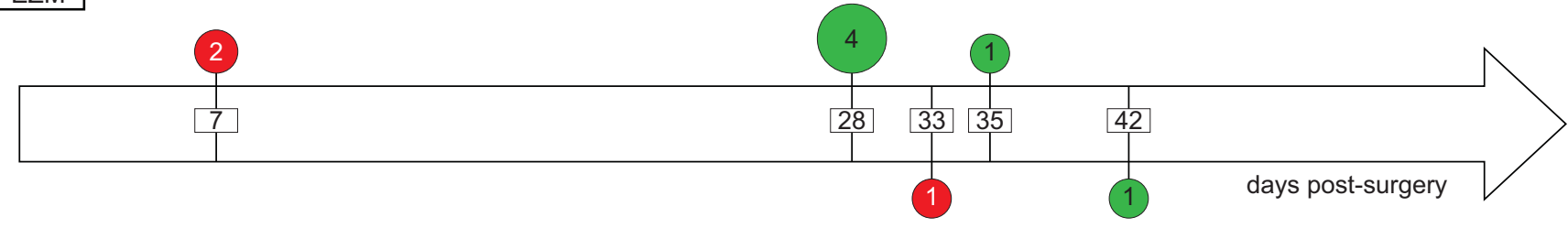

OF

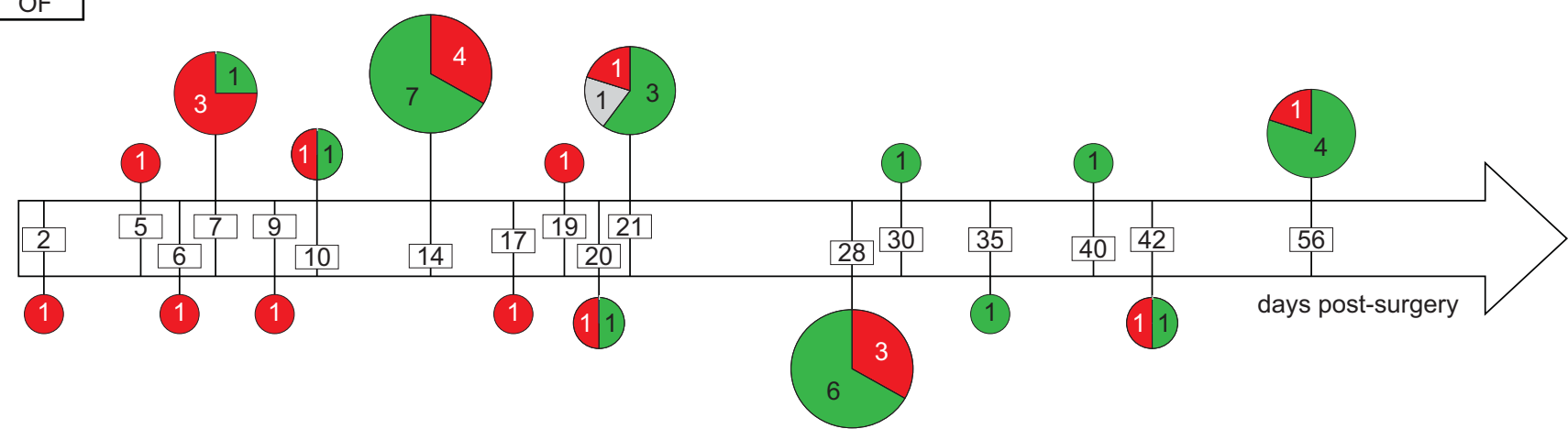

LD

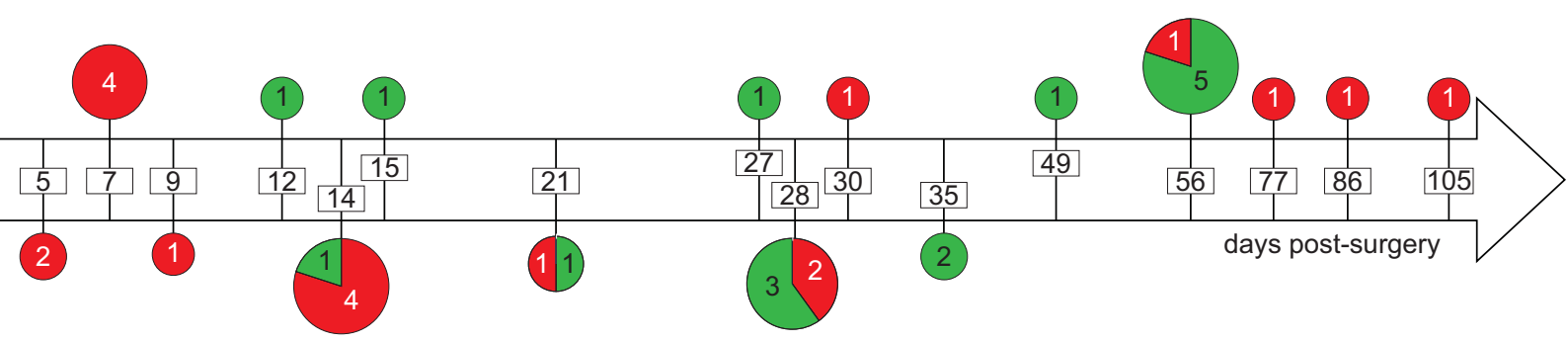

anxiety-like behaviour

Figure 3. 

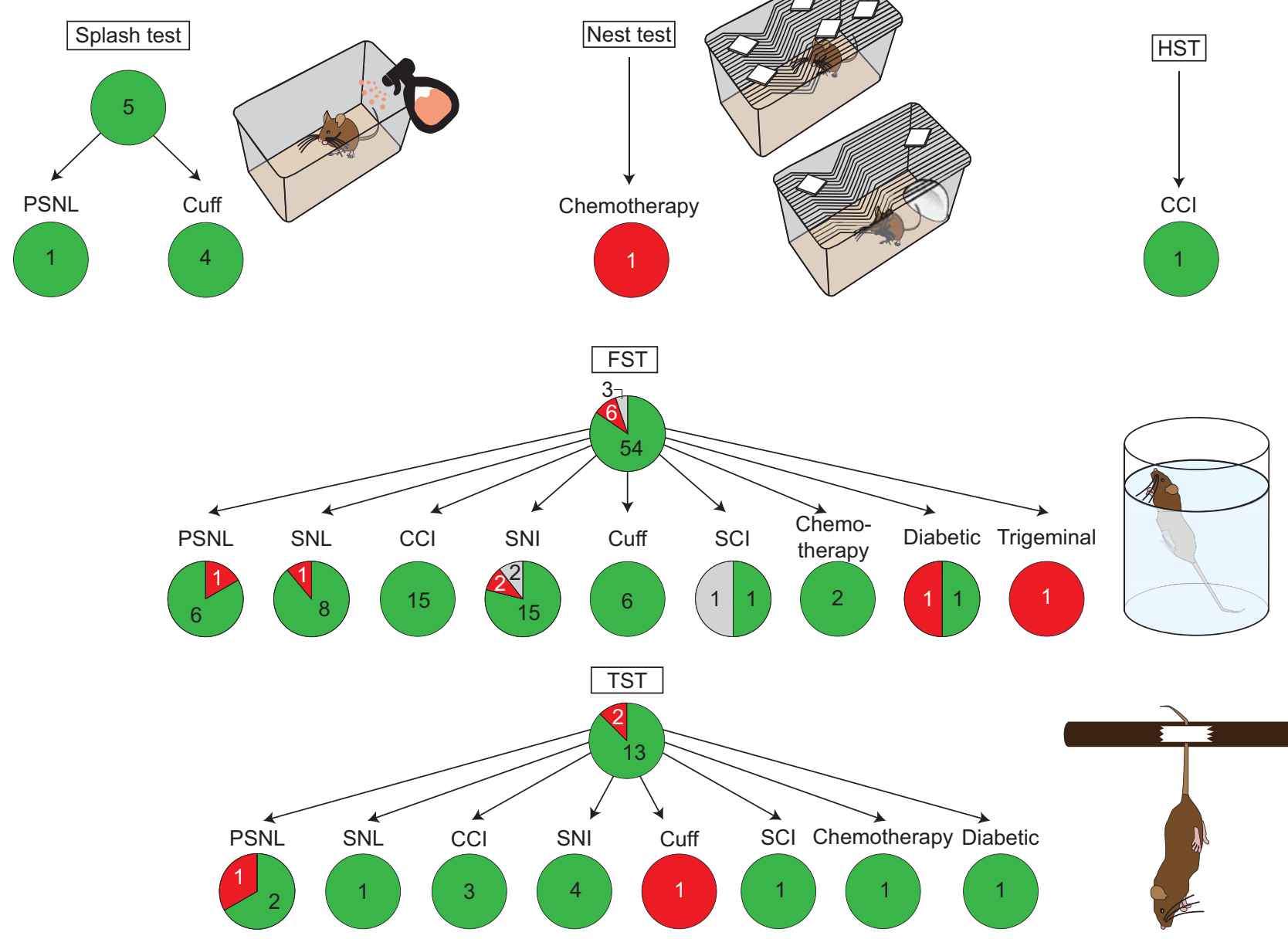

Sucrose preference
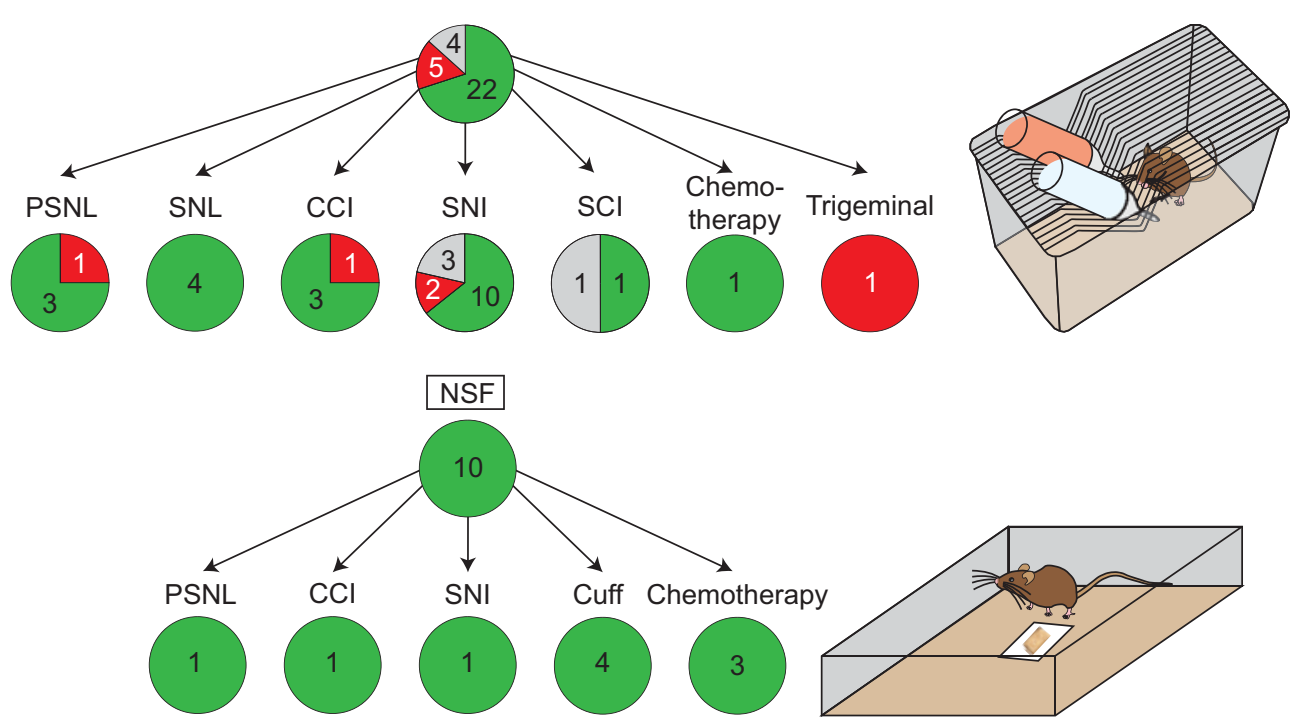
